\title{
GERMANIUM GLASS POLYALKENOATE CEMENTS FOR CRANIOPLASTY FIXATION.
}

by

\author{
Basel A. Khader \\ BEng, Turkey, 2007 \\ A thesis presented to Ryerson University \\ In partial fulfillment of the \\ Requirements for degree of \\ Master of Applied Science \\ In the Program of \\ Mechanical \& Industrial Engineering
}

Toronto, Ontario, Canada, 2015

(C) Basel A. khader, 2015 


\section{AUTHOR'S DECLARATION FOR ELECTRONIC SUBMISSION OF A THESIS}

I hereby declare that I am the sole author of this thesis. This is a true copy of the thesis, including any required final revisions, as accepted by my examiners.

I authorize Ryerson University to lend this thesis to other institutions or individuals for the purpose of scholarly research

I further authorize Ryerson University to reproduce this thesis by photocopying or by other means, in total or in part, at the request of other institutions or individuals for the purpose of scholarly research.

I understand that my thesis may be made electronically available to the public. 


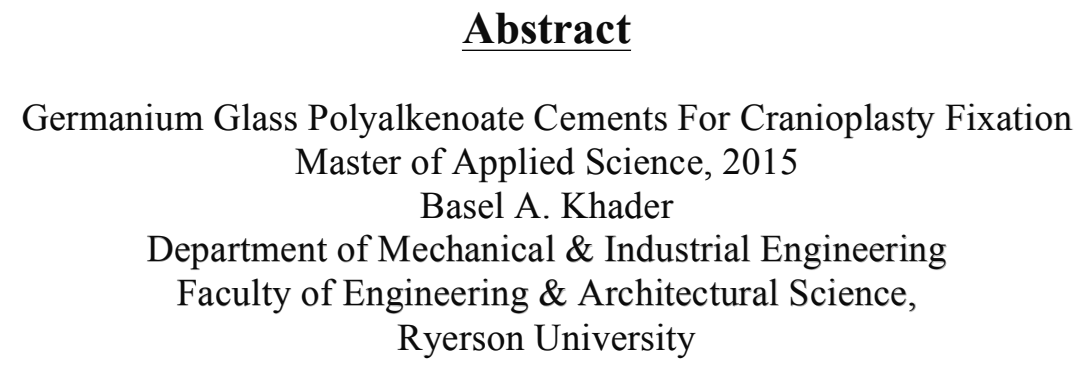

Glass polyalkenoate cements (GPCs) have potential for skeletal cementation. Unfortunately, commercial GPCs all contain and subsequently release aluminum ions, which have been implicated in degenerative brain disease. The purpose of this research was to create aluminumfree GPCs constructed from silicate $\left(\mathrm{SiO}_{2}\right)$-calcium $(\mathrm{CaO})$-zinc $(\mathrm{ZnO})$, glasses mixed with polyacrylic acid (PAA200) in order to evaluate the potential of these novel GPCs for attaching titanium miniplates directly to the skull, a clinical procedure known as cranioplasty. Three glasses were formulated: KBT01 $\mathrm{SiO}_{2}-\mathrm{CaO}-\mathrm{ZnO}$-sodium $\left(\mathrm{Na}_{2} \mathrm{O}\right)$ glass, KBT02 $\mathrm{SiO}_{2}-\mathrm{CaO}-\mathrm{ZnO}-\mathrm{Na}_{2} \mathrm{O}-$ germanium $\left(\mathrm{GeO}_{2}\right)$, with a $0.03 \mathrm{~mol} \% \mathrm{GeO}_{2}$ substitution for $\mathrm{ZnO}$ and $\mathrm{KBT} 03 \mathrm{SiO}_{2}-\mathrm{CaO}-\mathrm{ZnO}-$ $\mathrm{Na}_{2} \mathrm{O}-\mathrm{GeO}_{2}$, with a $0.06 \mathrm{~mol} \% \mathrm{GeO}_{2}$ substitution for $\mathrm{ZnO}$ in glass structure. X-ray diffraction (XRD) and particle size analysis (PSA) confirmed that all glasses were completely amorphous with similar mean particle sizes. Each glass in the series was mixed with $50 \mathrm{wt} \%$ a patented $\mathrm{SiO}_{2}$ $\mathrm{CaO}-\mathrm{ZnO}$-strontium ( $\mathrm{SrO}$ ) glass composition, BT101, and subsequently mixed with PAA200 at $50 \mathrm{wt} \%$ addition to produce a series of cements. The addition of $\mathrm{Ge}$ to the glass series resulted in decreased working times ( $\sim 142 \mathrm{~s}$ to $112 \mathrm{~s}$ ) and setting times ( $\sim 807$ to $448 \mathrm{~s}$ ) for the cements manufactured from them. This was due to the increase in crosslink formation during the setting reaction between the Ge-containing glasses and the PAA200. Regarding ion release, Atomic Absorption Spectroscopy (AAS) determined $\mathrm{Zn}^{2+}$ ion release to be 9.56, 8.02 and $5.83 \mathrm{ppm}$ after 30 days for KBT01, KBT02 and KBT03 cements respectively. Germanium ions were not released from the KBT01 cement since the glasses it was formulated from did not contain $\mathrm{Ge}^{4+}$. KBT02 and KBT03 cements released $1.23 \mathrm{ppm}$ and $1.94 \mathrm{ppm}$ of $\mathrm{Ge}^{4+}$ ions after 30 days. The mechanical properties (compressive $\sim \sigma_{\mathrm{c}}$, and biaxial flexural strength $\sim \sigma_{\mathrm{f}}$ ) of the resulting cements were examined over three time modalities, 1,7 and 30 days. $\sigma_{c}$ of the cements ranged from $\sim 27-56$ $\mathrm{MPa}$, while $\sigma_{\mathrm{f}}$ ranged from $\sim 17-33 \mathrm{MPa}$. Both strength modalities increased with maturation and increasing Ge content, as Ge may facilitate improved chemical bonding between the $\mathrm{COO}^{-}$ groups, thus creating stronger cements in KBT02 and KBT03. The bond strength of the titanium cylinder ( $\mathrm{Ti}$ ) to the bone that it was attached to by the cements increased from $\sim 0.23 \mathrm{MPA}$ to 0.63 MPa respectively from placement up to 14 days maturation. Failure of these constructs occurred at the interface between the Ti cylinder and the cement. The results of this research indicate that, due to their novel composition, Ge-based GPCs have suitable handling properties, strengths and adhesiveness for potential in cranioplasty fixation. 


\section{Acknowledgements}

I would like to genuinely express my gratitude to my supervisor Prof. Dr. Mark Towler for his guidance and encouragement during this research. Despite his many obligations, Mark always had time to discuss the development of this research and always pushed me to succeed. I have the utmost respect for Mark and feel very honored to have the opportunity to be the first student to graduate from Ryerson Univeristy under his supervision.

I would like to thank Dr. Declan Curran (Ryerson University, Toronto) for his advice and priceless discussions and taking the time from his busy schedule to follow up with this research. Thanks buddy!

Thank you for the awesome CMD group for their support. As well I would like to thank Alan Machin (technical officer, Mechanical Eng. Department) for his help with the mechanical testing of this research and Shawn McFadden (Chemistry Instructor \& Technical Specialist, Chemistry Department) for his assistance in the RUAC group lab.

I would like to acknowledge Dr. Anthony Wren and his group at Alfred University (NY, USA) for their assistance with the PSA tests as well Sean Peel at University of Toronto for his help with the Radiopacity test for this research.

I gratefully acknowledge the financial assistance of the Collaborative Health Research Project, CIHR/NSERC (315694-DAN).

On an individual note I would like to sincerely thank my family, especially my mother and father for their endless love, support and encouragement. To my wife Nadine, for your patience, I couldn't have completed this without you; you always push me to be the best I can be. Thank you so much for helping me follow this research.

Finally, I would like to thank my energetic boys for always testing my patience and reminding me of the reasons for pursuing my education. They always managed to put a smile on my face even through the stresses. 
This work is dedicated to my father

Abdullah Khader Ghanem.

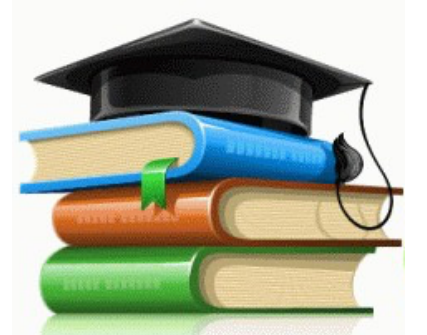




\section{Table of Contents}

Declaration

Abstract ii

Acknowledgment iii

Dedication iv

List of Tables viii

List of Equations viii

List of Figures $\quad$ ix

List of Appendices $\quad$ xi

\section{Chapter 1 Introduction}

1. Introduction

1.1 Background

1.12 The skull

1.1.3 Anatomy of the cranium 2

1.2 Cranioplasty 2

1.2.1 Fractures of the cranium 2

1.3: Craniotomy 3

1.4: Glass poly (alkenoate) cements GPC 3

1.5: Aim and objectives 3

Chapter 2 Literature Review

2.1 Cranioplasty and Materials 5

2.1.1 Xenograft 5

2.1.2 Autologous Bone Graft 6

2.1.3 Allograft 6

2.1.4 Metal Allografts $\quad 7$

2.1.4.1 Aluminum 7

2.1.4.2 Lead 7

2.1.4.3 Platinum

2.1.4.4 Tantalum 7

2.1.4.5 Titanium 8

2.1.4.6 Gold and Silver $\quad 8$

2.1.5 Non-Metal Allografts 9

2.1.5.1 Celluloids 9

2.1.5.2 Polyethylene and Silicon 9

2.1.5.3 Ceramics 9

2.1.5.4 Coral 9

2.1.5.5 Calcium Phosphates 10

2.1.5.6 Hydroxyapatite (HA)-Zirconia $\left(\mathrm{ZrO}_{2}\right) \quad 10$

2.1.5.7 Cortoss 11

2.1.6 Cranioplasty procedure $\quad 11$

2.2 Craniotomy Bone Flaps and Techniques $\quad 12$

2.2.1 Wire Fixation 13

2.2.2 Miniplate Fixation $\quad 14$

2.2.3 Titanium Clamp Fixation $\quad 16$

2.2.4 Comparison of case studies $\quad 17$

2.2.4.1 Discussion 20

2.2.5 Titanium Cranioplasty 21

2.2.5.1 Preparation of the Plate 21

2.2.6 Titanium-Strips Cranioplasty 23

2.2.7 Cementing 24

2.3 Poly-Methylmethacrylate (PMMA) In Cranioplasty 25 
2.3.1 Polymerization of PMMA 28

2.3.1.1 Case Study: Technique for Forehead Reconstruction 29

2.3.2 Improving the Mechanical Properties of PMMA

Bone Cements $\quad 29$

2.3.3 The Influence of PMMA on Immune Response $\quad 30$

2.4 Calcium Phosophate Cements (CPCs) 31

2.4.1 Setting of Calcium Phosophate Cements 31

2.4.2 CPCs: The Mechanical Properties $\quad 32$

2.4.3 CPCs: Surgical Uses $\quad 33$

\begin{tabular}{ll}
2.5 Polyalkenoate Cements & 34 \\
\hline
\end{tabular}

2.5.1 Glass Polyalkenoate Cements 34

2.5.2 Glass Component $\quad 34$

2.5.3 Inorganic Polymer Model 36

2.5.4 The Acid Component 37

2.5.5 The Setting Reaction of GPCs 37

2.5.6 Luting Cements 38

2.5.7 Mechanical Properties of GPCs $\quad 39$

2.5.8. Ion Release of GPCs $\quad 40$

2.5.9 Zinc Polyalkenoate Cements 41

2.6 Summary $\quad 42$

2.7 Rationale $\quad 43$

Chapter 3 Materials and Methods

3.1 Glass Syntheses and Characterization 45

3.1.1 Glass Synthesis $\quad 45$

3.1.2. Polyacrylic Acids (PAA) 46

3.1.3 Glass Characterization $\quad 46$

3.1.3.1 Network Connectivity (NC) 46

3.1.4 Powder X-Ray Diffraction (XRD) 46

3.1.5 Particle Size Analysis (PSA) 46

3.2 Cement Characterization $\quad 47$

3.2.1 Cement Preparation 47

3.3 Rheological properties $\quad 47$

3.3.1 Working and setting time $\quad 47$

3.4 Scanning Electron Microscopy \& Energy
Dispersive X-ray Analysis (SEM- EDS)

3.5 Mechanical properties 48

3.5.1 Compressive strength test 48

3.5.2 Biaxial Flexural Strength 49

3.6 Ion-release $\quad 50$

3.7 Radiopacity (X-Ray)- MicroCT 51

3.8 Adhesive properties $\quad 52$

3.8.1 Collection of samples and preparation 52

3.8.2 Bond Strength 53

3.9 Statistical Analysis $\quad 54$

\section{Chapter 4 Results and Discussion}

4.1 Glass Characterization $\quad 55$

4.1.1 X-ray Diffraction (XRD) 55

4.2 Particle Size Analysis (PSA) 55

4.3 Scanning Electron Microscopy (SEM) \& Energy
Dispersive X-ray Analysis (EDX)

4.4 Calculation Of Network Connectivity 57

4.5 Rheological Properties (Working Time \& Net setting Time) 
4.5.1 Working time

4.5.2 Net setting time

4.6 Mechanical Properties 59

4.6.1 Compressive Strength $\quad 60$

4.6.2 Biaxial Flexure Strength (BFS) Test 61

4.7 Ion Release

62

4.8 Radiopacity (X-Ray)- MicroCT

65

4.9 Bond Strength Test

Chapter 5 Conclusion and Future Work

5.1 Conclusion

70

5.2 Future Work

72

Appendices

73

Bibliography

83 


\section{List of Tables}

Table 1: Representation of load-bearing test results and mean fixation time for the three fixation methods presented

Table 2: Mean fixation time, initial offset and maximal load for three different fixations Techniques [66] study

Table 3: Mean fixation time, initial offset, and maximal load (the force to the failure of $\begin{array}{ll}\text { the fixation system for each fixation technique [64] study } & 18\end{array}$

Table 4: Indicates the details of titanium strips used in cranioplasty 24

Table 5: Indicates the details of screws, and dental burrs used in cranioplasty. $\quad 24$

Table 6: Yamamoto et al [118] summary of in-vivo and in-vitro compression strengths 33

Table 7: Properties of ZPC cement 42

Table 8: KT Glass compositions (Mol \%) 45

Table 9: BT101 Glass composition (Mol \%)

Table 10: Operating parameters for AAS $\quad 51$

Table 11: Composition in Wt\% as verified by EDX 57

Table 12: Calculation of Network Connectivity for KT glasses 57

Table 13: BT101 glass composition

\section{List of Equations}

Equation 1: Calculation of Network Connectivity of a glass 37

Equation 1: Calculation of Network Connectivity of a glass 46

Equation 2: Calculation of Compressive Strength 49

$\begin{array}{ll}\text { Equation 3: BFS calculation } & 50\end{array}$

Equation 4: Bond strength conversion $\quad 53$

Equation 5: (a) Example of NC calculation for KT01 glass $\quad 57$

(b) Example of NC calculation for KT01 glass 57 


\section{List of Figures}

Figure 1: Different areas of the skull

Figure 2: Autologous bone graft. Axial (upper) and 3D reconstructed (lower)

CT scans obtained after decompressive craniectomy (left) and subsequent autologous bone flap replacement (right)

Figure 3: Titanium mesh in vivo

Figure 4: (Left to right) The steps taken during a craniotomy technique 13

Figure 5: Cranial flap wire fixation technique 14

Figure 6: The five different types of screws used. 15

Figure 6A: The bond test method. 15

Figure 7: (Left to right) Titanium clamp used for bone flap fixation containing two discs $\begin{array}{ll}\text { on a threaded pin } & 16\end{array}$

Figure 8: Results of the load-bearing tests [66] study 18

Figure 9: Results of the load-bearing tests [64] study 19

Figure 10: Comparison of different cranial flap fixation techniques after load bearing tests [62] study

Figure 11: Titanium plate with drilled projections for retaining screws 22

Figure 12: Form fitting cranial plate. An acrylic mass attached to deep surface of plate $\begin{array}{ll}\text { fills dead space between dura matter and plate } & 22\end{array}$

Figure 13: (Left) Titanium mesh plate (Right) Titanium miniplate $\quad 23$

Figure 14: Titanium strips of various widths and lengths used for cranioplasty after debridement of missile wound

Figure 15: Drawing of PMMA preparation

Figure 16: (Left to right) Preoperative view of a 56-year-old female who underwent strip craniectomy And silicone block augmentation of her forehead for left unilateral coronal synostosis in childhood. A) Intra-operative view of the fractured calcified silicone block implant. B) After removal of the silicone block implant, the forehead surface contour deformity was defined. C) A wire rebar grid was created over the affected area. D) Wire reinforced methyl methacrylate before contouring

Figure 17: Temperature profiles developing during the setting reaction of a traditional PMMA cement

Figure 18:(A) To ensure fixation multiple grooves are cut in the outer table and fixation wires are placed in the supraorbital rims

(B) The firming methyl methacrylate is applied directly to the skull

(C) The scalping flap is replaced and precise contouring is done to assure symmetry with the oppsosite side

Figure 19: a) and b) SEM of monocytes/macrophages adhering on PMMA cement surfaces

Figure 20: Solubility phase of the ternary system $\mathrm{Ca}(\mathrm{OH})_{2} \mathrm{H}_{3} \mathrm{PO}_{4}-\mathrm{H}_{2} \mathrm{O}$, at

$25^{\circ} \mathrm{C}$. Illustrates solubility isotherms of TTCP, DCPA and HA 32

Figure 21: Continous random-network model for network glasses 34

Figure 22: The development of non-bridging oxygen's the network modifying

$$
\text { cation } \mathrm{Ca}^{2+}
$$

Figure 23: Isomorphic replacement of $\mathrm{Si}^{4+}$ with $\mathrm{Al}^{3+}$ in the silica glass network, and charge compensation provided by network modifying cations

Figure 24:Setting Reaction of a GPC

Figure 25: Crosslinking of GPC

Figure 26: Diagrammatic representation of the microstructure of ZPCs

Figure: 27: (a) Glass Production Procedure

(b) Bio-Glass after Production Procedure

(c) Powder Bio-Glass after grinded and sieved using $<45 \mu \mathrm{m}$ sieve 
Figure 28: X-Ray Diffractometer. XRD sample packed into stainless steel

disc using $20 \mathrm{~mm} \varphi$ slide of glass

Figure 29: (Left) Multisizer Four

(Right) Sample loaded in the PSA

Figure 30: (a) Setting time testing fixture by ISO9917

(b) Illustration of the mould used to determine the net setting time of cements, dimensions are in $\mathrm{mm}$

Figure 31: Scanning electron microscopy (JEOL Ltd Tokyo, Japan) 48

Figure 32: (a) Compressive Testing Rig

(b) ISO9917 for Compressive Strength test

Figure 33: (Left) Biaxial flexure strength fixture rig with sample

(Right) Biaxial flexure sample disk preparation $\quad 50$

Figure 34: Atomic Absorption Spectrometer Analyst 800 (AAS800) 51

Figure 35: X-ray imaging interferometer.

(a) Setup based on transmission gratings G0 through G2.

(b) A phase object in the beam path causes a slight deflection of $\mathrm{x}$ rays changing the locally transmitted intensity through the arrangement formed by the gratings G1 and G2.

(c) sample (plastic tube filled with water, cotton, bone standerd and cement sample).

Figure 36: (a)-(h) Process of collection and preparation of samples (Ti, Al and Bone

Figure 37: Aluminum Hollow Tube

Figure 38: (a) and (c) The titanium cylinder is inserted into the hollow tube

(b) and (d) The Ti, Al, Bone lays perfectly flat on the inside of the tube in order to start the Bond strength test

Figure 39: XRD patterns of the formulated glasses (KBT) series $\quad 55$

Figure 40: Mean particle size for each ground glass $\quad 56$

Figure 41: SEM for (a) KBT01, (b) KBT02 and (c) KBT03 56

Figure 42: Working times of the cement. 58

$\begin{array}{ll}\text { Figure 43:Net setting times of the cement } & 59\end{array}$

Figure 44: Compressive results for cement series (1,7 and 30 days) 60

Figure 45: BFS results for cement series (1,7 and 30 days) 61

Figure 46:(a) Si ion release $\quad 62$

(b) Ca ion release $\quad 62$

(c) $\mathrm{Zn}$ ion release $\quad 63$

(d) $\mathrm{Na}$ ion release $\quad 63$

(e) $\mathrm{Sr}$ ion release $\quad 64$

(f) Ge ion release 64

Figure 47: Radiograph image of the cement sample and bone standard 65

Figure 48: Comparison of the radiopacity of cement 66

Figure 49: (a) Bond strength for Ti (Cylinder) attachment to Bone by KBT cements 66

(b) Bond strength for Ti (Cylinder) attachment to Al plate by KBT cements 68

(c) Bond out strength for Ti (Cylinder) attachment to Ti plate by KBT cements 68

Figure 50: (a) 0-1 day,

(b) 0-7 day's

(c) 0 -14 day's $\quad 67$

Figure 51: The failure between the Ti cylinder and Al/Ti plate 69 


\section{$\underline{\text { List of Appendices }}$}

Appendix A: Determination of net setting time (ISO 9917-1:2007)

Appendix B: Determination of compressive strength

(ISO 9917-1:2007)

75

Appendix C: Energy Dispersive X-Ray analysis (EDS)

78

Appendix D: Ion Release

79

Appendix E: MicroCT Procedure 


\section{Chapter 1}

\section{Introduction}

\subsection{Background}

\subsubsection{Anatomy of the skeleton}

The human skeleton has 213 bones, not including the sesamoid bones [1]. The skeletal system offers structural support, protection of organs, locomotion and movement [2]. Bones can be categorized as long, short, irregular and flat bones. Long bones include the humeri, tibiae, femurs, phalanges, clavicles, radii, metacarpals, ulnae, metatarsals and fibulae $[1,2]$. Long bones consist of growth plates (epiphysis) at the ends, a shaft (diaphysis), a strong outer surface that is composed of compact (cortical) bone and a spongy inner trabecular (cancellous) bone where the bone marrow is situated. Also, to ensure bone protection and shock absorption, the growth plates of the long bones are sheltered with hyaline cartilage. Short bones include the sesamoid bones, tarsal, patellae and carpal bones. While, irregular bones consist of hyoid, coccyx, sacrum, and vertebrae bones [2]. Flat bones include the sternum, scapulae, ribs, mandible and skull [2]. These bones act as a base for muscle attachment and provide important organs with protection. Normally, bone strength is maintained by the modeling and remodeling process bone undergoes, which facilitates adaptation to the changes in biomechanical forces, substituting the micro-damaged old bone with new stronger bone [1].

\subsubsection{The skull}

The skull is a bony structure that protects the brain and supports other soft tissues of the head. It consists of 22 bones, formed by intramembranous ossification, which are merged together by fibrous joints [3]. The skull bones can be divided into two groups: the cranium and the face. 


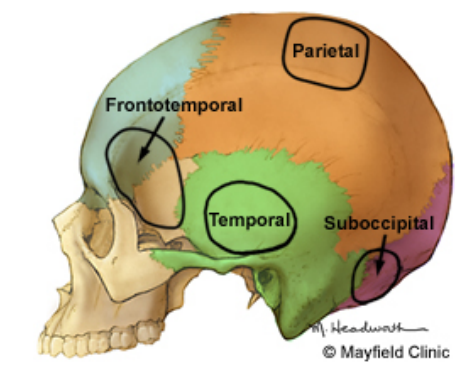

Figure 1: Different areas of the skull [4]

\subsubsection{Anatomy of the cranium}

The area of the skull that surrounds the brain is known as the cranium. It shelters the brain, meninges, and cerebral vasculature. The cranium contains eight cranial bones: two parietal, two temporal, frontal, occipital, sphenoid, and ethmoid. Cranial bones are considered thin and very robust for their weight [3]. The features of the cranial bones are as follows:

Two Parietal bones: major cranial bones that form part of the top and sides of the cranium. Two Temporal bones: these bones are on the sides of the head, under the parietal bones, and above and behind the ears. Frontal bone: a key cranial bone that forms the forehead and the front of the head. Occipital bone: a major cranial bone at the back and base of the cranium, forming the back of the skull. Sphenoid bone: a cranial bone that forms the eye orbit. Ethmoid bone: This bone forms part of the nasal and eye cavities [3].

\subsection{Cranioplasty}

A cranioplasty is performed to correct a deformity or defect of the skull [5]. The most common cause of skull defects includes birth defects, trauma, neurological procedures and infection of the cranial contents and, in children, the provision of an intact cranial vault for normal growth and development of the brain [6]. A cranioplasty is a surgical procedure that corrects these deformities/defects of the skull and it is usually performed following congenital problems, a traumatic injury to the skull or after a previous brain surgery such as a craniotomy [5].

\subsubsection{Fractures of the cranium}

A skull fracture is any break in the cranial bone (skull) occurring when a force is applied that is strong enough that it causes the bone to break [7]. 


\subsection{Craniotomy}

A craniotomy is the surgical removal of a section of bone (bone flap) from the skull for the purpose of operating on the brain [8]. The bone flap is replaced at the end of the procedure [8]. A craniotomy is most commonly performed within the head for brain tumor removal, trauma, infection and congenital problems, while it could be done to relive pressure inside the skull or to inspect the brain [8].

After craniotomy is performed or any damages occur to the skull, the bone that was removed from the skull is usually replaced with one or a combination of these materials [5]:

- Sutures

- Wires

- Miniplates

- Titanium mesh

- Screws

\subsection{Glass poly (alkenoate) cements (GPCs)}

Glass polyalkenoate cements (GPCs) were founded in 1969 [9]. The development of GPC is based on the reaction of an ion-leachable aluminosilicate glass and an aqueous solution of polyacrylic acid (PAA) [10]. The objective of this research is to design, produce and characterize a new series of GPC glasses that can be used in place of screws when performing cranioplasty. It is expected that this new glass series will decrease complications and infections that are associated with the use of screws, while allowing for a more stable and secure attachment to the skull.

\subsection{Aim and objectives}

This work will develop a series of Calcium (Ca), Zinc (Zn), Germanium (Ge) and Silicon (Si) glasses which will act as a component for a new class of Glass Polyalkenoate Cements (GPCs). The objectives of the research are:

- To produce the glass series by melt-quench fabrication.

- To evaluate the effect of increasing the Ge content in the series.

- To mix the glasses mixed with aqueous poly (acrylic acid) (PAA), resulting in cements with handling properties that follow industry standards for ISO9917 [11].

- To determine the role of Ge-containing GPCs in fixation and stabilization of the cranium through in-vitro studies. 
- To identify GPCs with mechanical properties equivalent to the bone that they are substituting in order to decrease stress-shielding effects that reduce bone density.

Even with growing research in this area, there has been no individual material currently found that fulfills all the requirements for robust cranial fixation. 


\section{Chapter 2}

\section{Literature Review}

\subsection{Cranioplasty materials}

Cranioplasty is the surgical repair of a deficiency or deformity of the skull [12]. The purpose of cranioplasty is to provide protection for the brain and give relief to psychological disadvantages while increasing the social performance following cranial surgery [12]. Blake [13] provides a list of the following characteristics that must be included for an ideal cranioplasty material:

- It must fit the cranial defect and achieve complete closure

- Radiolucent; to show up on an x-ray

- Resistance to infection

- Not dilated with heat

- Strong to biomechanical processes

- Easy to shape

- Inexpensive

Unfortunately, currently no material satisfies all of these features. Throughout the history of cranioplasty, there have been various types of materials used. The following considers the commonly used materials for cranioplasty.

\subsubsection{Xenograft}

Animal bones have been used to close cranial defects. Xenograft considers a transplanted tissue/organ taken from a donor in a different class than the recipient [14]. In 1682, Meereken used a dog's cranial bones to attain closure of cranial defects [15]. In 1917, the term "soup bone" was introduced, which considered the scapulae of cows acquired from hospital meals for the purpose of cranioplasty. Empirically, the success of autografts and bone substitution techniques provided little justification for further study using xenografts [16]. 


\subsubsection{Autologous bone graft}

For cranial restoration, it is customary for autologous bone flap replacement using the formerly detached bone flap to be performed. Autologous bone grafts are favored as this method reduces foreign materials being introduced into the body, and the bone flap can be readily accepted by the host and incorporated back into the skull. In 1821, Walther is credited with the first recorded autologous bone graft cranioplasty [17]. In 1889, plastic reconstruction of the cranium was first recorded by Deyde, who used pieces of tibia to cover a left parietal defect with uneventful recovery [12]. It was later discovered that tibial grafts were not ideal due to the risk of tibial fracture and the discomfort it caused patients [12]. The re-placement of the original bone detached during cranioplasty is ideal as no other graft or foreign materials are present (Figure 2). This is preferable in pediatric patients, as the child's bone will become reintegrated as they mature [18]. Although favored, autologous bone transplants have risks. A prevalent problem in pediatric patients is bone flap resorption, in turn resulting in structural breakdown. In addition to resorption, it was determined that autologous bone grafts had the highest rates of infection at 25.9\% when compared with polymethylmethacrylate (PMMA) [19], alumina ceramics and titanium mesh [19].

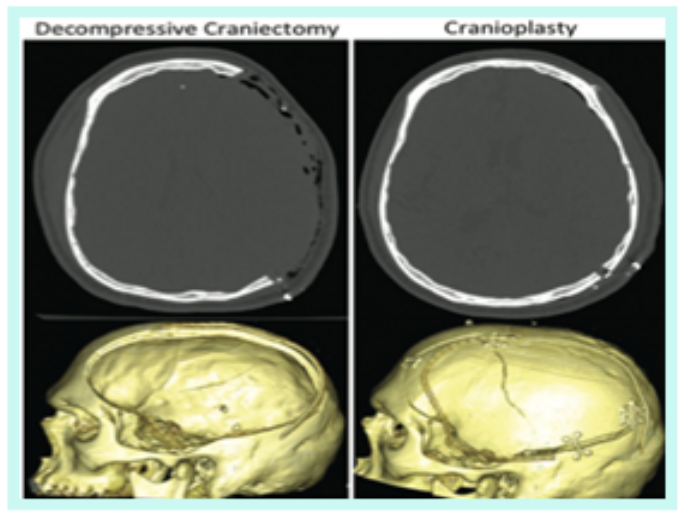

Figure 2: Autologous bone graft. Axial (upper) and 3D reconstructed (lower) CT scans obtained after decompressive craniectomy (left) and subsequent autologous bone flap replacement (right) [20].

\subsubsection{Allograft}

Allograft is defined as a transplanted tissue from a donor of the same class as the recipient who is not genetically the same [14]. Cadaveric cartilage was used as allograft during the First World War due to its elastic nature and resistance to infection. In 1917, 
Sicard and Dambrin investigated the use of cadaveric skull. The resected bone was treated with sodium carbonate, xylol, alcohol and ether and afterward sterilized by heat [14]. This reduced the thickness of the bone so that only the outer table remained, which could then be perforated for use [21]. These materials were not strong enough for use in cranioplasty and their use declined as they did not demonstrate calcification as anticipated and failed to provide sufficient mechanical protection [22]. This approach was susceptible to high infection rates and bone resorption. Autologous bone grafts and bone substitutes have gained more approval than allografts because of these complications.

\subsubsection{Metal allografts}

\subsubsection{Aluminum}

Aluminum was first introduced in the late $19^{\text {th }}$ century to perform cranial reconstructions but was affiliated with many infectious complications and epilepsy [12]. It is stated that aluminum was an insignificant bone replacement as it irritated surrounding tissues, prompted seizures and experienced a slow disintegration [23]. Aluminum was no longer used for cranioplasty based on these complications.

\subsubsection{Lead}

Lead was considered for cranioplasty application at the beginning of the $20^{\text {th }}$ century [12]. Lead is a naturally occurring metal; unfortunately lead is toxic to recipients [12].

\subsubsection{Platinum}

Platinum exhibited biocompatibility with no tissue reaction but was too expensive to be a widely sustainable option [24].

\subsubsection{Tantalum}

Tantalum (Ta) is resistant to tissue reaction, corrosion and infection [14]. Due to Ta's high heat conductivity, it has been reported to cause headaches in transplant recipients [25]. Tantalum-based grafts have shown biocompatibility and are safe to use in orthopedic, craniofacial, and dentistry surgeries. The bioactivity and biocompatibility of porous tantalum stems from its ability to form a self-passivating surface oxide layer [24], 
which leads to the development of a bone-like apatite coating in vivo allowing for rapid and substantial bone and soft tissue attachment [26]. These have produced successful early results in vitro and could become an alternative for joint resurfacing in the future. However, tantalum is found to be difficult to shape, transmits heat and cold too readily and its radio-opacity causes problems in postoperative imaging [27].

\subsubsection{Titanium}

Titanium has high overall strength and malleability. The use of titanium is inexpensive, bioacceptable, and radiolucent after mixing with other metals, even though it becomes hard to shape [28]. Titanium mesh has been used to support cement materials in order to allow for a stronger resistance [12]. It was demonstrated that titanium mesh had the lowest rate of graft infection of all cranioplasty materials at 2.6\% [19]. It was also found that the use of titanium mesh cranioplasty had decreased the rate of graft infection in patients who are at increased risk [14]. In addition, computer-assisted 3D modeling can be used to design titanium mesh implants that provide excellent cosmesis, even with large cranial defects [14].

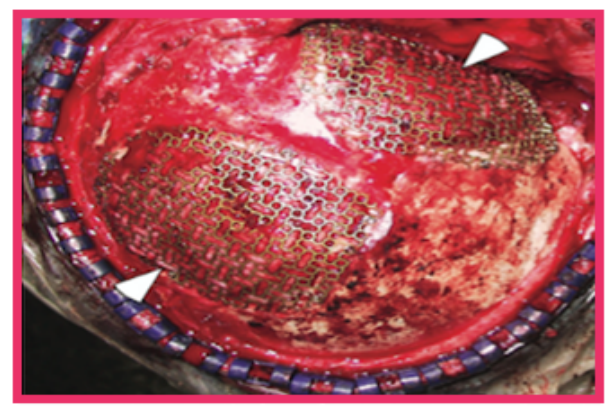

Figure 3: Titanium mesh in vivo. Intraoperative image showing titanium mesh covering skull defects. The left arrowhead indicates a left parieto- occipital skull defect with overlying titanium mesh. The right arrowhead indicates a left retrosigmoid skull defect with overlying titanium mesh [29].

\subsubsection{Gold and silver}

It was suggested in the $16^{\text {th }}$ century to replace skull defects with gold plates [30]. Gold delivered beneficial results as a cranioplasty material due to few complications and high malleability. Silver was first used by Sebileau in 1903. Since silver materials are soft, it became difficult for it to provide the mechanical protection required for cranioplasty [24]. Unfortunately, oxidization of silver resulted in pigment changes in the overlaying skin [24]. 


\subsubsection{Non-metal Allografts}

\subsubsection{Celluloids}

Celluloids are natural materials that were used up until the invention of tantalum and methylmethacrylate. Celluloids caused unfavorable tissue reaction [13]. The main disadvantage reported was postoperative fluid collection and the need for aspiration of this fluid [13].

\subsubsection{Polyethylene and silicon}

In 1968, Silicon was suggested as a cranioplasty material. Silicon is a natural chemical element that is commonly found in a crystalline form. Unfortunately, due to its soft build its use has been very limited [31]. Polyethylene can be melted into liquid form and remolded as it solidifies. Due to this, the material was well regarded [31].

\subsubsection{Ceramics}

Ceramics are compounds consisting of metallic and non-metallic elements, most frequently oxides, nitrides, and carbides [32]. Ceramic osteointegration can be comparable to acrylic depending on its components, yet their main drawbacks are their inadequate durability, lack of strength in anything other than compression [12]. Alumina ceramics have gained great attention for cranioplasty in the last few years due to their strength and aesthetic benefits [24]. These ceramics are almost as hard as diamond, chemically stable, and have comparable tissue compatibility to acrylics [24]. The addition of yttrium makes the alumina ceramic material slightly radiopaque [19]. Studies have revealed that custom-made ceramics have a very low postoperative infection rate of $5.9 \%$ [19]. The main disadvantages are that customized ceramics are expensive, they must be preformed, and they are susceptible to catastrophic failure regardless of their rigidity.

\subsubsection{Coral}

Natural coral bone graft substitutes (BGS) are found in the exoskeleton of marine madreporic corals [33]. Natural coral (Porires) consists of a mineral phase, principally calcium carbonate in the structural form of aragonite with impurities, such as $\mathrm{Sr}, \mathrm{Mg}$ and F ions, and an organic matrix. Corals were first evaluated as potential BGS's in animals in the 1970's and in 1979 in humans. Coral grafts act as an adequate carrier for growth 
factors and allow cell attachment, growth, spreading and differentiation [33, 34]. Though it was found to be an impressive BGS its main drawback is its inadequate durability [12].

\subsubsection{Calcium Phosphates}

Calcium phosphate $(\mathrm{CaP})$ based ceramics are used for bone reconstruction due to their ability to exhibit bioactivity as well as being available in both porous (for bony ingrowth) and dense (for enhanced mechanical properties) forms [35]. CaPs demonstrate an element of resorbability, which permits the re-growth of natural bone [36]. CaPs are well known for their use in biological applications [37]. The most commonly used materials in medical procedures are Hydroxyapatite (HA) and Tricalcium Phosphate (TCP) [38, 39], due to their chemical arrangement being comparable to that of bone mineral. CaPs are separated into different forms based on their calcium $(\mathrm{Ca})$ to phosphate $(\mathrm{P})$ ratio $(\mathrm{Ca} / \mathrm{P})$ [40]. Many forms of $\mathrm{CaP}$ fall under the category of apatites, defined as a group of compounds that share a similar structure [37, 41]. Changes in $\mathrm{pH}$ and reaction conditions, for example solvent, pressure, temperature, nature of precursors and the complexing agents utilized for controlling the reaction kinetics could also affect the apatites group [37].

\subsubsection{Hydroxyapatite (HA) - Zirconia $\left(\mathrm{ZrO}_{2}\right)$}

Hydroxyapatite (HA) is used in various medical applications as it is similar to the mineral phase of both bone and teeth [36, 42]. HA is both biocompatible [43] and osteoconductive [44-46], in turn stimulating the growth of new bone in-vivo without causing an immune response [47]. Due to HA's low strength and brittleness, it has been utilized as a bioactive layer on metallic or plastic porous implant materials for the purpose of stimulating bone growth, therefore it is not used as a load bearing implant [48, 49]. Calcium phosphate based decomposition products are created due to the sintering of HA at high temperatures; such as tetracalcium phosphate (TTCP), which can decompose further to tri-calcium phosphate (TCP) [50] and calcium oxide $(\mathrm{CaO})$. In some cases these resulting phases have been said to negatively affect biological response [51, 52]. Currently, much attention has been given to Zirconia $\left(\mathrm{ZrO}_{2}\right)$ based ceramics [53, 54] due to their high fracture toughness in comparison with other ceramics. It has been indicated 
that the mechanical properties of $\mathrm{HA}$ can also be enhanced using $\mathrm{ZrO}_{2}$ inclusions [55]. In order to completely densify $\mathrm{ZrO}_{2}$ high sintering temperatures $\left(>1500^{\circ} \mathrm{C}\right)$ are necessary [47]. It can be difficult to create dense $\mathrm{HA}-\mathrm{ZrO}_{2}$ composite bodies at these high temperatures as it could lead to dehydroxylation and following decomposition of HA to calcium phosphate forms that are more resorbable in-vivo or weak $[36,56,57]$.

\subsubsection{Cortoss}

Cortoss (Orthovita, Malvern, USA) is a advanced synthetic bone void filler that contains bis-glycidyl methylmethacrylate, bisphenol, trethylene glycol dimethylacrylate monomer, and bioactive glass [58]. It is intended to imitate cortical bone. It is offered in a double lumen cartridge with specially designed tips for mixing. Once the compound is expressed thorough these tips, polymerization begins [58]. The elasticity of Cortoss is similar to that of bone [12]. It is suggested that there are lower incidents of inflammation associated with Cortoss [58]. Despite the improvements Cortoss offers, there are a number of disadvantages associated with its use in skeletal applications including an excessively high exothermic reaction $\left(63^{\circ} \mathrm{C}\right)$ relative to the threshold associated with thermal necrosis of healthy bone tissue $\left(56^{\circ} \mathrm{C}\right)[59]$.

\subsubsection{Cranioplasty procedure}

This procedure is usually performed for trauma, fractures, skull/bony tumors, infections and congenital deformities [60]. Traditionally, surgeons will replace the patient's original bone flap if it has been detached. If the patient's bone flap cannot be reattached, artificial flaps can be created from various materials. During surgery the patient is placed under local anesthetic while the scalp is cut over the defect [60], at this time the defect is removed and smoothed as necessary [60]. If methyl methacrylate is used for reconstruction, the surgeon molds the material to fit the defect and allows it to harden; bone can also be harvested from the skull, rib or hip for reconstruction [60]. If an acrylic plate is used to cover the defect, holes are drilled in the periphery of the acrylic plate as well as the defect; the plate is placed over the defect to cover it, wires are threaded through the holes in order to secure the plate and the skin is then sutured closed [60]. Once the surgery is completed the patient undergoes a neurological assessment and evaluated for any complications that could occur. 


\subsection{Craniotomy bone flaps and techniques}

Craniotomy is a surgical technique where a bone flap is removed in order to access the brain underneath [8]. When craniotomy bone flaps are replaced it is due to either cosmetic or protective reasons. In order to meet these objectives, it is crucial for the bone flap to be secured to the edge of the bone defect. Sutures or wires have been used to fix the cranial flap to the skull in its original position [8]. Unfortunately, sutures tend to allow settling of the bone flap beneath the level of the outer table of the rest of the skull, in turn producing a suboptimal cosmetic result [8]. A fixation device must secure primary attachment while also ensuring fast and optimal bony healing [61]. Previously, the fixation of bone flaps had been implemented using steel wires, however, the introduction of computed tomography (CT) demonstrated extensive metal artifacts caused by these wires, which led to a worldwide shift to fixation by sutures [61]. The use of miniplates for the fixation of the bone flap has enhanced the safety of the attachment; however this method tends to be time-consuming and more costly. The development of CranioFix (CF) was a result of these conditions [61]. CF is an innovative system for fixation of cranial bone flaps [61]. It was suggested that this could be avoided when bone flaps are typically cut with a beveled edge using a high-speed drill [62]. This creates better cosmetic results, but does not entirely prevent settling [62]. Wires are also prone to failing, particularly if over twisted, and can be palpated through a thin scalp if they are not correctly buried [62]. Figure 4 displays the steps taken during a craniotomy technique (left to right); the patient's head is placed in a three-pin skull clamp; the clamp attaches to the operating table and holds the head still during the brain surgery [4]. The skin incision is usually made behind the hairline (dashed line); a craniotomy incision with a special saw called craniotome is made [4]. The bone flap is then removed to reveal the protective covering of the brain called the dura; the dura is opened and folded back to expose the brain; then the bone flap is replaced and secured to the skull with tiny plates and screws [4]. 


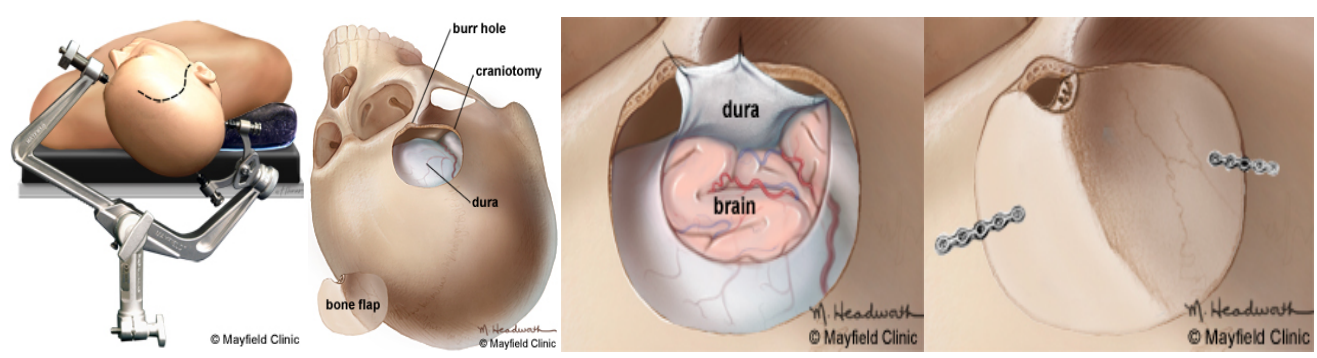

Figure 4: (Left to right) The steps taken during a craniotomy technique [4].

Estin, et al. [62] provides a description of an alternate cranial fixation system, consisting of two titanium discs attached to a pin. These discs perform as a clamp across the cut edge of both the skull and the bone flap. Placing three or four clamps around the perimeter of the craniotomy will allow the bone flap to be strictly fixated. Clamp sizes of $11 \mathrm{~mm}$ and $16 \mathrm{~mm}$ are used. An analysis was conducted to determine the capability, strength, timing and expenses of an alternate system for securing bone flaps. The system contains titanium discs that clamp the bone flap to the skull edge [62]. For the purpose of the analysis, Estin et al. [62] presented four formalin-fixed cadavers. Each cadaver head was restrained in a three-point pin fixation. Four circular craniotomies had been created in each hemisphere, in total 32. The four localities chosen for the craniotomies were frontal, temporal, anterior parietal and posterior parietal. The standard craniotomy diameter was $4.7 \mathrm{~cm}$. There were three varieties of fixation used for 10 craniotomy flaps each: wire, miniplates, and titanium clamps. The use of two surgeons was required to secure each flap. Ten flaps were secured with each of the three types of fixation [62].

\subsubsection{Wire fixation}

It was confirmed that wiring using Stainless Steel is the standard technique for cranioplasty due to its simplicity, strength, short healing time and rigidity [63]. This study started with twenty-four-gauge stainless steel wires; holes are then drilled in each flap and in the adjacent skull edge. Wires are then distributed through the holes in the skull edges and then throughout the holes in the flap. Each wire pair is then twisted until taut, the excess wire is trimmed and the loose end is buried in the hole made in the skull edge [62]. 


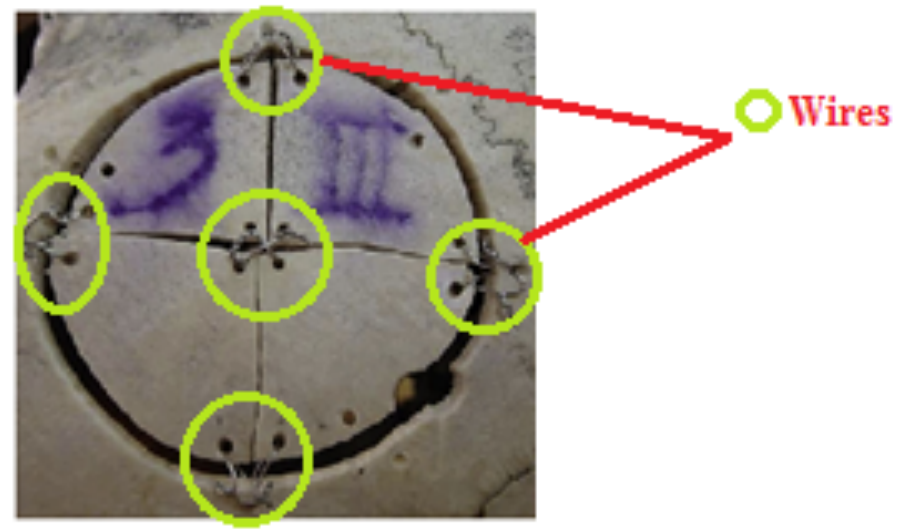

Figure 5: Cranial flap wire fixation technique [64].

\subsubsection{Miniplate fixation}

Cranioplasty using custom-made HA ceramic implants is a common procedure for skull defects. However, miniplate fixation using commercially available screws to stabilize the HA flap is associated with several problems due to the HA's characteristic brittleness. In this situation, the plates are accurately positioned 120 degrees apart along the perimeter of the craniotomy defect and initially secured to the free craniotomy flap. A hand-held drill was used to tap holes and screws were then applied. The flaps with attached plates are then situated in the skull defect and are fastened in to secure the skull edge [62].

A study was conducted to develop customized screws for HA implants in cranioplasty using hydroxyapatite (HA) blocks [65]. The HA blocks were prepared (APACERAM, provided by Pentax, Co, Ltd), that were synthesized (40\% porosity, 30x30x5 mm) from the most common HA ceramic implants for cranioplasty [65]. Holes for screw fixation were created perpendicularly through the HA plates in the center of the blocks using a specially designed HA drill that has a stainless steel tip; 3 holes were made in each whole titanium miniplates (Piolax Medical Devices Co.) [65], as shown in Figure 6A. The study evaluated five different screws that have been developed to secure the titanium miniplate [65]. Figure 6 explains the different types of screws used; screws No. 1, 2, 3 and 5 had a length of $3.3 \mathrm{~mm}$, while No. 4 had a length of $4.8 \mathrm{~mm}$. The edge height for No.1 was 0.15 $\mathrm{mm}$, No. 2, 4 and 5 were $0.3 \mathrm{~mm}$ and No. 3 was $0.2 \mathrm{~mm}$ as [65]. 


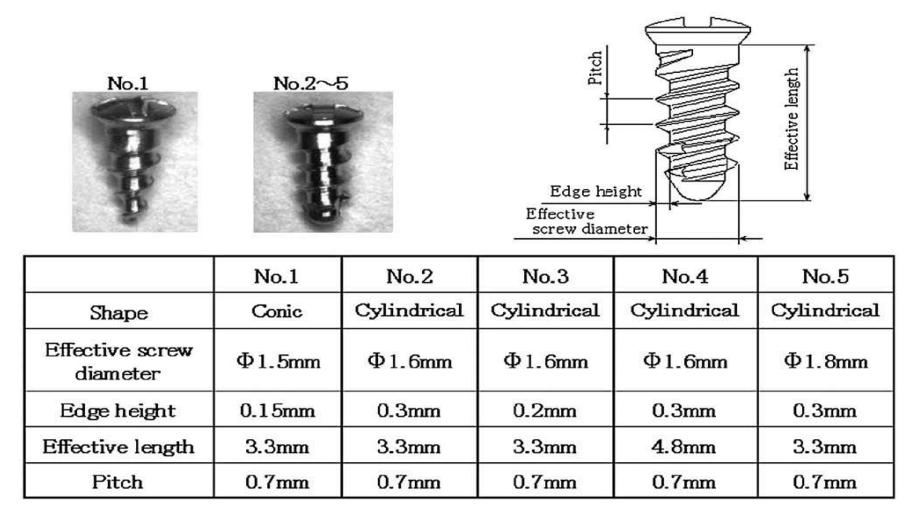

Figure 6: The five different types of screws used. The following points- the shapes, effective screw diameter, edge height, effective length-are evaluated under the same length of pitch, 0.7mm [65].

Pull out strength tests were used to determine fixation strength (Figure 6A). The miniplate was then pulled into a U shape; a screw was inserted through the middle hole to the HA hole; stainless steel (SUS304-WPB) wire was passed through the 2 outer holes and connected to an autograph AGS-H) (Shimazu Corporation, Tokyo, Japan) [65]. The head pulled the wire at a speed of $10 \mathrm{~mm} / \mathrm{min}$ and the breaking force was measured when the wire was pulled out [65]. It was found that screw No. 1 was not able to fix rigidly, and thus no data were obtained [65]. The pull-out strength for screw No. 2, 3 and 5 showed an average strength of $97 \mathrm{~N}$, while No. 4 had the longest length and a pull-out strength between 220 to $256.7 \mathrm{~N}$ [65]. It was also shown that only screw No. 5 presented cracking around the hole, while screw No. 1 was not fixed adequately and there was no damage around the HA hole after insertion of screw No. 2 to 4 [65]. The strength value of screws No. 1-5 was found more dependent on the length due to the skull needing to be drilled in order for the screws to be implanted into the bone.
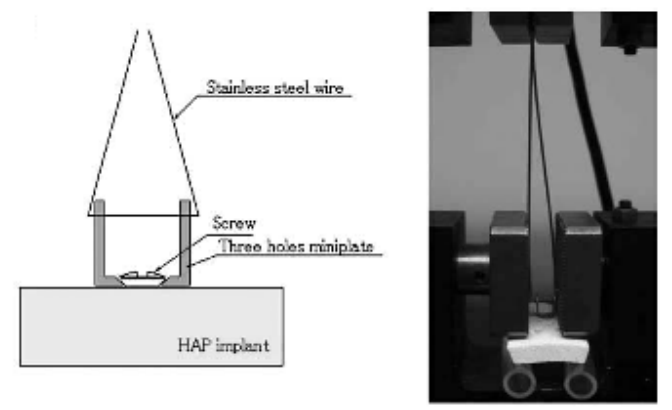

Figure 6A: The pull-out test method is shown. Three hole miniplate bent to U shape was fixed with screw in the center hole created previously by the exclusive drill (APACERATOME).The pull-out strength was measured to pull the wire passed though holes of the plate [65]. 


\subsubsection{Titanium clamp fixation}

Three clamps were used for each craniotomy flap presented in this analysis. Respectively, clamps consisted of two discs on a 50-mm-long threaded pin. These discs are 11-mm in diameter with somewhat curved and sharp edges. Each of the three clamps were arranged at 120 degrees apart along the circumference of the craniotomy defect, with the inner disc located partially in the epidural space under the bone edge [62].

After conducting the analysis, it was found that there was no substantial variance in the time it took to secure a bone flap between the different cranial locations and there was no significant difference found in the time taken to secure a bone flap between different cadavers [62]. The mean fixation time for the three fixation methods used, as well as the results of the load-bearing tests are represented in Table 1. It is indicated that the fixation time was notably shorter for the titanium clamps in comparison with wire and miniplates, while the fixation time was considerably shorter for wire compared to miniplates. The results of the load-bearing tests showed translation of wire-fixated bone flaps at 10 pounds of force and wire failure at 40 pounds. However, miniplate-fixated flaps started to display translation at 40 pounds although no failure was present, even at 100 pounds. Whereas, titanium clamp-fixated flaps revealed no translation until it reached complete failure at 60 pounds [62].

Table 1: Representation of load-bearing test results and mean fixation time for the three fixation methods presented [62].

\begin{tabular}{cccc}
\hline FIXATION & MEAN FIXATION & FORCE TO & FORCE TO \\
TECHNIQUE & TIME (IN MIN'S: & TRANSLATION & FAILURE \\
& SEC) & (LBS) & (LBS) \\
\hline Wire & $5: 40^{+}$ & 10 & 40 \\
Miniplate & $6: 52$ & 40 & $>100$ \\
Titanium clamps & $1: 45^{*}$ & 60 & 60 \\
\hline
\end{tabular}

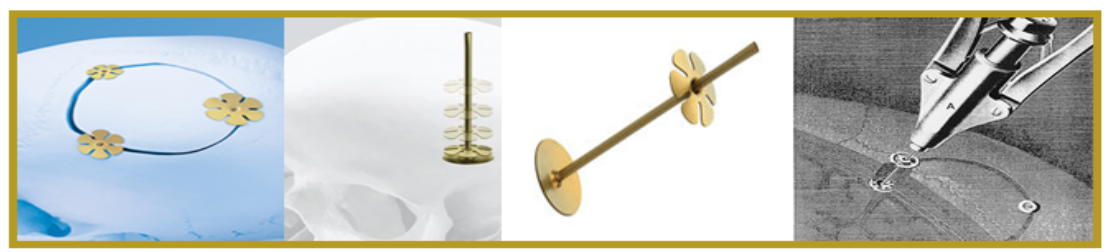

Figure 7: (Left to Right) The titanium clamp that is used for bone flap fixation containing two discs on a threaded pin. In order to secure the bone flap to the skull, the inner disc of the titanium clamp is inserted into the epidural space, partly under the bone flap and partly under the skull (arrow). The application forceps $(A)$ is then used to advance the outer disc down toward the inner disc [62]. 


\subsubsection{Comparison of case studies}

A study was conducted by Shu-xu et al [66] of fractured cranial flap refixation between sutures, wire and titanium clamps. The study consisted of twenty-four-cadaver craniotomy flaps. The results of the study were compared between sutures, wire and titanium clamps as represented in Figure 8 and Table 2.

\begin{tabular}{|c|c|c|c|}
\hline Fixation techniques & Suture & Wire & Titanium clamp \\
\hline No. flaps for fixation & 8 & 8 & 8 \\
\hline $\begin{array}{l}\text { Mean fixation } \\
\text { time }(\mathrm{s})\left(\sigma_{\mathrm{n}}\right)\end{array}$ & 631 (S.D. 47) & 1104 (S.D. 48) & 142 (S.D. 16) \\
\hline $\begin{array}{l}\text { Mean initial offset } \\
\qquad(\mathrm{mm})\left(\sigma_{\mathrm{n}}\right)\end{array}$ & 1.93 (S.D. 0.33) & 1.80 (S.D. 0.42) & 0.35 (S.D. 0.07) \\
\hline $\begin{array}{l}\text { Mean maximal load } \\
\qquad(\mathrm{N})\left(\sigma_{\mathrm{n}}\right)\end{array}$ & 89.43 (S.D. 13.76) & 285.51 (S.D. 10.46) & 384.06 (S.D. 24.89) \\
\hline
\end{tabular}

As shown in Table 2, the mean fixation time for suture fixation was $631 \pm 47 \mathrm{~s}(\mathrm{~N}=8)$, for stainless wire fixation was $1104 \pm 48 \mathrm{~s}(\mathrm{~N}=8)$, and for titanium clamp fixation was $142 \pm 16 \mathrm{~s}(N=8)$ [66]. Fixation time was significantly shorter for the titanium clamp compared with suture and wire, with a $\mathrm{P}$ value of $<0.001$ [66]. Fixation time was significantly shorter for suture than for wire with a $\mathrm{P}$ value of $<0.001$ [66]. The initial offset for suture fixation can be seen as $1.93 \pm 0.33 \mathrm{~mm}(\mathrm{~N}=8)$, with no significant difference compared with that of wire fixation $(1.80 \pm 0.42 \mathrm{~mm}, N=8, \mathrm{P}=0.612)$ [66], titanium clamp fixation was $0.35 \pm 0.07 \mathrm{~mm}(\mathrm{~N}=8)$, which was significantly shorter than that of suture $(P=0.001)$ and wire fixation $(P=0.001)[66]$. The maximal load for the titanium clamp fixation system is shown as $384.06 \pm 24.89 \mathrm{~N}(\mathrm{~N}=8)$, the wire system was $285.51 \pm 10.46 \mathrm{~N}(N=8)$ and the suture system was $89.43 \pm 13.76 \mathrm{~N}(\mathrm{~N}=8)$ [66]. The maximal load for titanium clamp fixation was significantly larger than that for suture and wire, with a $\mathrm{P}$ value of $<0.001$ for both [66]. Wire was found to be better than suture in terms of maximal load $(\mathrm{P}<0.001)[66]$. 


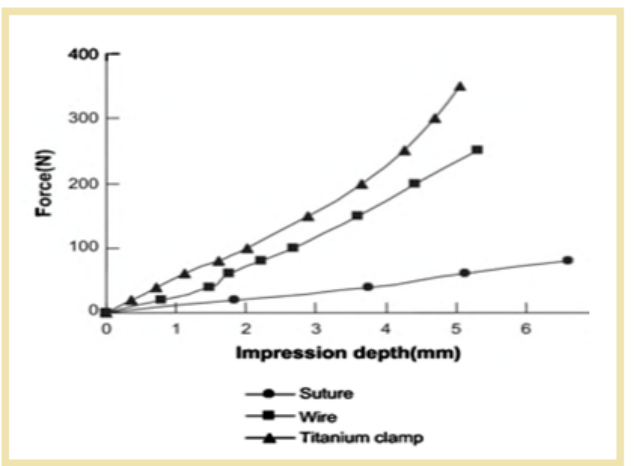

Figure 8: Results of the load-bearing tests. Load-shift curve of different impression depths with fractured skull flap fixation technique [66].

The results of load-bearing tests are demonstrated in Figure 8. It is shown that suture could endure only a significantly low force, and demonstrated to be the weakest fixation method with the highest variable deviation of impression from different applied forces [66]. The titanium clamp showed a good spring-elastic reserve with the most constant standard deviation, while wire displayed force-verses-impression value ranges between suture and titanium clamp, allowing wire to be much stronger than suture [66].

A study conducted by Wang et al [64] evaluates the biomechanical characteristics of the techniques of cranial flap fixation of suture, stainless steel wire and rivetlike titanium clamps. Twenty-four cadaver craniotomy flaps had been reattached using suture, stainless steel wire or rivetlike titanium clamp. The results of their study are presented in Table 3 and Figure 9.

Table 3: Mean fixation time, initial offset, and maximal load (the force to the failure of the fixation system) for each

\begin{tabular}{ccccc}
\hline $\begin{array}{c}\text { Fixation } \\
\text { techniques }\end{array}$ & $\begin{array}{c}\text { No. flaps for } \\
\text { fixation }\end{array}$ & $\begin{array}{c}\text { Fixation Time } \\
\text { (in second) }\end{array}$ & $\begin{array}{c}\text { Initial Offset } \\
\text { (in mm) }\end{array}$ & $\begin{array}{c}\text { Maximal Load } \\
\text { (in newton's) }\end{array}$ \\
\hline $\begin{array}{c}\text { Suture } \\
\text { Wire }\end{array}$ & 8 & $172 \pm 14$ & $2.20 \pm 0.24$ & $82.6 \pm 8.6$ \\
Titanium clamp & 8 & $399 \pm 45^{*}$ & $1.32 \pm 0.34^{*}$ & $332.5 \pm 53.2^{*}$ \\
& 8 & $94 \pm 13^{*+}$ & $0.20 \pm 0.12^{*+}$ & $385.4 \pm$ \\
& & & & $63.1^{*+}$ \\
\hline
\end{tabular}

Table 3 shows the mean fixation time, initial offset, and maximal load (the force to the failure of the fixation system) for 3 fixation techniques. Fixation time was significantly shorter for titanium clamp compared with suture and wire, with a $P$ value of $<0.001$ [64]. 
Initial offset of titanium clamp fixation was significantly smaller compared to suture and wire, with a $P$ value of $<0.001$ [64]. The maximal load was larger for titanium clamp compared with suture and wire, with a $P$ value of $<0.001$ and $<0.05$, respectively [64]. Also, fixation time was significantly shorter for suture than for wire, but for initial offset and maximal load wire proved to be better than suture [64].

Figure 9 shows the results of the load-bearing test performed for Wang et al. [64] study. It is shown that suture could withstand only significantly low force [64]. Stainless steel wire was stronger than suture but with a highly variable deviation of impression versus applied force, while rivetlike titanium clamp proved to be the strongest fixation device and with the most constant standard deviation [64]. Titanium clamp also offered a welldefined spring-elastic reserve up to the failure of fixation system, compared with suture and wire [64].

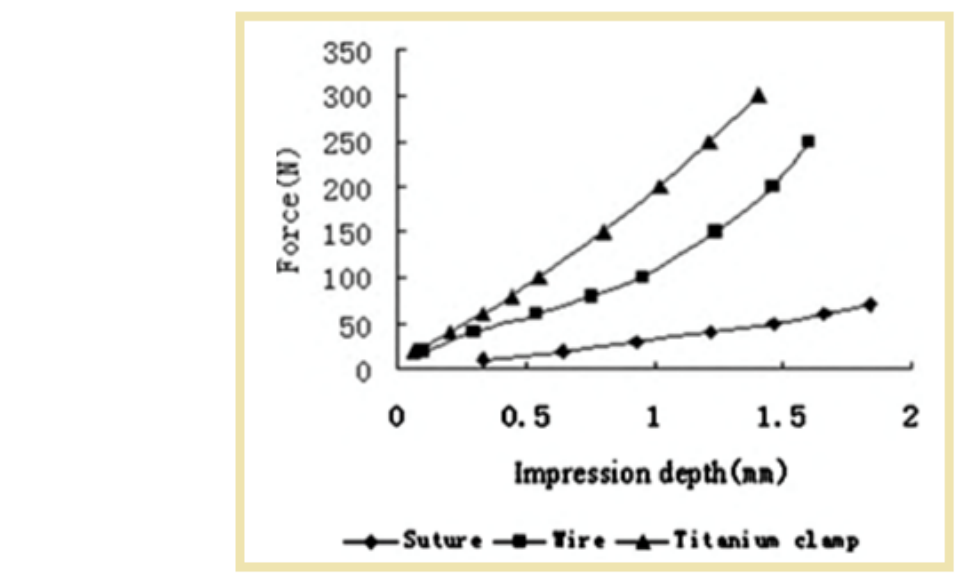

Figure 9: Results of the load-bearing test. Load-shift curve of different cranial-flap-fixation techniques' impression depth [64].

A study was performed on a total of eight craniotomies on four human cadaver skulls that have been fixed in methylacrylate [61]. The bone flaps were refixed several times as follows: 1) with multifil suture material 1-0 Synthofil (B. Braun, Inc., Melsungen, Germany); 2) using the Aesculap titanium plate technique (two-hole plates, $0.6 \mathrm{~mm}$ thick, 7-mm screws); 3) using the Quickflap miniplate system (Leibinger Inc., Freiburg, Germany) (0.4 mm thick, 4-mm screws); and 4) using the CF system. The results of the analysis are presented in Figure 10. 


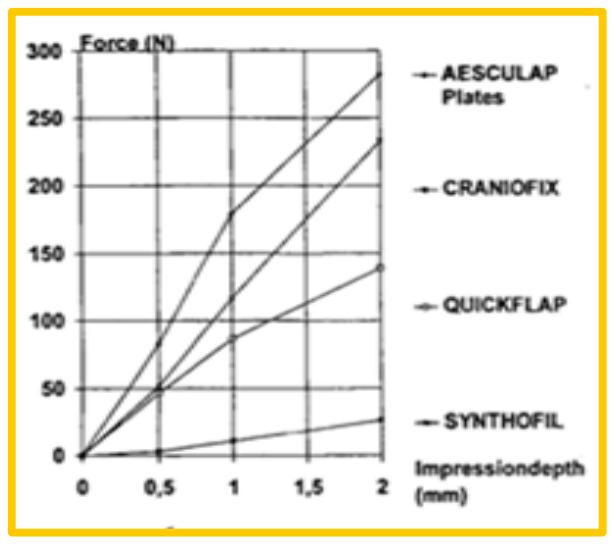

Figure 10: (Comparison of different cranial flap fixation techniques after load-bearing tests. Left-graph demonstrating applied forces in newtons in relation to the impression depth: AESCULAP, 0.6-mm miniplates and 6-mm-long screws; CranioFix titanium clamps; Quickflap, 0.4-mm miniplates and 4-mm-long screws; Synthofil sutures, 1-0 [61].

The analysis found that the thick Aesculap titanium plates showed to be the strongest fixation device, but with a high standard deviation of impression versus applied force. The thinner Quickflap miniplates can endure only significantly lower forces and display a highly variable standard deviation [61]. CF demonstrated force-versus-impression value, which implies a high reproducibility not dependent on bone thickness and consistency [61]. However, it was found that the weakest fixation was acquired by suturing. To date, no complications have occurred after bone flap fixation with CF. Lerch [61] witnessed 11 dislocations in the observable area of the forehead. One case had resulted in the need for reoperation, and 12 dislocations in nonvisible areas after suturing in a comparative group of another 100 cases [67]. The quality of postoperative CT and MRI is not reduced because the titanium alloy yields only minimal vulnerability artifacts [61].

\subsubsection{Discussion}

Shu-Xu et al [66] found that the titanium clamp system offers distinctive advantages compared to suture and stainless steel wire in fractured cranial flap refixation, as no dural separation from bone is necessary for placement. Shu-xu et al [66] demonstrated it to be a practical alternative method of fractured cranial flap refixation with respect to ease of use, time consumption, precision and strength. Estin et al [62] analysis attested that the titanium clamp cranial flap fixation system was not only easy to use but was also notably faster than wire or miniplate fixation. In comparison to the miniplate system, the titanium clamp system offered similar cosmesis and resistance to translation at a more affordable cost, although it did fail at a smaller force than miniplates. The titanium clamp system 
was found to be a rational substitute to contemporary craniotomy fixation techniques in relation to ease of use, strength, time consumption and cost efficiency [62]. Following this, Wang, et al [64] confirmed that the titanium clamp cranial flap fixation system was much easier and faster to implement than both suture and wire fixation. The titanium clamp system was found to offer better cosmesis and strength compared to suture or wire fixation as presented in Tables 2 and 3. It is best to say that the titanium clamp system is a rational alternative to existing craniotomy fixation methods. Lerch [61] has shown that both CF and miniplates are certainly better then suturing, and, CF was found to offer unique advantages over miniplates. It is still common today for many centers to use suturing. This said, the use of suturing should be reconsidered as a modern-day technique.

\subsubsection{Titanium cranioplasty}

Titanium cranioplasty focuses on repairing defects of the skull with titanium plates. It is easier for the skull shape to be precisely replicated using titanium [68]. This technique is simple compared to wiring or suturing methods. The material is inert, radiolucent and firm.

\subsubsection{Preparation of the plate}

The plate is prepared as follows: Once the impression is made, a dental plaster cast is prepared and built up to the necessitated contour with dental wax. The shaped cast is used to formulate a die in dental stone, which is later placed in a high-pressure hydraulic forming chamber [68]. The plate used to conceal the defect, is made from titanium I.M.I. 115, (Imperial Metal Industries Ltd) 0.024 in $(0.61 \mathrm{~mm})$ thick. A titanium blank, is secured in place by fastening the cover plate to the pressure vessel. Fluid pressure, applied to the surface of the rubber diaphragm by a high-pressure hydraulic pump moulds the titanium sheet on to the surface of the dye [69]. Once the forming is complete, the plate is cut to the precise size, which results in a series of peripheral projections. These are drilled to receive the retaining screws (Figure 11). The completed plate is anodized to offer an enhanced compact oxide surface layer [68]. 


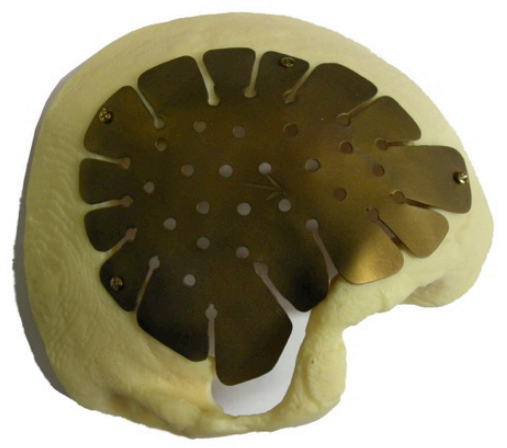

Figure 11: Titanium plate with drilled projections for retaining screws [70].

Twenty-five patients with large skull deficiencies initiated by gunshot or bomb explosion injuries that have had titanium cranioplasty have been observed [68], and the method has been reported to have several benefits.

1. Precision- the skull contour can be precisely replicated and slight alterations are easy to make.

2. Ease of Fixation- theoretically, the process of drilling the skull and adding screws is simpler and much easier compared to wiring or suturing methods. With wiring and suturing dissection of the bone edge and the extradural space are commonly performed. Use of an onlay technique allows for a significant reduction in operating time.

3. Good Tissue Acceptance- Anodized titanium is an inert implant material. There is no reactive oedema of the scalp and no postoperative subgaleal effusion [68].

4. Dead space- Previous metal onlay techniques did not include provision for obliterating the dead space between the plate and the dura. When there is a large space a heat-cured acrylic resin mass can be processed to the tissue fitting surface of the plate (Figure 12) [68].

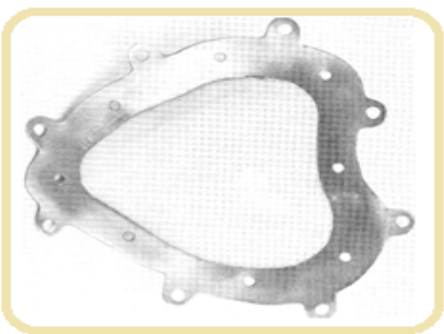

Figure 12: Form fitting cranial plate. An acrylic mass attached to deep surface of plate fills dead space between dura matter and plate [68].

5. Radiolucency- Radiological studies are possible because Titanium is adequately radiolucent.

6. Strength-Since the titanium sheet is designed to a molded contour it becomes firm therefore, enduring substantial external force. 
7. Lightness- Titanium has a density that is lower than other metals and alloys.

8. Sterilization- unlike majority of plastic materials, titanium plates and screws can be autoclaved.

The following is an image of cranioplasty plates and their method of installation.

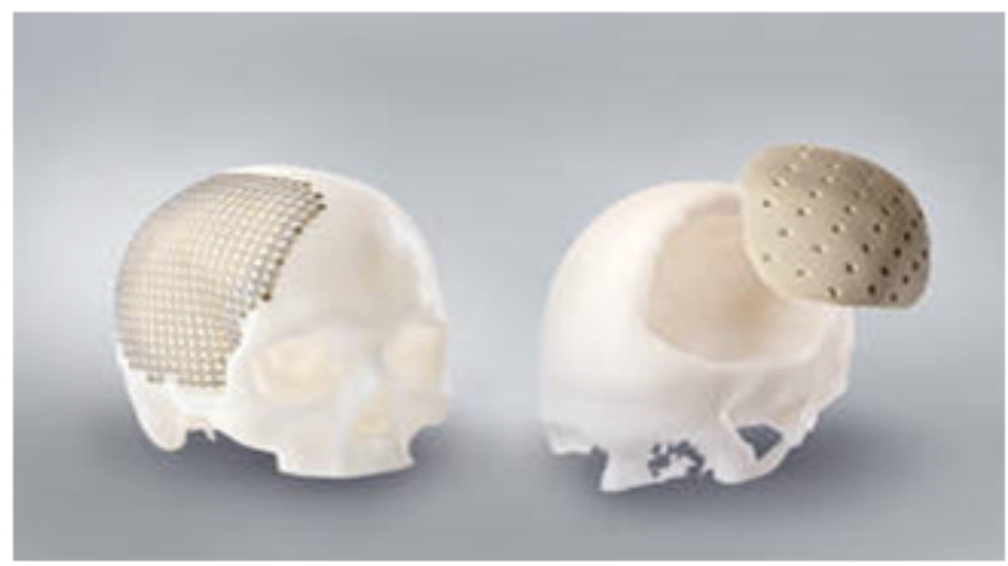

Figure 13: (Left) Titanium mesh plate (Right) Titanium miniplate [71].

\subsubsection{Titanium-strips cranioplasty}

Titanium strips have been used to repair skull defects in situations where pre-formed metal plates are not obtainable and wiring is not adequate [72]. This particular method is simple, does not require dissection of the dura mater, and offers better resistance to additional impact injury than an inlay technique [72]. The strips of titanium IMI 115, 0-6$\mathrm{mm}$ thick, are cut to numerous widths and lengths as shown in Table 4. Once polishing is complete, the strips are submerged for a couple of minutes in a preserving solution that is used to eliminate any metallic impurities and then they are anodized to a final anode voltage of $60 \mathrm{~V}$. This process is performed to change the surface color from grey to gold since dark grey plate would be visible through hairless parts of a thin scalp. Anodizing also provides the plate with an enhanced oxidized surface layer; this may decrease the risk for tissue reaction [72]. 
Table 4: Indicates the details of titanium strips used in cranioplasty.

\begin{tabular}{cccc}
\hline & \multicolumn{3}{c}{ Titanium strips } \\
\hline \hline Widths $(\mathrm{cm})$ & 1.5 & 1.0 & 0.5 \\
Lengths $(\mathrm{cm})$ & $4-20$ & $4-20$ & $4-20$ \\
Diameter of holes & 3 & 3 & 2 \\
$(\mathrm{~mm})$ Distances & 2.0 & 1.0 & $0-8$ \\
between centres of & & & \\
holes $(\mathrm{cm})$ & & & \\
\hline
\end{tabular}

Table 5: Indicates the details of screws, and dental burrs used in cranioplasty.

\begin{tabular}{ccc}
\hline $\begin{array}{c}\text { Screws: } \\
\text { Types }\end{array}$ & JCH 342 (Down & GT 464 (Down \\
Bros) & Bros) \\
\hline Lengths $(\mathrm{mm})$ & 5,6 , and 7 & 5,6 and 7 \\
Dental burrs: & Round 8 & Round 6 \\
Sizes & & \\
\hline
\end{tabular}

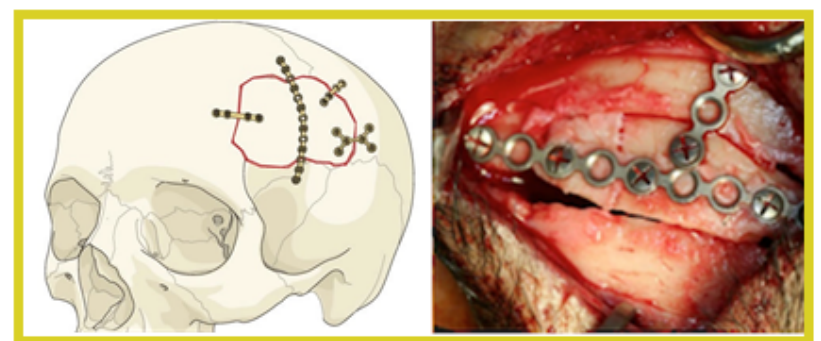

Figure 14: Titanium strips of various widths and lengths used for cranioplasty after debridement of missile wound [73].

Titanium is radiolucent, making it beneficial in cases where radiography becomes necessary. It is suggested when titanium strips are shaped to the skull, they offer greater resistance compared to unformed strips to high-impact loading [72]. Once secured, the strips provide a strong protective cover. All metals previously mentioned have caused some sort of complication (loose screws, stability concerns), infection and possibility of tissue damage. Due to these issues, there has been a great interest in biomedical cements as an alternative biomaterial for cranioplasty attachment.

\subsubsection{Cementing}

The practice of biomedical cements or adhesives in skeletal applications has increased substantially. A detail of two effective cement systems and their disadvantages will be discussed. Polymethylmethacrylate (PMMA) cements had initially been produced for use in dentistry due to their handling properties [74] and have been used since for fixation of 
hip replacements [74]. Today polymethylmethacrylate is known as the primary synthetic load bearing biomaterial in orthopaedics [75]. However, PMMA provides no chemical bond to bone, rather it is fixed in place by mechanical interdigitation at the bone-cement interface [75]. The cement is also based on a toxic monomer and cures at high temperatures, known to damage healthy bone stock [75]. The survivability of prostheses cemented with PMMA bone cement is only 10-15 years [74]. Calcium phosphate cements (CPCs) are a second cement system. Since CPCs sets in ambient situations to produce hydroxyapatite (HA), which is the mineral period for bone and tooth, this form of cement systems has been known as reconstructive materials in orthopaedics. This cement system demonstrates exceptional biocompatibility. Yet, their existence in the medical field are restricted due to the low setting times and insignificant strength in vivo. Both PMMA and CPCs systems are available despite their individual disadvantages and thus are able to offer a comparison among probable skeletal cement systems and medically recognized systems [74].

\subsection{Poly-methylmethacrylate (PMMA) in cranioplasty}

PolyMethyl methacrylate (PMMA) is a polymerized organic compound of acrylic acid that is comparable to bone [76]. Acrylic is easy to shape, lighter, and is radiolucent [77]. Acrylic in the form of PMMA was originally used in animal models, and later in humans [78]. Animal experiments revealed that acrylic adheres to the dura mater with no reaction to other underlying layers [78]. Charnley first introduced PMMA in the 1960's [79]. Attempts have been made to reinforce PMMA with steel or titanium meshes. Aydin, et al. [12] reports that PMMA is still the most extensively used cranioplasty material.

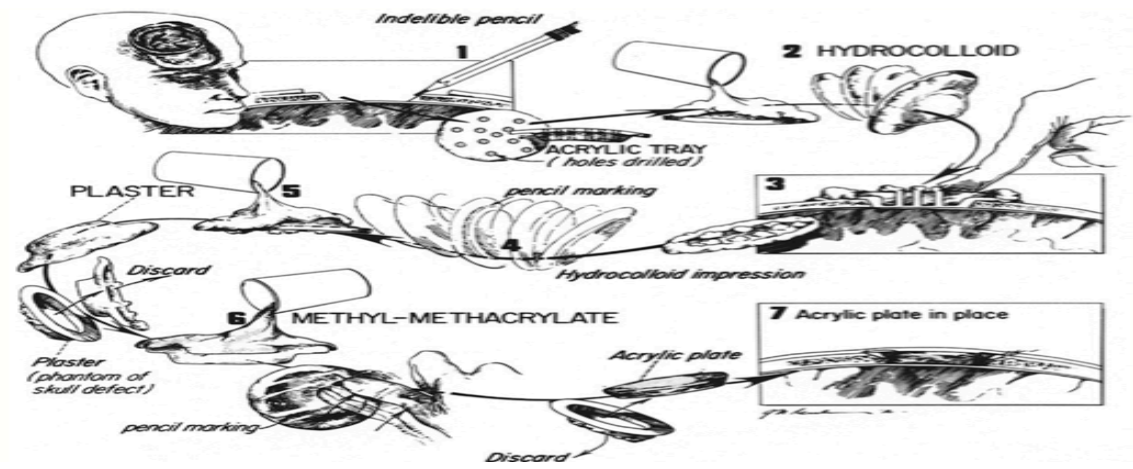

Figure 15: Preparing MMA. Drawing showing the steps required in molding the MMA to the defect and placing it in position. While being mixed, the substance can cause an exothermic reaction. This makes the substance a malleable paste but may also cause burn injuries [80]. 
PMMA consists of many other drawbacks such as:

1. High curing exotherm producing thermal necrosis of healthy bone tissue [75].

2. The PMMA monomer is poisonous and can lead to chemical necrosis of healthy bone [75].

3. PMMA can produce huge osteolysis due to fragmentation [75].

4. PMMA has also been implicated in the impairment of chemo-taxis, and phagocytosis of PMNs thereby increasing susceptibility to infection [81].

5. Lack of a chemical bond to surrounding bone [82].

6. Fibrous encapsulation in-vivo [82].

In cranioplasty applications, PMMA cements have had limited success. For instance, a study (of 36 patients) exhibited increased intracranial pressure, infection and traumatic bone destruction occurred in a number of cases resulting in four subject deaths, and 14 severely disables [83].

PMMA is used to repair various parts of the body and it is also used to reconstruct the cranial vault; it is a naturally inert alloplastic material when set [84]. Methyl methacrylate does not allow tissues to combine together, unfortunately, making it more vulnerable to dislocation and/or fracture. Wire reinforced masonry methods are used in this study to ensure that the tensile strength of methyl methacrylate as an onlay cranioplasty is increased [84]. Figure 16 (left) represents a 56-year-old female patient who was chosen by Greene et al. [84] to validate the effectiveness of this new technique. The female suffered from forehead asymmetry that was caused by dislocation and fracture of a silicone alloplastic implantation. The patient was treated with onlay wire reinforced methyl methacrylate. During this process (Figure 16 (right)), wire is distributed across 2$\mathrm{mm}$ outer cortex tunnels, and around the enclosing area of the defect, which in turn forms a rebar grid. Methyl methacrylate is carefully dispensed onto the rebar grid and once hardens it is contoured. It was found that wire-reinforced methyl methacrylate is an easy method that can be used to improve the tensile intensity of calvarial alloplastic restorations [84]. 

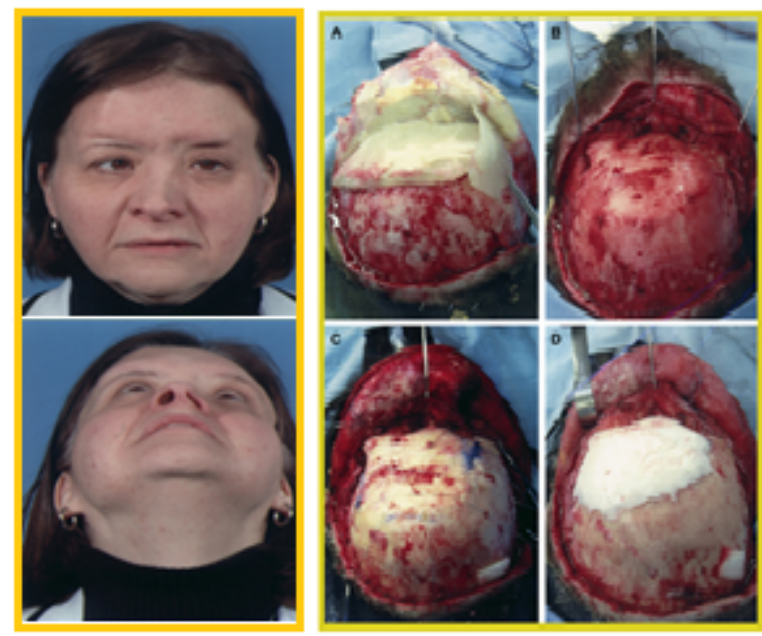

Figure 16: (Left) Preoperative view of a 56-year-old female who underwent strip craniectomy and silicone block augmentation of her forehead for left unilateral coronal synostosis in childhood. She presented for treatment of worsening forehead asymmetry secondary to contracture and malposition of her left frontal silicone cranioplasty [44]. (Right:(A) Intra-operative view of the fractured calcified silicone block implant.

(B) After removal of the silicone block implant, the forehead surface contour deformity was defined (C) A wire rebar grid was created over the affected area (D) Wire reinforced methyl methacrylate before contouring. (E)Wire reinforced methyl methacrylate before contouring [84].

Although it has many benefits, polymerized methyl methacrylate (PMMA) proffers smooth surface characteristics that tend to avert tissue ingrowth and bonding [85-87, 24]. Consequently, it has low composite tensile strength and it can be sheared and removed [84]. Furthermore, PMMA has a classic cleavage step river fractographic pattern (i.e. crack initiation and propagation of brittle PMMA flows through the material and coalesces like tributaries through a headwater to form a river) that causes cracks to propagate $[88,89]$. This explains the multiple fracture fragments found when operating on a dislodged/fractured PMMA cranioplasty. In order to reduce dislodgment and/or fracture propagation, we have adapted wire reinforced mansonry techniques to increase the tensile strength of partial thickness and surface contour PMMA cranioplasty reconstructions [84].

Methyl methacrylate does not suffer resorption and will not affect computed tomography (CT) or magnetic resonance imaging (MRI) [90, 86, 87]. Even with its many advantages, methacrylate has a high chance of infection [87]. $6.7 \%$ of PMMA alloplastic cranioplasties have been reported as having displacement and fractures [91-97, 86]; also numerous techniques (e.g miniplates, mesh, wire, manipulation of adjacent bone etc.) 
have been established to stabilize the construct [91-97, 86]. The wire-reinforced technique is simple to accomplish, quick, safe, effective and cost efficient.

\subsubsection{Polymerization of PMMA}

Polymerization of PMMA occurs by a free radical polymerization process between a polymer powder, diBenzoyl-Peroxide (BPO), and n,n-dimethyl-p-toluidine (DMPT), a liquid monomer component [27]. BPO becomes an initiator for radical polymerization material. The main component of the liquid phase is Methylmethacrylate (MMA) $[98,99]$ and, in some bone cements, other esters of acrylic acid or methacrylic acid, one or more amines (i.e. activators/co-initiators), a stabilizer and a colorant [98, 99]. The powder polymer and liquid monomer component are mixed which causes an exothermic reaction. The temperature of the paste increases significantly during this process; at this time the paste may also reach temperatures greater than $70{ }^{\circ} \mathrm{C}$ during the reaction $[100,101,102]$. Some disadvantages may stem from these high temperatures, such as tissue damage and consequently, the loosening of the prosthesis [27]. Nonetheless, the temperatures reached in the polymerization process depend on the amount of paste used. During surgery, the occurrence of an exothermic reaction and, thus, of a heated material close to the surface of the brain or dura could possibly cause issues [27]. Figure 17 shows temperature profiles developing in a Teflon reactor during the polymerization process of commercial bone cement characterized by a 2:1 weight ratio between the solid and the liquid phases [27]. Temperature peaks occur in the bulk of the cement and these values may be as high as $100^{\circ} \mathrm{C}$ [27]. In most situations, a damp gauze with saline solution may be placed between the acrylic resin and dura tissue during cranioplasty as an attempt of protection from the polymerization heat.

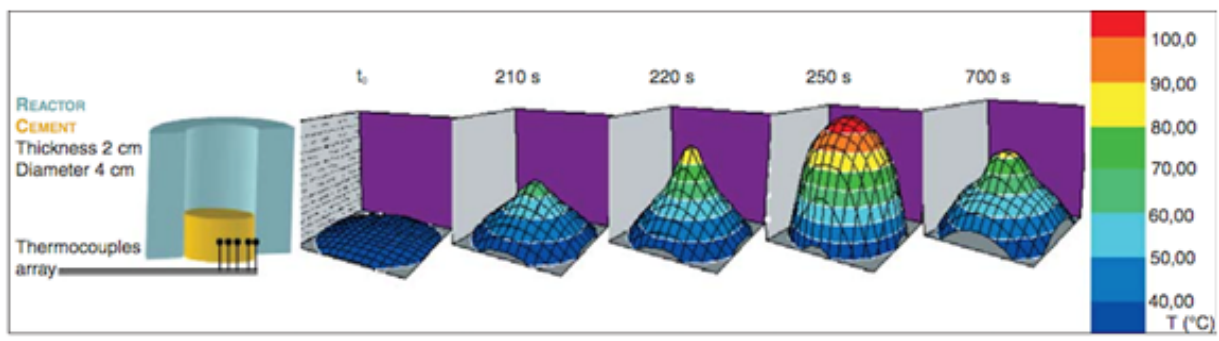

Figure 17: Temperature profiles developing during the setting reaction of a traditional PMMA cement [27]. 


\subsubsection{Case study: Technique for forehead reconstruction}

The use of methyl methacrylate for forehead restoration in congenital irregularities, a tumor infection, trauma and cosmetic defect were presented in this study [103]. 71 patients were examined [103]. The technique applied (Figure 18) has low complication rates and a short operating time.

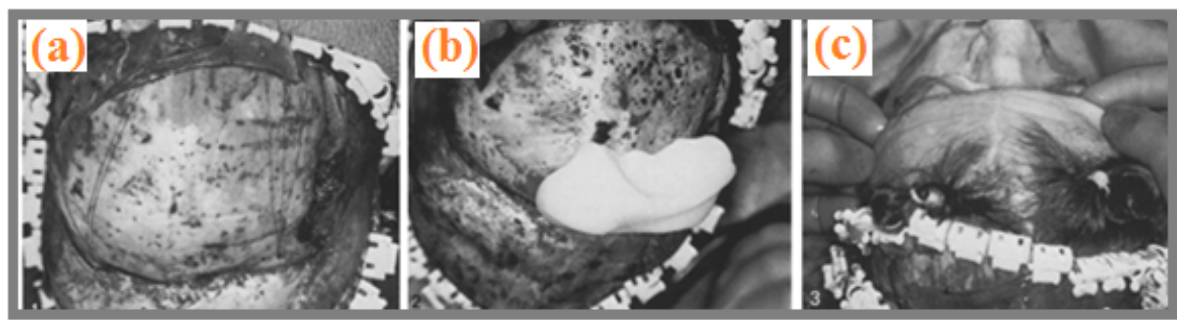

Figure 18 a): To ensure fixation multiple grooves are cut in the outer table and fixation wires are placed in the supraorbital rims b): The firming methyl methacrylate is applied directly to the skull c): The scalping flap is replaced and precise contouring is done to assure symmetry with the opposite side [103].

71 patients were subjected to reconstruction of the frontal cranium with methyl methacrylate. There were follow-ups with these patients for a minimum of one year. In some circumstances, twelve of these patients have been monitored for over eight years and 27 for over five years. The implantations have been well tolerated by the patients who were treated [103]. Operating time averaged 2.5 hours and hospitalization time averaged two days. Unfortunately, three patients required removal of the cranioplasty as a result of infection. In one patient, infection occurred only two months after surgery for reasons that were unknown. It was decided the cranioplasty needed to be removed but it was successfully replaced six months later. A patient that suffered from recurring brain tumors was left with a visible cranioplasty due to habitually peeling the scalp. Regrettably, she had to have her cranioplasty removed. The patient passed away before any reconstruction was performed [103].

\subsubsection{Improving the mechanical properties of PMMA bone cements}

PMMA particles have an important influence on the curing and mechanical properties of the cement [104]. A decrease in the magnitude of the exotherm is due to the larger prepolymerized PMMA beads and therefore reduces the modulus of the cement. However, once the bead size is increased, the setting time is doubled from 800 seconds to 1400 seconds [104]. Not only the size of the particle but many different variables can affect the flexural strengths of PMMA cements [104]. A study was performed on the likelihood of 
increasing bone in-growth into PMMA [105]. Through extensive sampling of PMMA it was shown that the addition of bone particles increases fatigue properties. On the down side, adding bone also amplified the viscosity, in turn shortening working time, as well as increased modulus [105].

\subsubsection{The influence of PMMA on immune response}

PMMA bone cement has been involved in the damage of complement activation causing infection [81]. Polymorphonuclear leukocytes (PMNs) are known to be drawn by two clusters of substances. The first substance being the parts produced by the complement cascade of our immune system while the second are elements that are released by bacteria as they mature [81]. As described by Jones [106] through the polymerization of PMMA, Methylmethacylate (MMA) can be released, allowing a high possibility of polymerized material leaking and affecting nearby tissue. Laskin [74] reveals this possibility of leaking as the reason for chemical necrosis of bone. It was exhibited that before the complement is stimulated, any MMA existing in serum will actually inhibit development of the complement since it delays the progress of cascades [81]. The study determines that the depression of chemotaxis by methyl methacrylate could permit the spread of contaminated microbes that would usually be demolished by a completely competent immune mechanism [81]. The consequence of methyl methacrylate on microbial phagocytosis by human PMNs in vitro was observed [81]. It was shown that a bacterium was more expected to survive in media that has MMA compared to media that has no PMMA [81]. The outcome suggests that PMMA monomer could lead to a rise in infection due to it being more susceptible to bacteria [81].

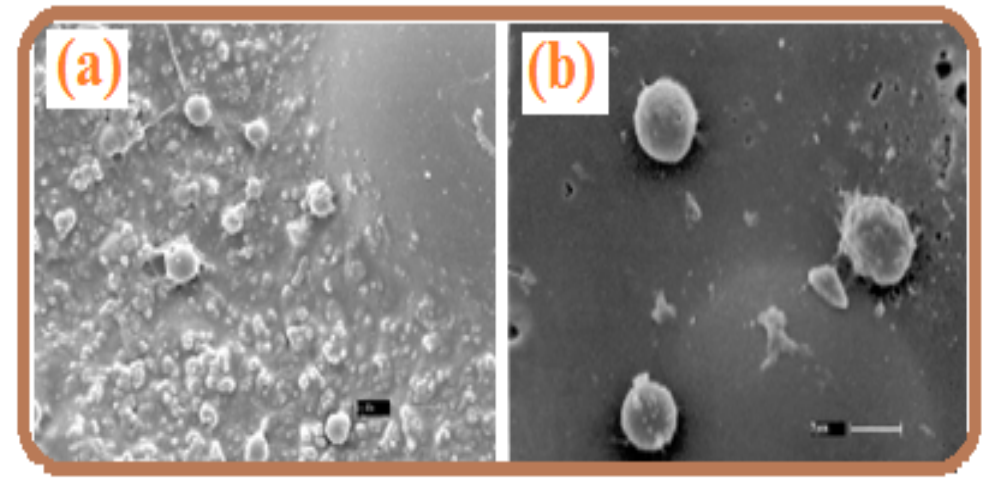

Figure 19 a) and b) SEM of monocytes/macrophages adhering on PMMA cement surfaces [107]. 
A severe effect of the persistent usage of PMMA based orthopaedic cements is evident since emboli occur as a consequence of initiation of the blood coagulation cascade by bone cement [108].

Below is a list of the major concerns related with PMMA [75]:

1. Up to $22 \%$ shrinkage [109].

2. High curing exotherm up to $120^{\circ} \mathrm{C}$ leading to necrosis [75].

3. Lack of chemical bonding [75].

4. Stress shielding [75].

5. Susceptibility to fatigue failure [75].

6. Impairment of the bodies natural defense systems leaving patients susceptible to infection [75].

7. Chemical necrosis [75].

8. Increased risk of cardiac arrest, and the potential for massive pulmonary emboli to occur at any time during the cemented surgeries [75].

The assumption that current PMMA-based cement systems are insufficient are as a result of these concerns. Hence, any alternate cement system would be of significant interest if they could aid in solving the concerns related with PMMA bone cement.

\subsection{Calcium phosphate cements (CPCs)}

In the early 1980s CPCs were discovered during the development of a re-mineralizing paste for dental cariers [110]. Since then, CPCs have been used as bone substitutes [110]. The first forms of CPCs included tetracalcium phosphate (TTCP) and dicalcium phosphate anhydrous (DCPA), however, once combined it develops into a form of HA at neutral $\mathrm{pH}$. Due to this, CPCs are extremely osteoconductive and osseointegrative [110, 111]. Unfortunately, CPCs suffer from long setting times and insufficient mechanical properties for load bearing applications particularly in tensile and sheer [110].

\subsubsection{Setting of calcium phosphate cements}

CPCs are acquired by mixing one or more reactive calcium phosphate powders with an aqueous solution in order to create a paste that will harden in a short period of time [112]. The setting of CPCs starts with the dissolution of the salts in an aqueous system [113]. 
Dissolution takes place when the nearby aqueous solution is undersaturated with a mineral mixture; supplying the surrounding aqueous environment with $\mathrm{Ca}$ and $\mathrm{P}$ ions, in turn leading to the formation of HA [111]. Figure 20 illustrates the isotherms while depicting the solubility of the distinct mechanisms TTCP, DCPA \& HA, which are found in the initial CPC system [110].

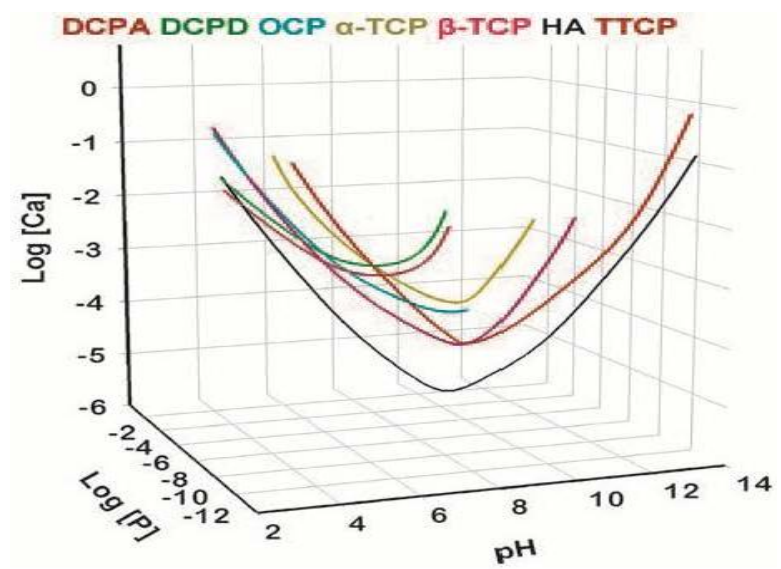

Figure 20: Solubility phases of the ternary system $\mathrm{Ca}(\mathrm{OH})_{2} \mathrm{H}_{3} \mathrm{PO}_{4}-\mathrm{H}_{2} \mathrm{O}$, at $25^{\circ} \mathrm{C}$. Illustrates solubility isotherms of TTCP, DCPA and HA [114].

Precipitation responses tend to be time-consuming and if two conditions encounter one another it produces a material of significant strength [115]. To start, it is necessary for the precipitate to develop in the shape of clusters of crystals; these crystals must consist of a suitable level of firmness [75]. Next, the morphology of the crystals authorizes the predicament of precipitated crystal clusters [115]. Unfortunately, it has been noted that use of the original $\mathrm{CPC}$ form had resulted in increased setting times. The in vivo setting performance of quick setting calcium phosphate cement was reported by Miyamoto et al [116]. The results suggested that this form was comparable to the initial form of CPCs [110]. The conventional CPC setting time was said to set 30 minutes in vitro, while in vivo it took an additional 18 minutes [116]; a rather long setting time for orthopaedic applications [113].

\subsubsection{CPCs: The mechanical properties}

CPCs are self-hardening cements that result in the formation of HA [117]. Growth and entaglements of the calcium phosphate crystals provide mechanical rigidity to the cement [118]. With regards to the quick setting CPCs presented previously, if the mixtures 
concentration stays within $0.25 \mathrm{~mol} / \mathrm{L}$ to $1.00 \mathrm{~mol} / \mathrm{L}$ then the phosphate solution has no substantial influence on mechanical properties [119]. The concluding mechanical properties of the cements were proposed autonomous of the setting time due to the insignificant difference found in the final set strength of the cements when comparing the quick setting CPCs with the conventional CPC's [119].

The strength of calcium phosphate cements in vivo and in vitro was examined by Yamamoto et al [118] who considered two distinct cement formulations. The first consisted of 95\% $\alpha$-TCP and 5\% DCPD [75]; the second consisted of 90\% $\alpha$-TCP and $10 \%$ DCPD [75]. Regardless of how each formulation was composed, the cements presented a substantial decrease in strength in vivo against in vitro. An outline of Yamamoto et al [117] findings is illustrated in Table 6.

\begin{tabular}{|c|c|c|c|c|}
\hline \multicolumn{5}{|c|}{ in vitro compressive strengths (MPa) } \\
\hline & 3 Days & 1 Week & 2 Weeks & 4 Weeks \\
\hline Cement A & 51 & 64 & ----------. & 57 \\
\hline Cement B & 57 & 57 & ---------. & 47 \\
\hline \multicolumn{5}{|c|}{ in vivo compressive strengths ( MPa) } \\
\hline & 3 Days & 1 Week & 2 Weeks & 4 Weeks \\
\hline Cement A & 27 & 31 & 38 & 32 \\
\hline Cement B & 31 & 29 & 22 & ---- \\
\hline
\end{tabular}

\subsubsection{CPCs: Surgical uses}

The use of CPCs in cranioplasty has been increasing, specifically in craniofacial reconstruction. Since the initial discovery of CPCs in the 1980's, the applications of a wide range of CPCs have been amplified as a substitute for alloplast or bone grafts in craniofacial reconstruction. CPCs are applied for contouring in the form of a paste and harden in minutes. With the presence of a minor exothermic reaction, the CPCs offer structure integrity in hours. Furthermore, the minor exothermic nature of the CPC setting, together with the fact that no special fixation elements e.g. miniplates or suture materials are needed to fix the CPC, makes this material ideal for craniofacial reconstruction. [120126].

Depending on the end product of the setting reaction, two different cements are formed: apatite and brushite (dicalcium phosphate dihydrate) cements [127] Brushite cements 
tend to resorb quicker than apatite cements [118, 128, 123-126, 129-133]. In regards to the mechanical strength, apatite calcium phosphate cement is somewhat stronger than brushite calcium phosphate cement [118]. Brushite calcium phosphate cements have high biocompatibility [127] and due to its no heat production during the hardening process, it could be placed directly onto the dura. Additionally, its malleability allows for suitable contouring before the hardening process [134]. Once set, fine utensils (e.g. a knife) could be used to remove unwanted irregularities, while also achieving adequate intraoperative strength for closure of the scalp with fewer or no problems [134]. In this case, calcium phosphate cements have proven to be better for attachment than acryl cement (PMMA). However, the CPC should not be applied to large craniofacial bone defected areas, due to its low compressive and tension strengths [134].

\subsection{Polyalkenoate Cements}

\subsubsection{Glass polyalkenoate cements (GPCs)}

Glass polyalkenoate cements (GPCs) were developed in 1969 [9]. The reaction of an ionleachable alumino silicate glass and an aqueous solution of polyacrylic acid (PAA) are the basis of GPCs formation [10]. During 1975, the first marketable dental GPC was introduced [9]. GPCs are known to attach directly to tooth and bone mineral [99], as well GPCs are likely to be color coordinated to enamel and the exterior is transparent [135].

\subsubsection{Glass component}

The development of GPCs relies heavily on whether a glass is capable of degrading and discharging cations in acidic solutions [9]. Figure 21 shows the structure with red circles representing oxygen atoms and the small black dots representing silicon atoms [136].

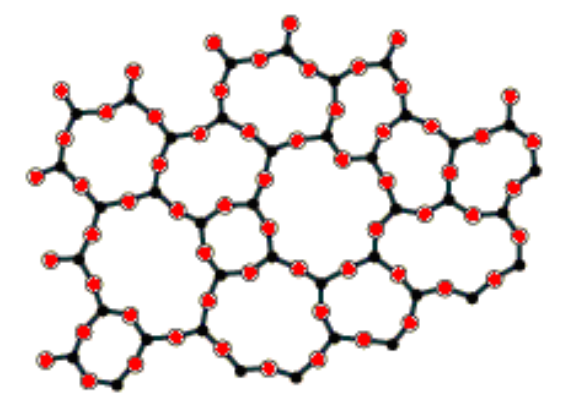

Figure 21: Continuous random- network model for network glasses [137]. 
Zachariasen [138] offered a random network model for glass. This model depicts an approach to understanding glass structures, the outcome of elemental species on glass formation and properties, concepts that are important when considering glass compositions for GPCs [138].

As part of the random network model, Zachariasen [138] outlined a number of criteria that had to be fulfilled by an oxide species in order to have the ability to form a glass. Those criteria are [138]:

1. An oxygen atom must not be linked to more than 2 cations.

2. The number of oxygen atoms surrounding a central cation must be small.

3. The oxygen polyhedra must share corners, not faces or edges.

4. For a 3-D network, at least 3 corners of the polyhedra must be shared.

$\mathrm{MO}$ and $\mathrm{M}_{2} \mathrm{O}$ are examples of Oxides that regrettably do not fulfill the criteria stated above; therefore, they are incapable of forming glasses in seclusion. Nonetheless, these particular species could be used as network modifiers when combined into a glass structure [138]. The existence of calcium oxide within a glass network has been suggested to enable structural changes among the network, classifying it as a network modifier. Wilson \& Nicholson [139] explain that instead of bridging oxygens involving two $\mathrm{SiO}_{4}$ tetrahedra the combination of the divalent $\mathrm{Ca}^{2+}$ could actually separate them from one another.

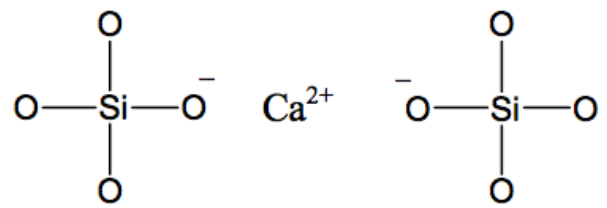

Figure 22: The development of non-bridging oxygen's the network modifying cation $\mathrm{Ca}^{2+}[75]$.

It is suggested with the existence of the network modifier $\left(\mathrm{Ca}^{2+}\right)$, oxygen that is affected acquires a unit negative charge that results in a charge balance [139]. However, once the $\mathrm{Si}-\mathrm{O}-\mathrm{Si}$ bond is fragmented it results in glass that develops reduced network connectivity, a decrease in melting temperature and a reduction in melt viscosity. Paul [140] explains with the production of ionomer glasses that the $\mathrm{Ca}^{2+}$ ion is straightforward, while holding a lower electrostatic field compared to $\mathrm{Si}^{4+}$, hence due to its presence, it produces a disrupted network among localized groups of expanding oxygen polarization and an 
increased local basicity [139] These elements enable glass degradation via acidic solutions [141].

Network formers like $\mathrm{MO}_{2}, \mathrm{M}_{2} \mathrm{O}_{3}$ and $\mathrm{M}_{2} \mathrm{O}_{5}$ are examples of oxides that have the capability to form glass. However, in some materials such as, $\mathrm{Al}_{2} \mathrm{O}_{3}$, unfortunately, do not possess the ability to form glass during isolation $[138,140]$. It is common within the glass network for $\mathrm{Al}^{3+}$ to isomorphically substitute $\mathrm{Si}^{4+}$ as it holds comparable ionic radius [142]. If the substitution occurs, the network obtains a unit negative charge. In order to guarantee local electrical neutrality, it is necessary for the negative charge to be counterbalanced by presenting a supplementary unit of negative charge [141]. Paul [140] explains that species like aluminum could be expressed as network intermediates. Hill and Wilson [141] claim that a $\mathrm{Ca}$ : $\mathrm{Al}$ ratio must be more than 1:2 as well the $\mathrm{Al}$ : Si ratio must be equivalent to, or more than 1 for aluminum to continue in 4 fold co-ordination within the glass construction.

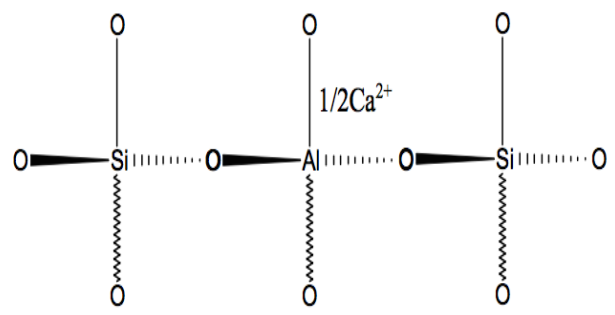

Figure 23: The isomorphic replacement of $\mathrm{Si}^{4+}$ with $\mathrm{Al}^{2+}$ in the silica glass network, and charge compensation provided by network modifying cations [75].

\subsubsection{Inorganic polymer model}

It is proposed that glasses can be considered as inorganic polymers [143]. Inorganic polymers consist of macromolecules of atoms other than carbon and are connected to each other via primarily covalent bonds [143]. In regards to the oxygen cross-link density, the physical and chemical properties of a glass could perhaps be demonstrated through merging the concepts of the random network theory as well considering glasses as inorganic polymers [144]. De Barra [145] defines the network connectivity (NC) of a glass as the average amount of bonds that join each repeat unit in the network it is further calculated using the Equation 1. 


$$
N C=\frac{\text { No.BOs-No.NBOS }}{\text { Total No.Bridging species }} \quad \text { Equation } 1 \text { [144]. }
$$

Where:

$\mathrm{NC} \sim$ Network Connectivity

$\mathrm{BO} \sim$ Bridging Oxygens

$\mathrm{NBO} \sim$ Non-Bridging Oxygens

When taking into account acid degradability it is extremely imperative to consider the connection of a glass network. A glass holds an increased chance of being vulnerable to acid outbreak if the network is more disordered; consequently, this permits the release of additional ionic species. With regards to GPCs, the rheology and mechanical properties of the cement can be affected by the speed in which a glass degrades and discharges ions [144].

\subsubsection{The acid component}

Poly (acrylic acid), PAA, is the most commonly used acid in polyalkenoate cements. PAA has many benefits including, low toxicity and higher solubility in water in comparison with other acids used in the fabrication of GPCs such as, polyvinyl acid and maleic [139]. Polyacids are generated by free-radical polymerization in an aqueous solution using ammonium persulphate as the motivator and propan-2-ol (isopropyl alcohol) as the chain transfer agent. PAA concentration is maintained below $25-\mathrm{wt} \%$ in order to prevent explosion [145]. The tensile strength of GPCs intensifies with PAA concentration and molecular weight [146]. As the molecular weight of PAA increases, tensile strength, fracture durability, resistance to corrosion and wear are also enhanced Mun, G.A et al [147].

\subsubsection{The setting reaction of GPCs}

The cement forming reaction of GPCs takes place in various interrelating phases (Figure 24). These involve [139]:

1. Attack by the acid on the glass

2. Migration of the liberated ions from the oxide or glass into the aqueous stage

3. Ionization of the poly acid

4. Consequent unwinding of the polymer chain, the interaction among the charged chains and oxide or glass cations leading to ion binding and gelation,

5. Hardening phase signified by the continuation of ion binding. 
Following the mixture of the glass and the polyacid liquid, $\mathrm{H}^{+}$ions divide off the $\mathrm{COOH}^{-}$ groups from the acid-chains and react with the glass particles. The outer surface of the glass particle is transformed into a single gel coat where ions are secreted. This process is because of a partial dissolution. The metal ions react with the carboxyl $\left(\mathrm{COO}^{-}\right)$groups to form a polyacid salt, in turn producing the cement matrix, and the surface of the glass develops a silica hydrogel. While the clinical set is achievable in a couple of minutes, the ongoing maturation stage happens over subsequent months. A study recently discovered that the setting of acid base cements could be extended to up to six months [148].

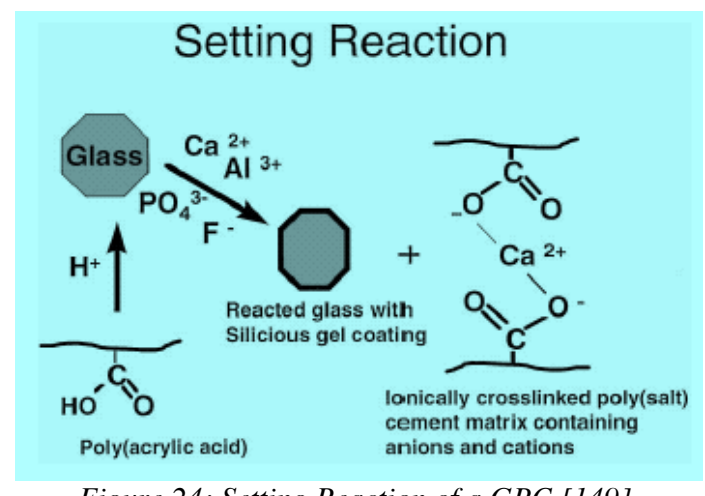

Figure 24: Setting Reaction of a GPC [149].

The addition of modifiers such as tartaric or maleic acid to the GPCs can impact the working and setting time. The addition of these modifiers will result in an increase in the time at which cement is set while keeping the working time constant [139]. There can also be an improvement or weakening of the strength of GPCs when modifiers are added [150].

GPCs are utilized in dentistry as restorative materials and luting cements.

\subsubsection{Luting cements}

Luting cements consist of various types of materials that are used for the attachment and closure of dental repairs and prostheses to teeth [151]. ZPC has been the most utilized luting agent, despite possessing disadvantages, such as high clinical solubility, lack of chemical adhesion and low setting $\mathrm{pH}[152,153]$. GPC luting agents have fluoride ion release and a low coefficient of thermal expansion [154, 155]. Resin-modified GPC similarly release fluoride and include resin components for enhanced physical and mechanical properties [156-158]. Resin luting cements have excellent mechanical 
properties and exhibit increased retention abilities [159-162]. Resin luting agents are technique-sensitive and demand cautious handling/manipulation during bonding and through the elimination of excess material, which may prove to be problematic once set $[152,163,164]$. There is a significant difference in the physical and biological properties of resin luting agents due to the chemical and physical variances in their polymeric and inorganic stages, and also the efficacy of their setting mechanisms [165-170]. In order to avoid micro-leakage, cement with a high modulus of elasticity is vital [171]. A high modulus of elasticity is predominantly vital in areas of high stress or in long span prostheses [152,172]. Various studies comparing the post-cementation sensitivity of GPCs or ZPCs revealed no substantial variances between the two cements and that sensitivity could be avoided with a proper insertion technique [173-175].

\subsubsection{Mechanical properties of GPCs}

The ultimate luting agent has enough mechanical properties to withstand functional forces over a lifespan. Variation of the physicality and chemistry of the reagents can alter the properties of GPCs. These involve [139]:

1. The influence of PAA concentration. With the increase of PAA concentration, Young's modulus increases [176].

2. The influence of PAA molecular weight. When the molecular weight of PAA increases so does strength [149].

3. The influence of maturation time. GPCs strength increases with maturation [177].

4. Powder: Liquid Ratio (P: L) of the cement mixes. The lower the (P: L), the lower the shear strength of the cement [178].

PAA concentration and molar mass, recently, have been presented as the most vital parameters in determining the mechanical properties of GPCs [179-181]. Although PAA is crucial in all phases of the GPC, it is particularly imperative in the early stages of the setting process and the development of a silicate phase, which controls the long-term properties [176]. Compressive strength increases with both concentration of the PAA and molar mass [182]. The influence of the polymer concentration on compressive strength increases as the polymer molar mass of the cement is increased. It has also been indicated that there is an increase in strength with maturation [183]. GPC aging mechanisms are 
complicated; its strengthening results from additional crosslinking and build-up of a silica gel phase (Figure 25) or the reaction rate falls with maturation [184].

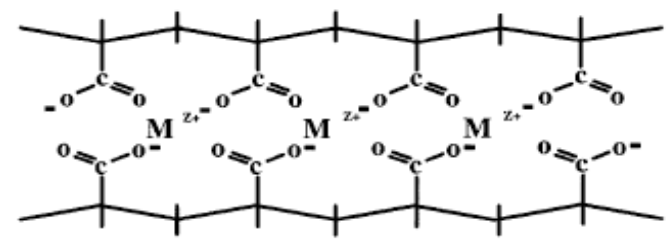

Figure 25: Crosslinking of GPC [75].

The flexural strength of GPCs expands with the powder/liquid (P/L) ratio. Nonetheless, a surplus of glass powder in the system can result in difficulty incorporating the components [185]. It has been recognized that an ideal $\mathrm{P} / \mathrm{L}$ ratio exhibits both good mechanical strength and adequate handling features [184]. The $\mathrm{P} / \mathrm{L}$ ratio also has an influence on the working times of the cement, therefore the greater the $\mathrm{P} / \mathrm{L}$ ratio the shorter the working time [182].

\subsubsection{Ion release of GPCs}

Conventionally it has been assumed that soluble ionic species are fabricated by the reaction between the acidic component of the cement (polymeric acid, tartaric acid) and the glass [186]. Ion release arises due to GPCs containing roughly $8-20 \mathrm{wt} \%$ of water, thus permitting the occurrence of interchange with a surrounding liquid. Ions may be monovalent, such as sodium and fluoride $\left(\mathrm{Na}^{+}, \mathrm{F}^{-}\right)$, divalent $\left(\mathrm{Ca}^{2+}, \mathrm{Sr}^{2+}, \mathrm{Ba}^{2+}, \mathrm{Zn}^{2+}\right)$, trivalent $\left(\mathrm{Al}^{3+}\right)$ or complex ion formers $(\mathrm{Si}, \mathrm{P})$ [186]. Ions that are released by the cement fabricating process are thus existent in the matrix made by cross-linked polymeric acid. Unfortunately, It is not clear if the glass (or powder) plays any additional part in the ion release process but it could be part of the setting reaction, also it has not been proven why distinctive cements take different times to reach a steady state [186]. Analyses reviewing ion release can measure it from 'pure' cements or those, which have had ions added to the matrix as chemical compounds (solid or liquid) [187]. Interchange happens with a surrounding liquid by virtue of the water performing as the continuous stage, therefore, ions travel from the matrix into the liquid and vice versa. 'Pure' GPCs follow a two or three stage progress [137]. Primarily there is a quick burst of ion release non-linear in regards to time associated with the setting reaction [187]. Afterward release is either: 
1. Proportional to setting time, signifying diffusion to be the controlling force

2. Proportional to time, signifying dissolution is the controlling force

3. A mixture of both, but it is not clear for how long ion release lasts

\subsubsection{Zinc polyalkenoate cements}

First created by Smith in 1968, Zinc Polyalkenoate Cements (ZPC), are comprised of aqueous polyacrylic acid and zinc oxide [188]. Zinc phosphate and zinc polycarboxylate cements have been used for a number of years in clinical dentistry [189]. ZPCs are prepared from an adapted zinc oxide powder and a liquid polymeric acid (polyacrylic acid (PAA)) (Figure 26) [9]. An acid-base reaction defines the setting process of ZPCs, and results in a set cement microstructure that consists of reacted and unreacted metal oxide particles embedded in a zinc polyacrylate matrix [9, 190, 191].

The process of the setting reaction of ZPCs is as follows [9, 135, 139]. The polymeric acid is hydrolyzed in the presence of water, generating a population of protons.

○ These protons attack the surface of the zinc oxide powder.

- Zinc ions are then released.

- Zinc ions cross-link the polyacid chains and render them insoluble.

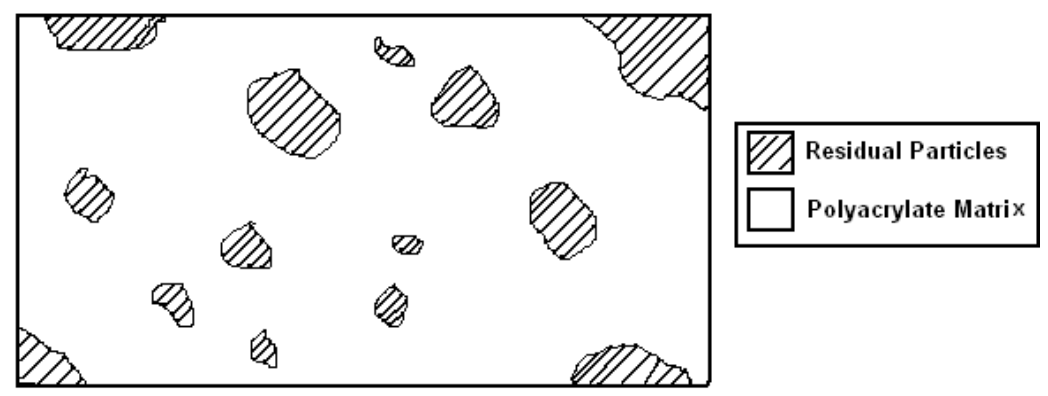

Figure 26: Diagrammatic representation of the microstructure of ZPCs [137].

ZPC's have various benefits including [192]:

1. The ability to form a chemical bond with enamel and dentine due to the consequent chelation of calcium ions by free carboxyl groups in the acrylic polymer [193]. Therefore blocking bacteria or biofilm from gaining access in the space between the tooth and the filling [9]

2. The ability to modify the setting time from a few minutes to a few hours [192]

3. Mechanical properties that develop with maturation [188]. 
Table 7: Properties of ZPC cement [9].

\begin{tabular}{cc}
\hline Property & Typical components/values \\
\hline Liquid & $40-45 \%$ polyacid \\
P:L & $2.5-3.0: 1$ \\
Setting time/min & $2-4$ \\
Compressive strength/MPa & $80-100$ \\
\hline
\end{tabular}

ZPCs act as thermoplastic composites with weak crosslinks between the polyacrylate chains [194]. Once the cement is set it becomes a result of a chemical bond between $\mathrm{Zn}^{2+}$ ions and four adjacent carboxyl groups in the polyacrylic (PAA) molecule [188] ZPCs are able to create a chemical bond with different metals, therefore enabling their use as adherents for use in dentistry [192]. The bond between zinc and polycarboxylate cement is stable as a result of the zinc being solubilized the cement [192]. Zinc is lethal to pathogenic bacteria and a contributing factor in preventing bacterial infection directly at the implantation site [188]. There is an assumption that once the bacteria cell wall comes into contact with the zinc ion, the bacterial cell is strongly bound to the surface of the zinc by the numerous chemical groups it contains [195], resulting in the zinc ion killing the bacteria by damaging or destroying the cell walls of the bacteria. ZPC can also set at body temperatures without polymerization shrinkage and without significant heat, it has also been established that ZPC can chemically bond to the apatite phase existing in bone [196] and the oxide layer on medical grade alloys [197].

\subsection{Summary}

Today, the most frequently used material for skull reconstruction is polymethylmethacrylate (PMMA) [198]. Long-term results of cranioplasties using PMMA have been accepted $[198,199]$ but the exothermic setting reaction with consequent thermal necrosis and long-term inflammation of the nearby tissue [200, 201], as well as the poor osteointegration [202] of this non-resorbable material all validate the search for improved biomaterials. Another disadvantage mentioned in the literature is that PMMA provides no chemical bond to the bone. Presently, calcium phosphate cements (CPCs) have drawn great interest among craniofacial surgeons as they meet many of the requirements for an ideal bone substitute material. However, CPCs for cranioplasty 
attachment indicated problems associated with slow bio-resorbability and delayed inflammatory reactions [198]. Unfortunately, none of the previously mentioned materials have fulfilled the criteria for ideal cranioplasty cement according to Blake's [13] characteristics. As discussed earlier, there are still many complications and infections associated with the use of these materials and are still very expensive, specifically more common materials such as sutures, wires or screws. The main concern of this research is to develop a new Glass polyalkenoate cement (GPC) containing germanium (Ge) in order to substitute the use of screws for the attachment of miniplates to the skull. The addition of germanium to the glass phase of glass polyakeonate cements (GPC) improves the major limitations associated with GPCs [203]. In this study, KBT glass has been developed with the addition of germanium to create a new alternative in hopes to reduce complications and infections that are originally associated with the use of screws such as swelling, infection and the risk of screw detachment, while fulfilling the criteria of an ideal cranioplasty cement.

\subsection{Rationale}

Titanium miniplates and screw fixation of bone flaps in craniotomy have attracted attention owing to their rigid stability [204, 205]. While these techniques have been used with HA implants, success has been limited by problems related to the characteristic brittleness of ceramic materials [206, 207]; HA implants have a tendency to break easily as they are not always able to resist self-tapping screw impact. Though holes are made to prevent damage, breakage could occur to the material around the hole when loose fitting screws are used. Additionally, as a result of inadequate fixation strength screws can easily detach or could fail to secure the miniplates.

Bioactive glass materials had been used in-vitro and in-vivo and specific ion dissolution from these materials, which was reported to offer therapeutic effects. Though the use of GPC's has primarily been in dentistry; recent studies conducted have allowed for the development of these cements to be considered for orthopedic applications by altering the glass chemistry. For example, titanium was used in the glass phase of GPCs as a substitute for silica to improve the cement's mechanical and biological properties. 
Germanium (Ge), is a known network-forming component, and is theoretically capable of isomorphically replacing $\mathrm{Si}$ in the glass network [208]. Zinc and silver ions were added to the glass phase because of their antimicrobial activity. Zinc caused improved bone mass and bioactivity to be used in orthopedic applications as skeletal cement. Yet, the mechanical properties of $\mathrm{Zn}$-containing cements have reduced load-bearing properties. $\mathrm{Sr}^{2+}$ was used as a substitute for $\mathrm{Ca}^{2+}$ in the glass phase of GPCs in order to improve both therapeutic action and radiopacity. Also, Strontium has exceptional antimicrobial activity in-vitro. However, in order to prevent the negative effect on the mechanical and handling properties, the addition of Strontium must be monitored. Germanium (Ge), is a known network-forming component, and is theoretically capable of isomorphically replacing $\mathrm{Zn}$ in the glass network. Also, Ge compounds have been shown to inhibit cancer development [208], an attribute that could be exploited given both ion release capabilities of GPCs.

This paper aims to investigate the incorporation of $\mathrm{Ge}$ and $\mathrm{Zn}$ into the GPC glass composition of a KBT glass series $\left(\mathrm{SiO}_{2}-\mathrm{CaO}-\mathrm{ZnO}-\mathrm{Na}_{2} \mathrm{O}\right)$ and what effects this will have on the handling and mechanical properties of the resulting GPC. These findings will be used to evaluate the novel Al-free GPCs as injectable bone cements for attachments in cranioplasty fixation.

The objective of this study is to perform further required investigations for the suitability of using Ge-GPCs for cranioplasty application for titanium mini plate attachment to the skull to avoid the need for screw attachment. 


\section{Chapter 3}

\section{Materials and Methods}

\subsection{Glass synthesis and characterization}

\subsubsection{Glass synthesis}

Three glass compositions, KBT01, KBT02, and KBT03, were formulated. The KBT glass series was formulated by combining KT glass series and BT101 $\mathrm{Sr}-\mathrm{CaO}-\mathrm{ZnO}-\mathrm{SiO}_{2}$ glass [209]. The Control KT01 was a $\mathrm{GeO}_{2}$-free $\mathrm{SiO}_{2}-\mathrm{CaO}-\mathrm{ZnO}-\mathrm{Na}_{2} \mathrm{O}$ glass; KT02 and KT03 contain incremental concentrations of $\mathrm{GeO}_{2}$ added into this Control composition at the expense of $\mathrm{Zn}$ (Table 8). Glasses were prepared by weighing out appropriate amounts of analytical grade reagents and ball milling $(1 \mathrm{~h})$. The mix was then oven dried $\left(100{ }^{\circ} \mathrm{C}, 1\right.$ h) and fired $\left(1500{ }^{\circ} \mathrm{C}, 1 \mathrm{~h}\right)$ separately in a pure Silica ceramic crucible and shock quenched into water. The resulting frit was dried, ground and sieved to retrieve a glass powder with a maximum particle size of $<45 \mu \mathrm{m}$.

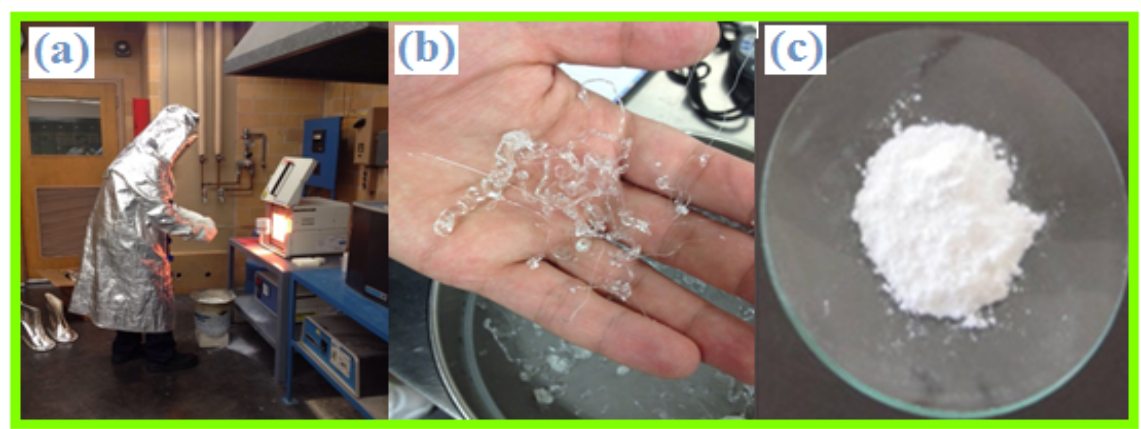

Figure 27 a) Glass Production Procedure. b) Bio-Glass after Production Procedure. c) Powder Bio-Glass after grinded and sieved using $<45 \mu \mathrm{m}$ sieve.

Table 8: KT Glass compositions (Mol.\%)

\begin{tabular}{llllll}
\hline Nomenclature & $\mathbf{S i O}_{2}$ & $\mathbf{C a O}$ & $\mathbf{Z n O}$ & $\mathbf{N a}_{2} \mathbf{O}$ & $\mathbf{G e O}_{\mathbf{2}}$ \\
\hline KT01 & 0.50 & 0.10 & 0.30 & 0.10 & 0 \\
KT02 & 0.50 & 0.10 & 0.27 & 0.10 & 0.03 \\
KT03 & 0.50 & 0.10 & 0.24 & 0.10 & 0.06 \\
\hline
\end{tabular}

Table 9: BT101 glass composition (Mol.\%) [75, 146].

\begin{tabular}{lllll}
\hline Nomenclature & $\mathbf{S i O}_{\mathbf{2}}$ & $\mathbf{C a O}$ & $\mathbf{Z n O}$ & SrO \\
\hline$B T 101$ & 0.48 & 0.12 & 0.36 & 0.04 \\
\hline
\end{tabular}




\subsubsection{Polyacrylic acids (PAA)}

Advanced Healthcare Limited (Kent, UK) supplied the PAA (Mw, 213,000). The acid was freeze-dried and ground and sieved to contain a maximum particle size of $<45 \mu \mathrm{m}$.

\subsubsection{Glass characterization}

\subsubsection{Network connectivity (NC)}

The network connectivity of the glasses was calculated with Equation 1 using the molar compositions of the glass considering that $\mathrm{SiO}_{2}$ and $\mathrm{GeO}_{2}$ as network former, $\mathrm{CaO}, \mathrm{ZnO}$ and $\mathrm{Na}_{2} \mathrm{O}$ as network modifiers.

$$
N C=\frac{\text { No: BOs-No: NBOS }}{\text { Total No: Bridging species }} \text { Equation } 1[75]
$$

Where:

$\mathrm{NC}=$ Network Connectivity

$\mathrm{BO}=$ Bridging Oxygens

$\mathrm{NBO}=$ Non-Bridging Oxygens

\subsubsection{Powder x-ray diffraction (XRD)}

XRD patterns were collected using a PANanlytical X'Pert PRO (PANanlytical Inc., St Laurent, QC, Canada). Glass powder samples were attached on a stainless steel disc using $20 \mathrm{~mm} \varphi$ slide of glass. The powder compacts were then placed in the X-Ray Diffractometer for initial scan covering range of $10^{\circ}<2 \theta<80^{\circ}$ (Figure 28), at scan step size $0.05^{\circ}$ and step time of $10^{\circ} \mathrm{s}$. A generator voltage of $45 \mathrm{kV}$ and a tube current of 40 $\mathrm{mA}$ were employed using $\mathrm{Cu} \mathrm{k} \alpha$ x-ray source.

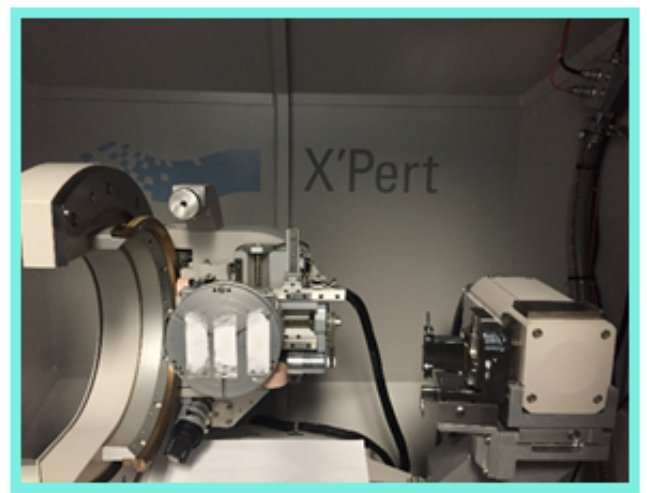

Figure 28. X-Ray Diffractometer. XRD sample packed into stainless steel disc using 20mm $\varphi$ slide of glass. 


\subsubsection{Particle size analysis (PSA)}

Particle size analysis was performed using a Coulter Ls 100 Fluid module Particle size analyzer (Beckman Coulter, Fullerton, CA, U.S.A) (Figure 29 left). The glass powder samples (Figure 29 right) were evaluated in the range of $0.375 \mu \mathrm{m}-948.2 \mu \mathrm{m}$ and the run length took 60 seconds. The fluid used in this case was glycerol and was used at a temperature range of between $10-37^{\circ} \mathrm{C}$. The relevant volume statistics were calculated on each glass.

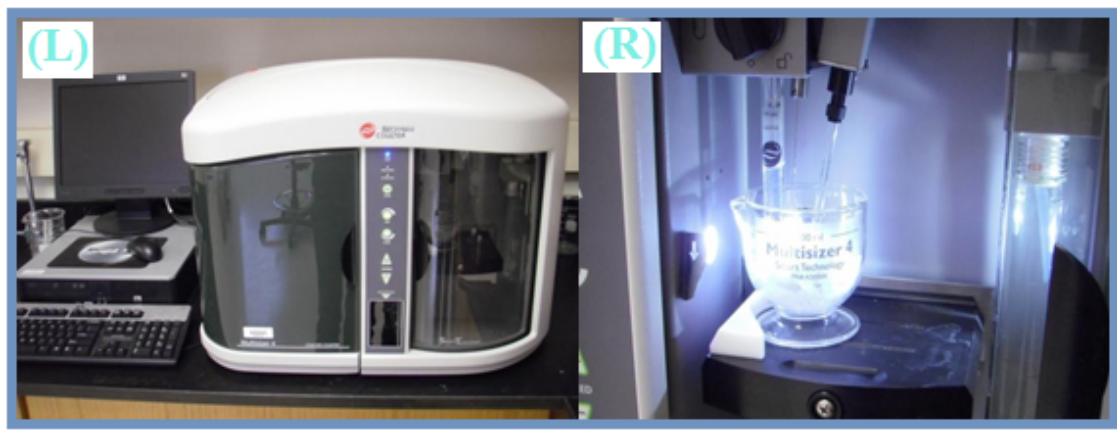

Figure 29 (Left) Multisizer Four. (Right) Sample loaded in the PSA.

\subsection{Cement characterization}

\subsubsection{Cement preparation}

Cements were prepared by thoroughly mixing the glass powders $(<45 \mu \mathrm{m}) \mathrm{KT}$ series glasses and BT101 (all un-annealed) with PAA200 (Advanced Healthcare Limited, Kent, UK) and distilled water on a glass plate. To determine if the glasses have the ability to form cements, each formulation was mixed at a $\mathrm{P}$ : $\mathrm{L}$ ratio of $1: 1 \mathrm{using}$ a $50 \mathrm{wt} \%$ solution of PAA200 ( $0.5 \mathrm{~g}$ of acid and $0.5 \mathrm{ml}$ of water) and $50 \mathrm{wt} \%$ of $1 \mathrm{~g}$ of glass powder $(0.5 \mathrm{~g}$ of KT and 0.5g BT101).

\subsection{Rheological properties}

The rheological properties of the cements produced from these glasses will influence their suitability as cranioplasty cements.

\subsubsection{Working and setting time}

The working times of cements were determined using a stopwatch by measuring the time from the start of mixing to the time when the cement was no longer pliable. The setting time of cements was measured in accordance with ISO9917 [11]. An empty mould, 
illustrated in Figure 30 (a-b) was placed on aluminum foil and filled to a level surface with mixed cement. Sixty seconds after mixing the entire assembly was placed on a metal block $(8 \mathrm{~mm} \times 75 \mathrm{~mm} \times 100 \mathrm{~mm})$ in an oven maintained at $37^{\circ} \mathrm{C}$. Ninety seconds after mixing, a Vicat needle indenter (mass, 400g) was lowered onto the surface of the cement. The needle was allowed to remain on the surface for five seconds, the indent was then observed, and the process repeated every thirty seconds until the needle failed to make a complete circular indent when viewed at $\mathrm{x} 2$ magnification. The net setting time of three tests was recorded.

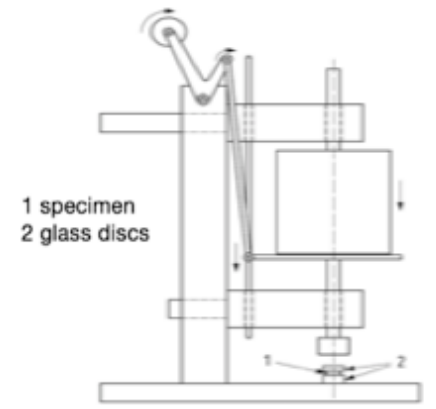

(a)

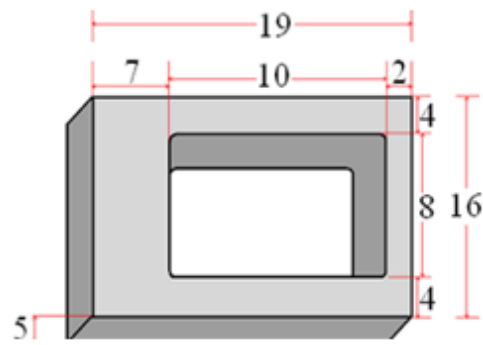

(b)

Figure 30 a) Setting time testing fixture by ISO 9917 [11].

b) Illustration of the mould used to determine the net setting time of cements, dimensions are in $\mathrm{mm}$.

\subsection{Scanning electron microscopy \& energy dispersive x-ray analysis (SEM-EDS)}

Backscattered electron (BSE) imaging was carried out with a JEOL Co. JSM-6380LV Scanning Electron Microscope (JEOL Ltd.Tokyo, Japan) (Figure 31). Additional compositional analysis was performed with an EDAX Genesis Energy-Dispersive Spectrometer (Figure 31). All EDS spectra was collected at $20 \mathrm{kv}$ using a beam current of 26 nA. Quantitative EDS spectra was subsequently converted into relative concentration data.

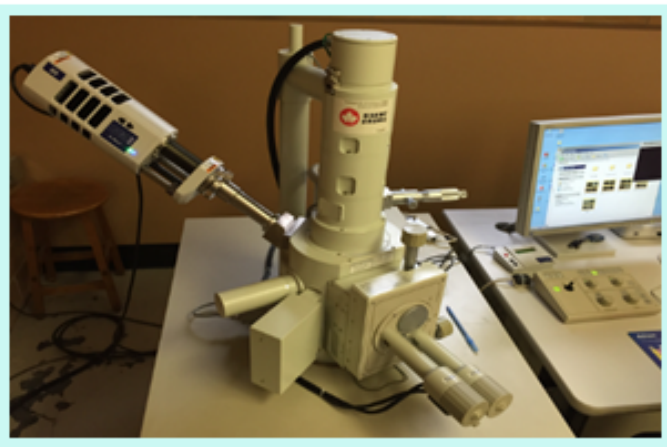

Figure 31: Scanning electron microscopy (JEOL Ltd Tokyo, Japan) 


\subsection{Mechanical properties}

\subsubsection{Compressive strength test}

The compressive strengths $(\sigma c)$ of 5 cement samples from each cement formulation were evaluated in ambient air $\left(23 \pm 1^{\circ} \mathrm{C}\right)$ according to ISO9917 [11]. Samples were tested after 1, 7 and 30 days. Testing was undertaken on a United Testing Systems (United Testing System Ontario, Canada) using a $\pm 2 \mathrm{kN}$ load cell at a crosshead speed of $1 \mathrm{~mm} . \mathrm{min}-1$ (Figure 32.a).

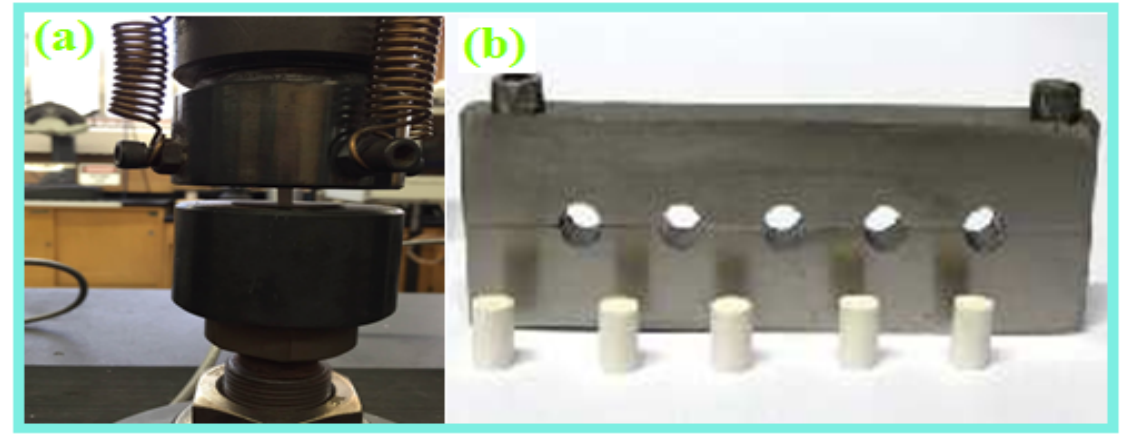

Figure 32. (a) Compressive Testing Rig, (b) Split ring moulds and cement sample required by ISO9917 [11] for compressive strength testing

The moulds (Figure 32.b ISO9917 [11] 4mm Ø, 6mm height) were filled to excess with freshly mixed cement then covered with acetate. The moulds were then sandwiched between two stainless steel plates, clamped, and incubated $\left(37{ }^{\circ} \mathrm{C}, 1 \mathrm{~h}\right)$. Following incubation, the moulds were removed from the clamps. Flash around the moulds was removed using a grinding wheel (100 rpm) and 1200 grit silicon carbide paper. Once ground the samples were de- moulded, placed in distilled water and incubated $\left(37^{\circ} \mathrm{C}\right)$ for 1,7 and 30 days.

Compressive strength, C, was calculated according to Equation 2 [11]:

$$
C=\frac{4 \rho}{\pi d^{2}} \quad \text { Equation } 2 \text { [11] }
$$

Where:

$\rho=$ Maximum applied load $(\mathrm{N})$.

$\mathrm{d}=$ diameter of sample $(\mathrm{mm})$.

\subsubsection{Biaxial flexural strength}

The biaxial flexural strength $(\sigma f)$ of cements was determined in a similar fashion to that used by Williams J.A el al. [210] using three support bearings on the test rig (Figure 33). 
The test rig was fixed to a United Testing Systems (United Testing System Ontario, Canada.) mechanical test using a load cell of $1 \mathrm{kN}$ at a crosshead speed of $1 \mathrm{~mm} \mathrm{~min}^{-1}$. Five samples for each cement formulation and incubation time were tested. Biaxial flexural strength was calculated according to Equation 3 [210].

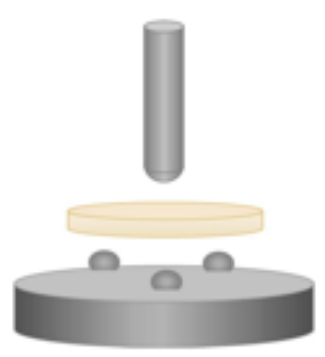

(L)

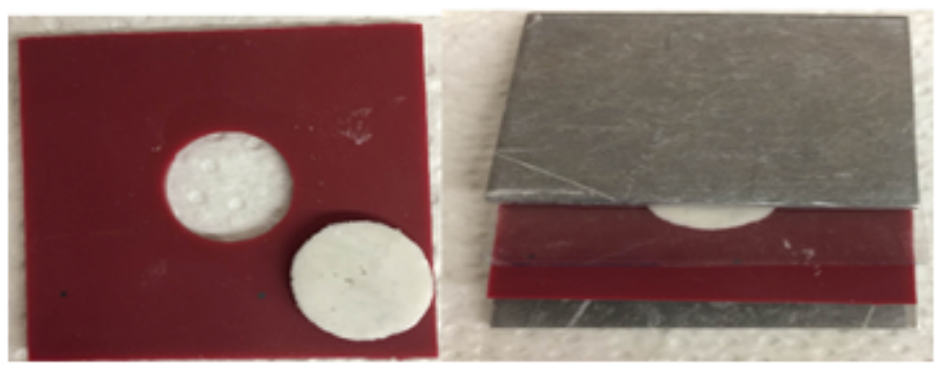

(R)

Figure 33: (Left) Biaxial flexure strength fixture rig [211] with sample. (Right) Biaxial flexure sample disk preparation.

$60 \mathrm{~s}$ after mixing, rubber moulds $(8 \mathrm{~mm} \varnothing, 2 \mathrm{~mm}$ thick) were filled to excess with cement and placed between 2 stainless steel plates, clamped, and incubated $\left(37^{\circ} \mathrm{C}, 1 \mathrm{~h}\right)$. The samples were de-moulded and flash was removed using 1200 grit silicon-carbide paper. Samples were placed in distilled water and incubated for $1,7 \& 30$ days.

$$
B F S=\frac{\rho(N)}{t^{2}}\{0.63 \operatorname{In}(r / t)+1.156\} \quad \text { Equation } 3[210] .
$$

Where:

$\rho=$ Fracture load $(\mathrm{N})$.

$\mathrm{t}=$ Sample thickness $(\mathrm{mm})$.

$\mathrm{r}=$ Radius of the support diameter $(\mathrm{mm})$.

\subsection{Ion-release}

The ion concentrations of Silicon ( $\mathrm{Si}$ ), Zinc ( $\mathrm{Zn})$, Strontium (Sr), Sodium (Na), Ge (Germanium) and Calcium ( $\mathrm{Ca}$ ) being released from the cements were determined from water extracts in which the samples were stored using a Perkin Elmer atomic absorption spectrometer 800 (AAS800) (Perkin Elmer, Massachusetts, USA) (Figure 34) and placed in $10 \mathrm{ml}$ aliquots of deionized water and kept at $37^{\circ} \mathrm{C}$ in lidded containers. Samples $(\mathrm{n}=5)$ of each cement were then stored for 1 day, 7 days and 30 days. Following removal of cement samples from their aliquots, a 1:10 dilution of the storage water was made using purified water. Calibration standards for $\mathrm{Ge}, \mathrm{Ca}, \mathrm{Zn}$ and $\mathrm{Si}$ elements were prepared from a stock solution on a gravimetric basis. Five target calibration standards were prepared 
for each ion with $0.1,0.3,0.5,0.7$ and 1.0 part per million (PPM) concentrations while distilled water was used as a blank. Samples for $\mathrm{Ca}, \mathrm{Zn}$ and $\mathrm{Ge}$ analysis were diluted in a ratio of 1:10; that is, each $1 \mathrm{ml}$ of concentrated sample was mixed with $10 \mathrm{ml}$ of distilled water while samples for $\mathrm{Si}$ analysis were diluted in a ratio of 1:30. A pilot study was conducted to determine the appropriate ratio for dilution of all elements. The optimal working conditions are listed in Table 10.

Table 10: Operating parameters for $A A S$.

\begin{tabular}{|lcccccc|}
\hline $\begin{array}{l}\text { Lamp } \\
\text { current (mA) }\end{array}$ & 5 & 5 & 10 & 5 & 10 & 10 \\
\hline $\begin{array}{l}\text { Wavelength } \\
\text { (nm) }\end{array}$ & 251.6 & 213.9 & 239.9 & 330.2 & 460.7 & 265.16 \\
\hline
\end{tabular}

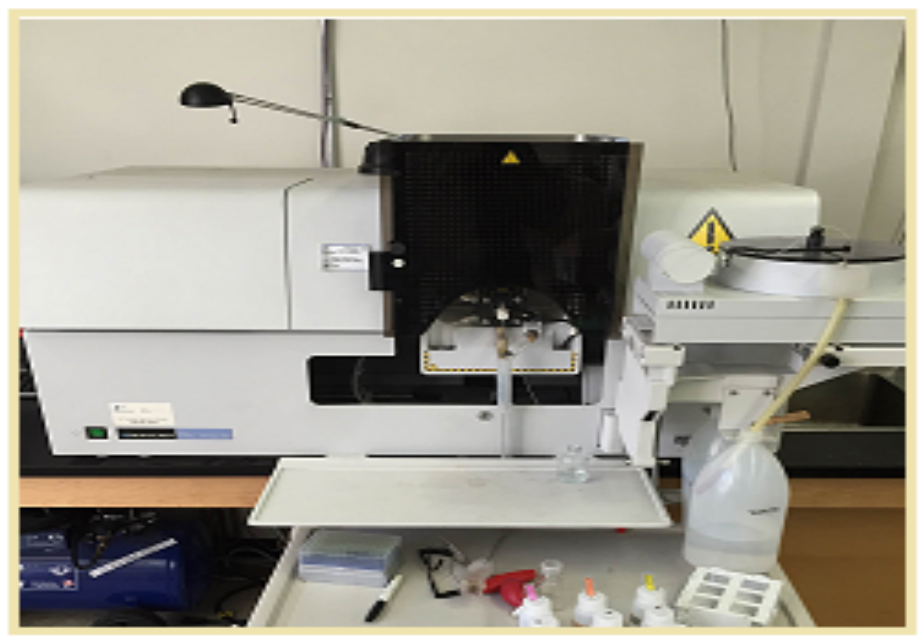

Figure 34: Atomic Absorption Spectrometer Analyst 800 (AAS800) for Ion release

\subsection{Radiopacity (x-ray)- micro-CT}

Radiographic testing was performed in order to determine whenever that the KBT cement is radiopaque and there is a recordable difference between the cement and the bone standard on an x-ray image (Figure $35 \mathrm{a}$. b). The specimens were imaged using a General Electric Healthcare eXplore Locus SP microCT scanner. An initial scout scan was performed, giving an overall x-ray image and the density value for the cement from which an area of focus was then selected for scanning at full resolution $(30 \mu \mathrm{m})$. Each of the KBT cement samples were paired with a bone standard and placed into a full 
resolution scan that utilized the manufacturer's protocol "x-ray tube, 120 minutes" (Figure $35 \mathrm{c}$ ).
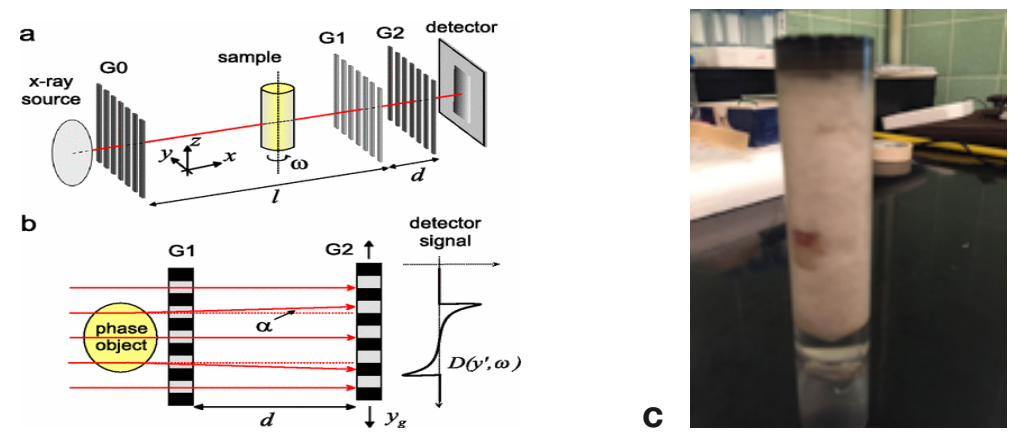

Figure 35: X-ray imaging interferometer. (a) Setup based on transmission gratings G0 through G2. (b) A phase object in the beam path causes a slight deflection of $x$-rays changing the locally transmitted intensity through the arrangement formed by the gratings G1 and G2 [212]. (c) Sample (plastic tube filled with water, cotton, and bone standard and cement sample).

\subsection{Adhesive properties}

\subsubsection{Collection of samples and preparation}

To determine the adhesive properties of the GPCs to titanium alloy (ASTM B348), a cylinder of $19.05 \mathrm{~mm}$ diameter titanium alloy (McMASTER CARR). Figure 36 illustrates a) the flat side of the titanium cylinder, b) the side that has been drilled in the center for the purpose of bond strength testing. Using a layer of the cement (KBT01, KBT02 and KBT03) applied with a spatula, the bone, aluminum (ASTM B209) and titanium plate (ASTM B265) were bonded together and excess material was removed using a scalpel (Figure $36 \mathrm{c}-\mathrm{h}$ ). Figure 36.d shows the preparation of the cement as described previously in section 3.3.1. Titanium and Aluminum plates were chosen to be used for bond strength testing in order to assess the adhesive properties of the cement to both metal and bone. Five samples were prepared for each cement; samples were then left to harden for 1 hour at $37{ }^{\circ} \mathrm{C}$ before being submerged in a single container of distilled water (excluding 0 day). Day 0 was left out of water in order to test the binding of the cement with $\mathrm{Ti}, \mathrm{Al}$ and bone. The container was kept at $37^{\circ} \mathrm{C}$. The same procedure was followed for 1,7 , and 14 day investigations. 


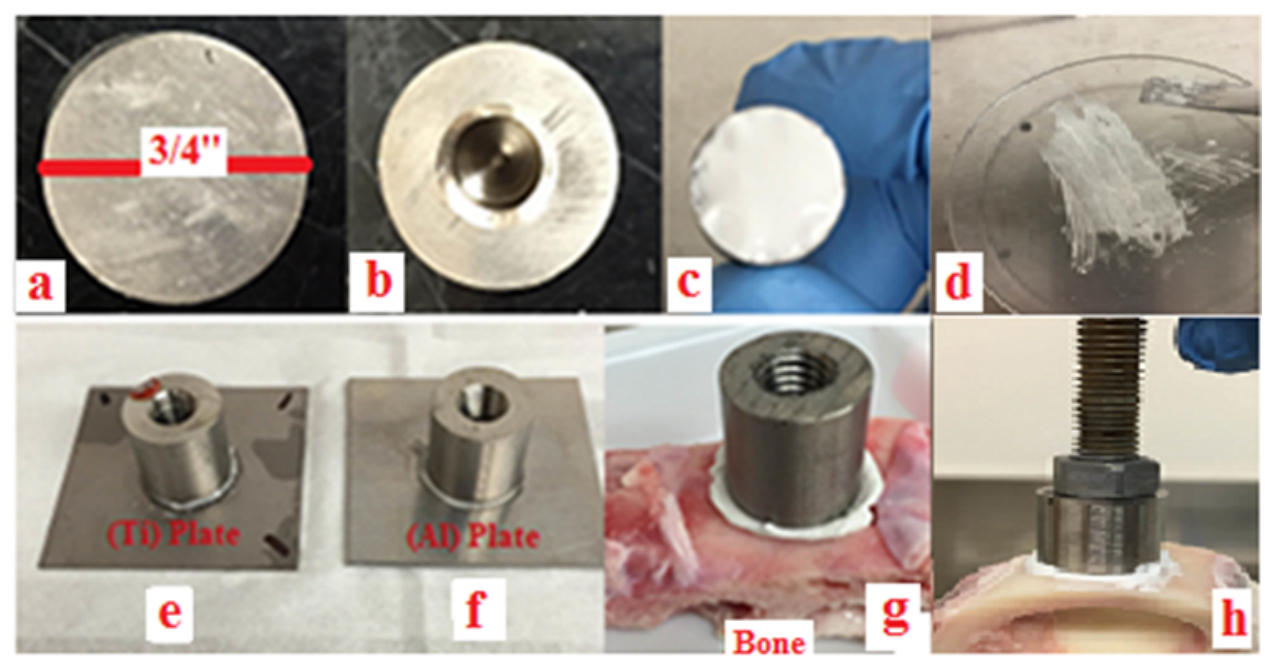

Figure 36 a-h: Process of collection and preparation of samples (Ti, Al and Bone)

\subsubsection{Bond strength}

A model was designed for the bond strength of 5 ovine cranial bones for each of $0,1,7$ and 14 days. The aluminum hollow tube is $8 \times 8$ inches and has a 1 inch drilled hole at the top for purposes of pull-out strength testing (Figure 37). The titanium cylinder is then inserted through the hole, once the $\mathrm{Ti}, \mathrm{Al}$ and bone hit perfectly flat (Figure $38 \mathrm{a}-\mathrm{d}$ ) the titanium cylinder can begin pulling upwards and testing the strength of the sample. The bond strength was performed in ambient air $\left(23 \pm 1{ }^{\circ} \mathrm{C}\right)$ according to ISO9917 [11]. Samples were tested during 0 days and after 1, 7 and 14 days. Testing was undertaken on a United Testing Systems (United Testing System Ontario, Canada) using a $\pm 2 \mathrm{kN}$ load cell at a crosshead speed of $1 \mathrm{~mm}$.min-1 and converted into bond strength using the Equation 4 below.

$$
\sigma=F / A \quad \text { Equation } 4
$$

where $\sigma$ is the bond strength (MPa), F is the maximum force applied $(\mathrm{N})$ and $\mathrm{A}$ is the bonded area $\left(\mathrm{mm}^{2}\right)$. 


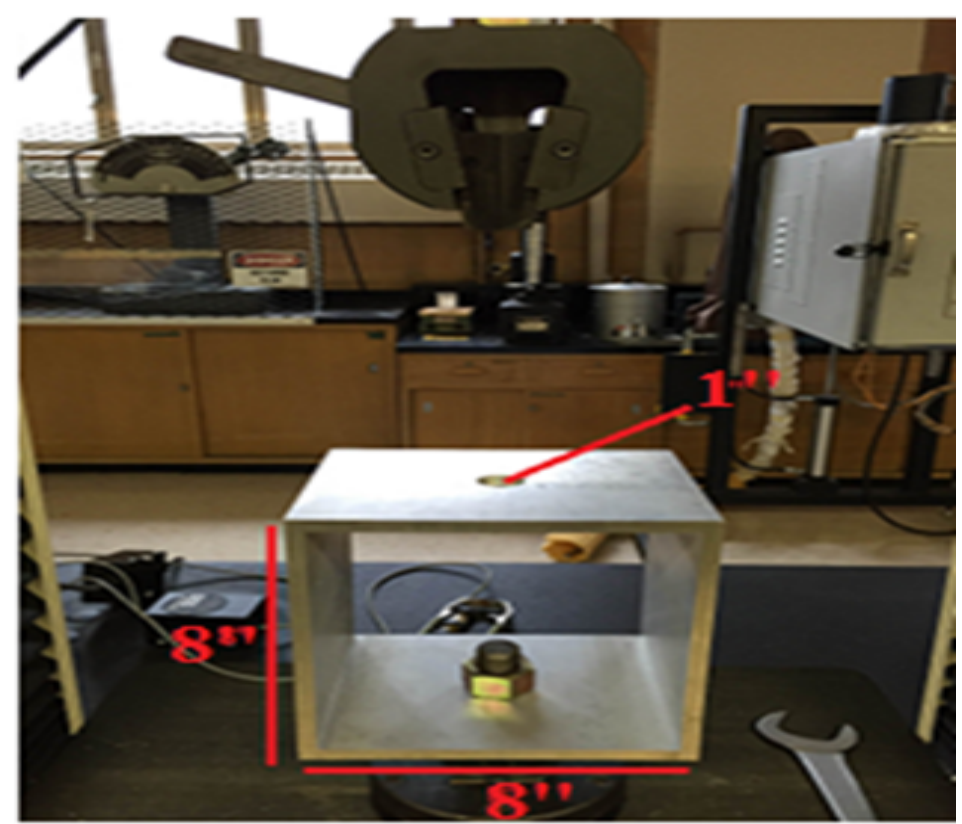

Figure 37: Aluminum Hollow Tube

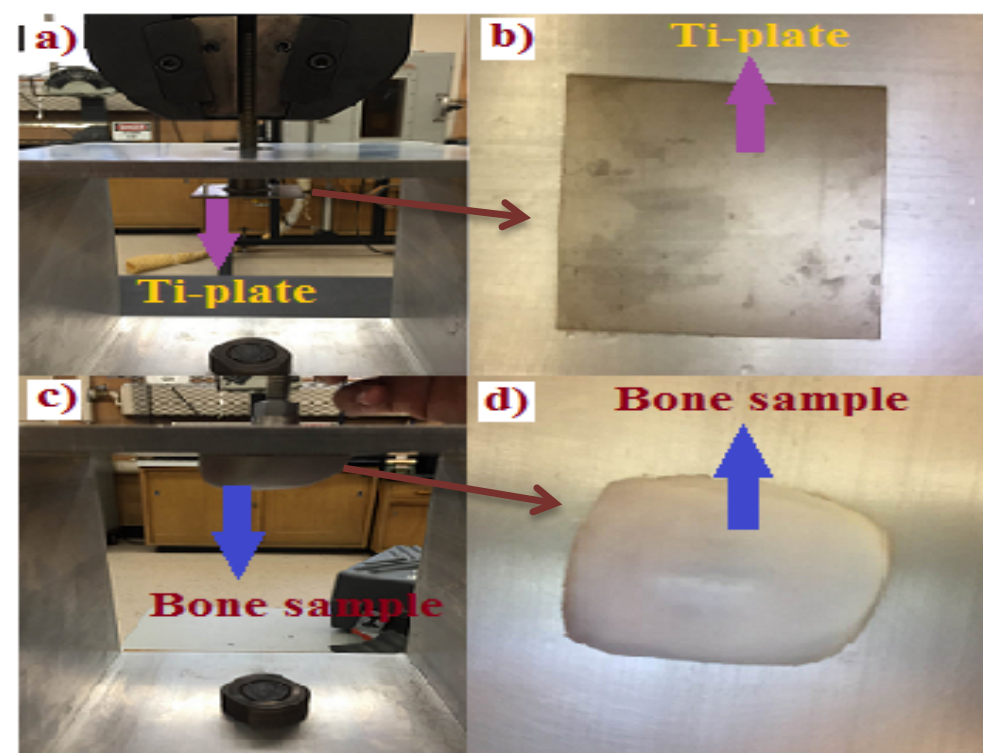

Figure 38: a) and c) The titanium cylinder is inserted into the hollow tube b) and d) The Ti, Al, Bone lays perfectly flat on the inside of the tube in order to start the bond strength test

\subsection{Statistical analysis}

One-way analysis of variance (ANOVA) was used to analyze the data. Post-hoc Bonferroni test was used to compare the relative means and to report the statistically significant differences when $\mathrm{p}<0.05$. Statistical analysis was performed using SPSS software (IBM SPSS statistics 21, IBM Corp., Armonk, NY, USA). 


\section{Chapter 4}

\section{Results and Discussion}

\subsection{Glass characterization}

\subsubsection{X-ray diffraction (XRD)}

XRD was performed to determine if any crystalline phases were present within the starting phases of the glass. Figure 39 shows the XRD data which confirmed that all fired glasses were fully amorphous with no crystalline species present.

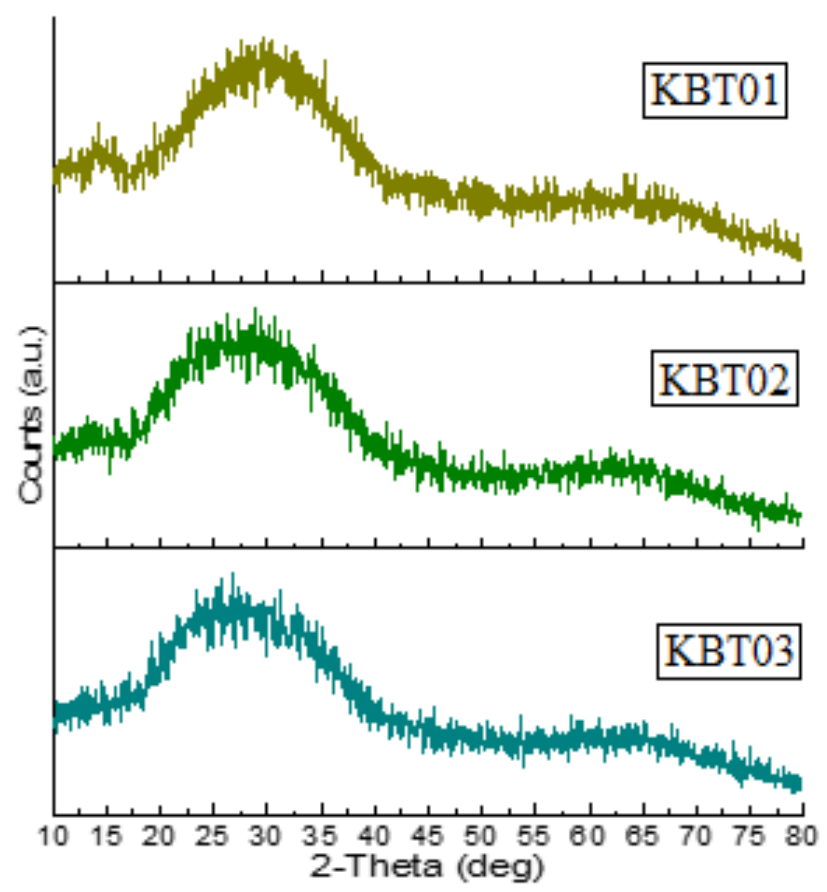

Figure 39: XRD patterns of the formulated glasses (KBT) series.

\subsection{Particle size analysis (PSA)}

Particle size analysis was performed in order to determine the mean particle size of each of the formulated glasses. Particle size of $<45 \mu \mathrm{m}$ were required for cementitious purposes; however as shown the average in Figure 40. The mean particle size was confirmed to be closer to $8.6 \mu \mathrm{m}$ for each glass. Particle size does have an impact on 
rheology and mechanical properties of GPCs. There is an increase of the surface area of the glass component when the particle size is smaller, in turn reducing the St [213] and increasing Cs [213].

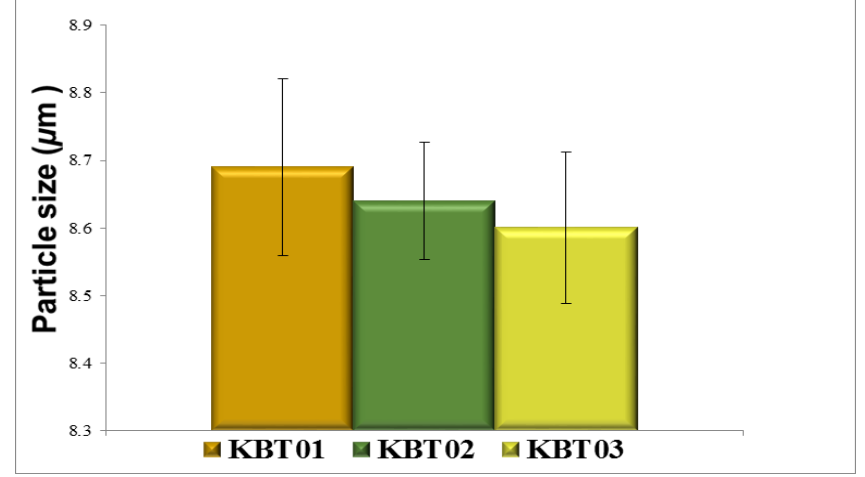

Figure 40: Mean particle size for each ground glass (5 samples for each glass).

\subsection{Scanning electron microscopy (SEM) \& energy dispersive $x$-ray analysis (EDX).}

Each glass was exposed to SEM and is portrayed in Figure 41 a-c. The KBT01 (a), KBT02 (b) and KBT03 (c) glasses all have a similar particle size, corresponding with the outcomes from the PSA.

EDX was carried out to confirm the presence of the ions that were incorporated in the starting glass. Appendix C shows the EDX scan peaks for the KT01, KT02 and KT03 glasses. Peaks show the composition of each glass and confirm the starting formulation of the glass whereby it was found that the KT01 glass contains Zn, Si, Ca and $\mathrm{Na}$. On the other hand, KT02 and KT03 were found to have the same elements but with the addition of $\mathrm{Ge}$ as presented in Table 11.

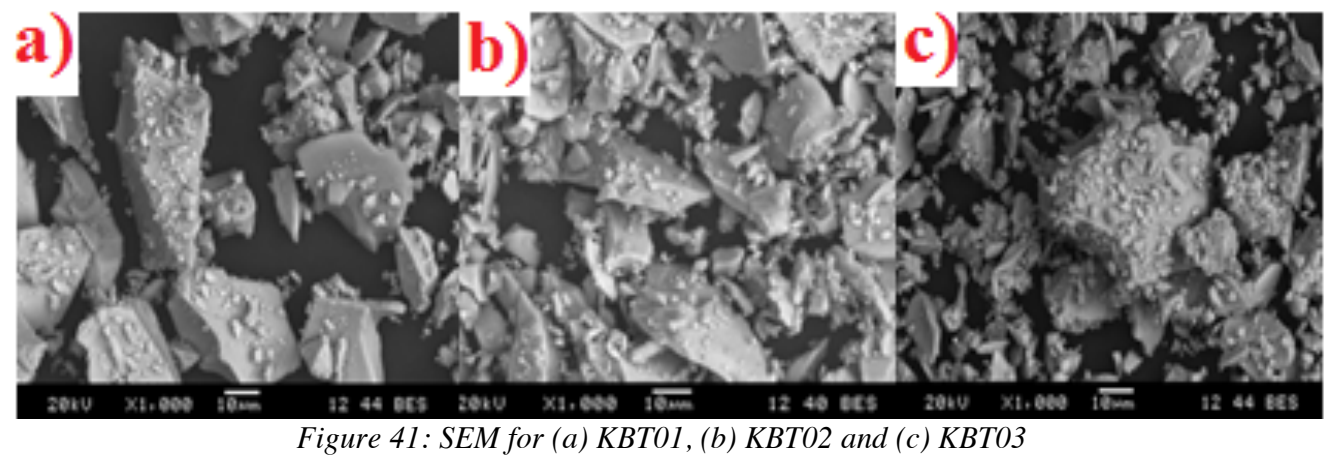


Table 11: Composition in Wt\% as verified by EDX

\begin{tabular}{cccc}
\hline & KT01 & KT02 & KT03 \\
\hline $\mathrm{O}$ & 44.5 & 48.1 & 44.1 \\
$\mathrm{Si}$ & 18.3 & 17.7 & 18.2 \\
$\mathrm{Ca}$ & 2.8 & 2.5 & 2.8 \\
$\mathrm{Zn}$ & 26.5 & 22.1 & 22.1 \\
$\mathrm{Na}$ & 7.9 & 7.5 & 7.6 \\
$\mathrm{Ge}$ & - & 2.1 & 5.2 \\
\hline
\end{tabular}

\subsection{Calculation of network connectivity}

Calculation of Network Connectivity for (KT) glasses, BT101 and the KBT glasses (KT glasses and BT101).

Where:

$\mathrm{SiO}_{2}, \mathrm{GeO}_{2}$ are network formers.

$\mathrm{CaO}, \mathrm{ZnO}, \mathrm{SrO}$ and $\mathrm{Na}_{2} \mathrm{O}$ are network modifiers.

There are no intermediates

Table 12: Calculation of Network Connectivity for KT glasses

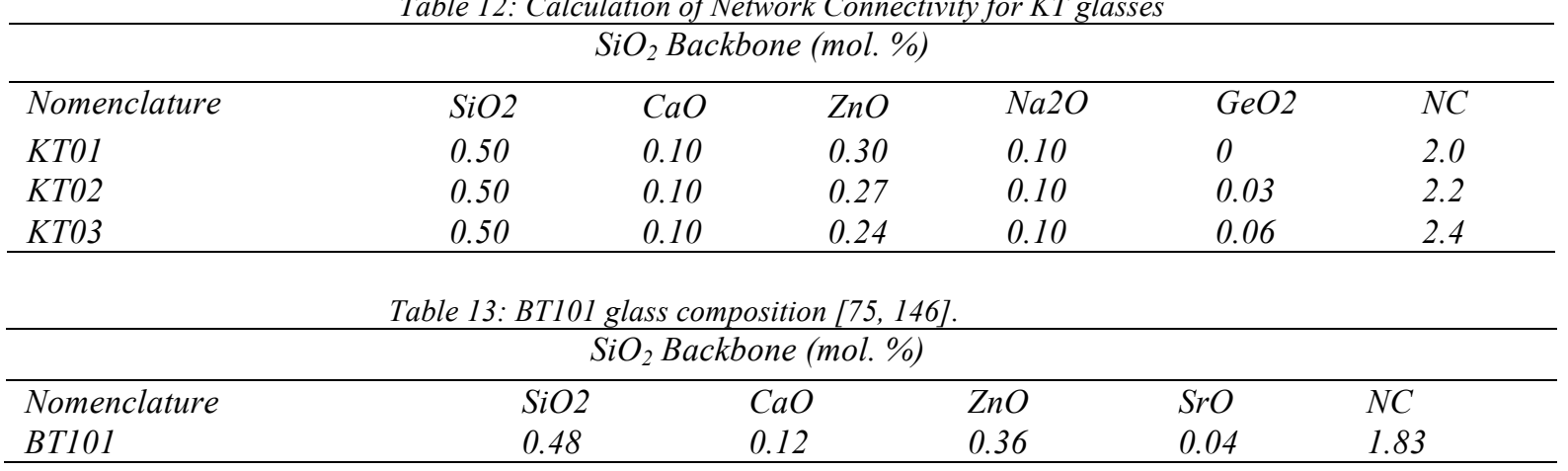

Example for NC calculation for KT01 glass:

$$
\begin{gathered}
N C(K T 01)=\frac{(50 X 4)-((10+30+10) X 2)}{50} \text { Equation 5.a } \\
N C\left(\text { KT01) }=\frac{(200)-(100)}{50} \text { Equation } 5 . b\right. \\
N C(\text { KT01) }=2.00
\end{gathered}
$$

\subsection{Rheological properties (working time \& net setting time)}

\subsubsection{Working time}

In regards to the cranioplasty fixation for miniplate attachment, it is assumed that the working time should be within the span of 1 to 2 minutes in order to allow the surgeon to apply the cement while being able to manipulate its content on the cranium. Figure 42 
displays the working times of the cement series. Comparable to the net setting time, Tw decreased, from $\sim 142$ to $112 \mathrm{~s}$, as the concentration of Ge increased from 0.00 to 0.06 mol\%. There was a statistically important variance $(\mathrm{P}<0.05)$ between the three glasses in the series in terms of Tw. A significant decrease in Tw was also recognized with the addition of Ge; decreasing from 123 to 112 s for KBT02 and KBT03 respectively. Results from the rheological properties signify that KBT03 offers a material with handling properties more appropriate for craniotomy applications since Tw ( 112) and Ts ( 448 s).

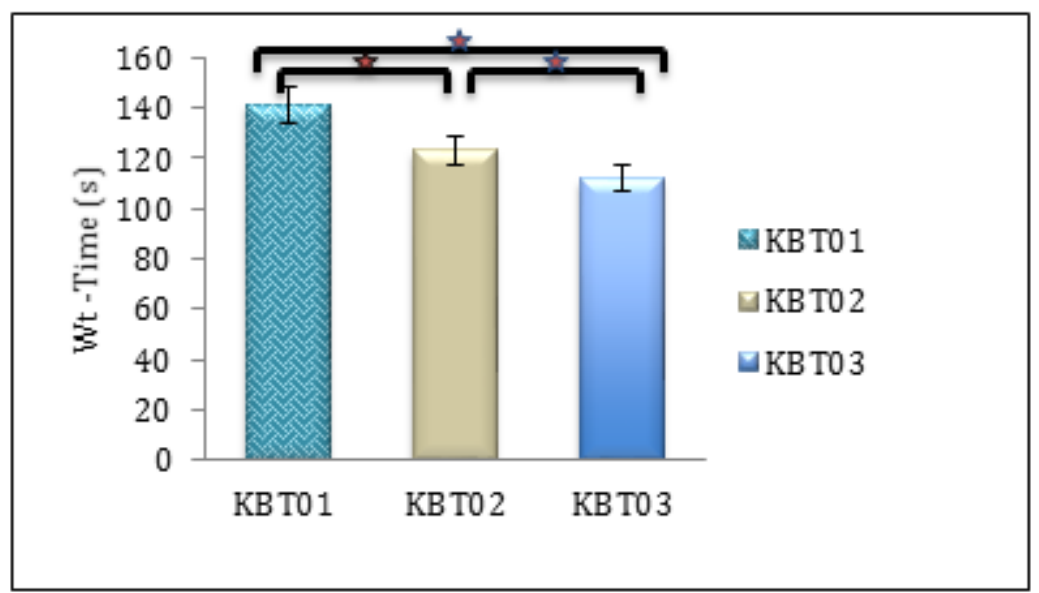

Figure 42: Working times. Stars and bars show statistical significance $(p<0.05)$ (5 samples for each glass).

\subsubsection{Net setting time}

The setting time is the time needed for the cement to become a solid form. Based on the ISO9917 [11] standard for dental-based cements, a setting time between 1.5 and 6 min is essential. During craniotomy, the surgeon needs adequate time to apply the material on the cranium before setting occurs. Though there are no specific criteria for these cements outside of orthopedic applications, a setting time that extends more than 6 minutes could result in some problems such as cement movement and failure to control the incision. Thus, it was vital to find the effect of Ge addition on the net setting time considering the craniotomy surgical operation. Figure 43 portrays the net setting times of the cement series. Ts decreased from $\sim 807 \mathrm{~s}$ for KBT01 to $448 \mathrm{~s}$ for KBT03. There is a statistical variance $(\mathrm{P}<0.05)$ between the three glasses in the series when tested for the Ts. A significant decrease in Ts was also recognized with the addition of Ge; decreasing from 583 to 448 s for KBT02 and KBT03 respectively. It is assumed the cause for the decrease 
in setting time is due to the particle size as shown in SEM images as a lesser particle size results in a greater area and the glass composition of the glass particles throughout the acid attack therefore quickening the setting reaction. GPC setting reactions are determined by the rate at which cations are released from glass during the acid attacks and chelated by the PAA polyanion chains [138]. Since the $\mathrm{Zn}^{2+} \mathrm{Ca}^{2+}, \mathrm{Na}^{2+}$ and $\mathrm{Sr}^{2+}$ cations take on roles as network modifiers, in turn depolymerizing the glass networks by producing non-bridging oxygens $[189,146,214]$. The less polymerized a glass network is, the more vulnerable it becomes to acid attack, resulting in the material setting more quickly. There will be a decrease in the working time and setting time since the high concentration for PAA (210 mw\%) was used [215].

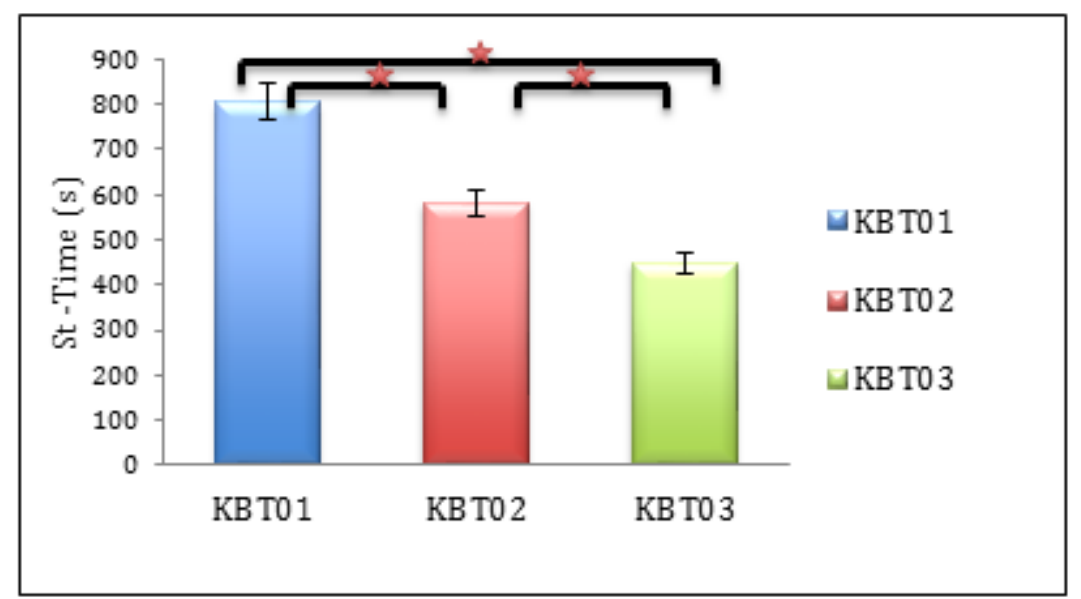

Figure 43: Net setting times. Stars and bars show statistical significance $(p<0.05)(5$ samples for each glass).

\subsection{Mechanical properties}

\subsubsection{Compressive strength}

Compressive strength was recorded according to ISO9917 [11]. Samples were suffused in distilled water for 1, 7 and 30 days prior to testing. Figure 44 displays the compressive strength results for all cement formulations. At 30 days testing the KBT03 glass had the highest strength ( 56 MPa), KBT01 had the lowest ( 43 MPa) and KBT02 had higher strength ( $\sim 52 \mathrm{MPa})$ than KBT01, all the samples have comparable levels of water content $(10 \mathrm{ml})$ at $1 \mathrm{day}$, and the same water contents when matured at 7 and 30 days. Hence, the mechanical properties appear dependent on the time and addition of Ge to the KBT02 $(0.03 \mathrm{~mol} \%)$ and KBT03 $(0.06 \mathrm{~mol} \%)$. There is a high probability that the KBT03 samples presented greater strengths due to the increased level of cross-linking when 
compared to the KBT01 and KBT02 samples. It was also discovered that the KBT02 had greater strength in comparison to the KBT01 sample. Due to the addition of germanium of $0.03 \mathrm{~mol} \%$ in KBT02 there was a small increase and in KBT03 of $0.06 \mathrm{~mol} \%$ a greater increase was portrayed in 30 days testing. Ge is the component liable for the increased strength. Mechanical properties of GPCs have been ascribed to the cross-link density of cations that chelate the polyanion chains of the acid, and the degree to which these chains are entangled with one another [181]. It is possible an increased cross-link density of divalent cations is liable for the increase in strength as such a mechanism would see a synchronized increase to strength, as displayed in Figure 44 . Hill et al. described the entanglement of polyanion chains to limit their lateral movement, while interactions with neighboring chains limit their longitudinal movement [180]. Thus, it is probable that relations between multi-valent $\mathrm{Ge}^{4+}$ ions, or complexes thereof, interrelate with more than two polyanions to increase chain entanglement thus decreasing reptation to create stronger cements. GPCs have shown an increase in mechanical properties as the cement matures and increases the number of crosslinks by bonding more ions and polyer $\mathrm{COO}^{-}$bond together $[181,215-217]$. Wilson attributes this characteristic to the continuous and more complete acid-base reaction between the glass and the PAA [139]. The results indicate that increasing the concentration of PAA used in the cement formulation causes considerably stronger cement, both in compression and biaxial flexure.

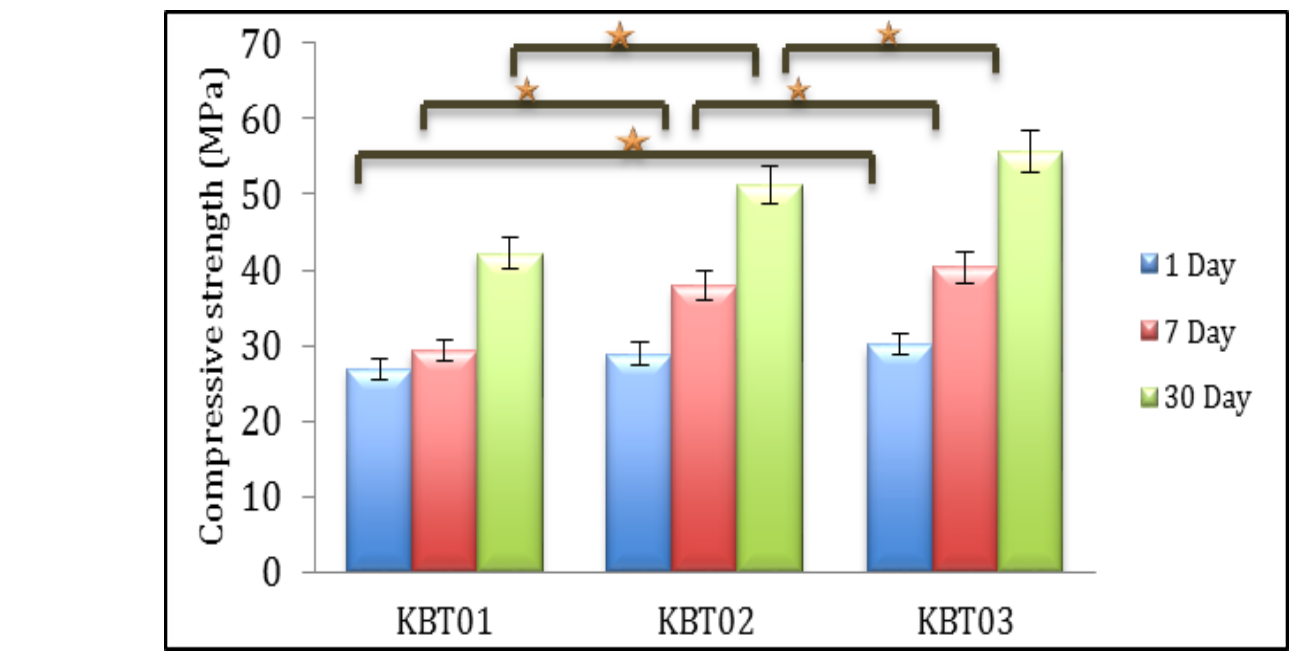

Figure 44: Compressive survey results for the cement series over 1, 7 and 30 days. Stars and bars show statistical significance $(p<0.05)$ (5 samples for each cement). 


\subsubsection{Biaxial flexure strength (BFS) test}

BFS testing was conducted in order to examine the effect of the KBT glasses series addition on the mechanical properties of GPCs when matured in distilled water for 1, 7, and 30 days. Figure 45 presents the BFS results. The BFS $\left(\sigma_{\mathrm{f}}\right)$ attained exhibit minor changes between KBT02 and KBT03 samples over the 1,7 and 30-days. The addition of Ge was found to increase both $\sigma_{c}$ and $\sigma_{f}$; however, there was a statistical difference between KBT01 and KBT02-03 and for 1, 7 and 30 days measurements of $\sigma_{\mathrm{c}}$ and for 1,7 and 30 days measurement of $\sigma_{\mathrm{f}}$. The results signify that KBT02 and KBT03 can deliver a statistically improved biaxial flexural strength and a compressive strength comparable to that of the KBT01 glass after the addition of germanium in KBT02 and KBT03, as mentioned in the compressive strength section; it is dependent on the time and the extent of germanium addition. This is due to increased sensitivity of the biaxial flexural testing in comparison with compression testing because of the elimination of the influence of intersecting planes of shear and edge defects from the results [218]. Ge appears to be the component responsible for increased strength. Mechanical properties of GPCs, such as strength and modulus, have been attributed to the cross-link density of cations, which chelate the polyanion chains of the acid, as a result of the extent to which these chains are entangled with one another [219]. It is assumed an increased cross-link density of divalent cations is responsible for the increase in stiffness due to a concurrent increase to strength.

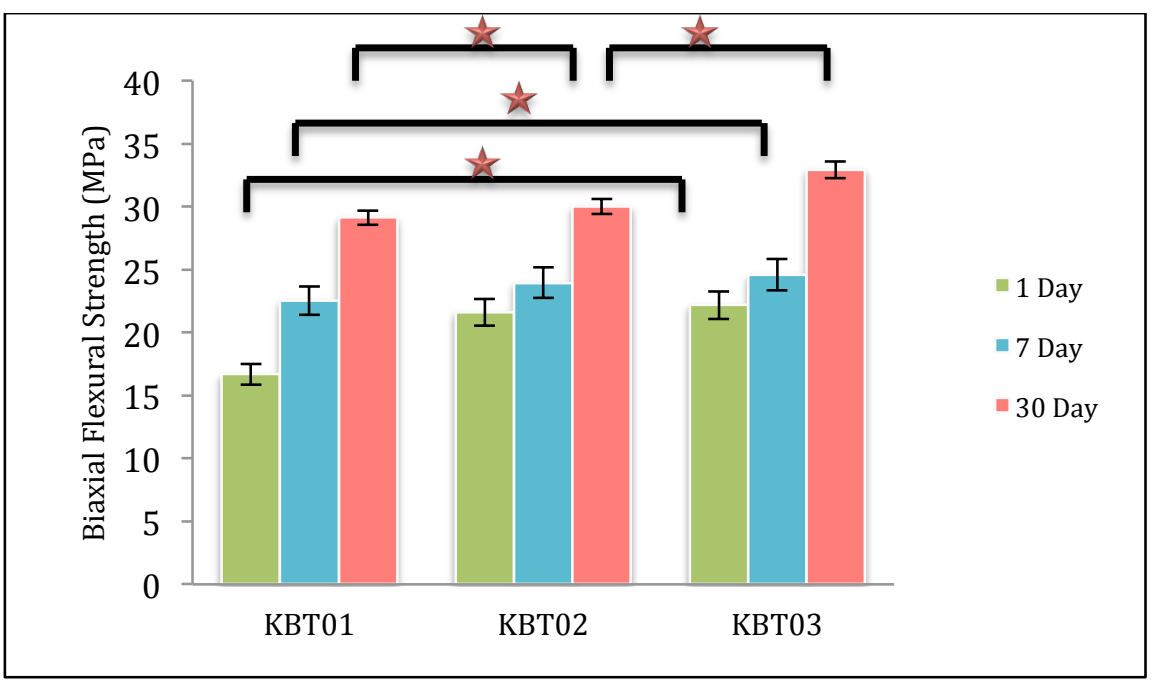

Figure 45: Biaxial flexural strength survey results for the cement series over 1, 7 and 30 days. Stars and bars show statistical significance $(p<0.05)$ (5 samples for each cement). 


\subsection{Ion release}

Ion release from these cements is vital in order to verify the possible therapeutic or cytotoxic effect they may have following implantation. Ion release was examined cumulatively over 1,7, and 30 days. The recorded ion release levels are shown in Figures 46.a-46.f, for silicon, calcium, zinc, sodium, strontium and germanium respectively. Starting with silicon it is noted in Figure 46 (a) that the release of silicon remains unchanged all throughout the 30-day period, with a slight increase after 7 days. This confirms that the glass network degrades during the setting reaction. Following setting, there will be a considerable quantity of free silica in the cement and insecurely bound at the surface of the residual glass particles. Once set there will be a considerable number of free silica in the cement and loosely bound at the surface of the residual glass particles. After the cement is submerged in water silica molecules will be dissolved and free silicon will transfer into solution. This procedure decelerates considerably as time progresses as is apparent as the amount of ions released does not increase excessively over the increasing time durations, implying that following 30 days there is an insufficient amount of Si left that is not coordinated and charge balanced in the residual glass particles.

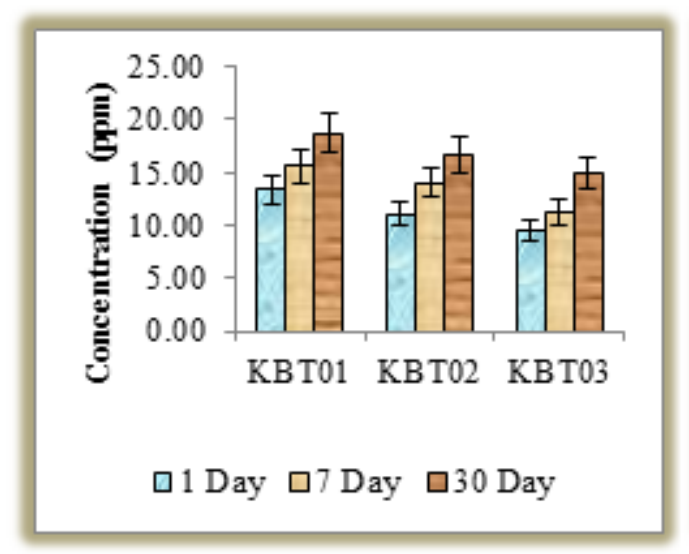

Figure 46.a. Si ion release (bars represent standard deviation (SD) for 5 samples for each cement).

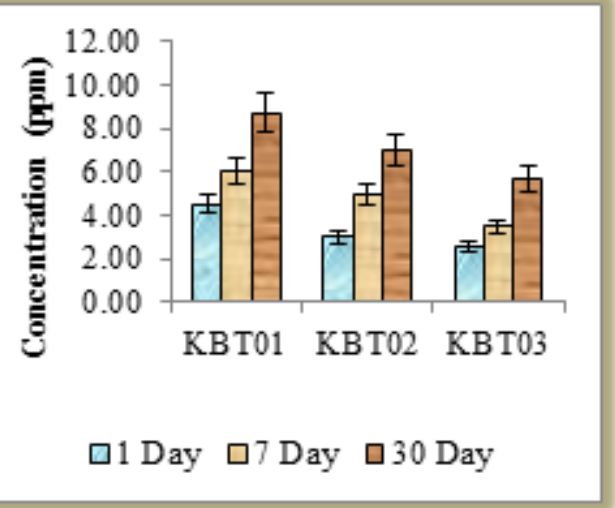

Figure 46.b. Ca ion release (bars represent SD for 5 samples for each cement).

Calcium release is displayed in Figure 46 (b) and zinc ion release is displayed in Figure 46 (c). It can be observed that there is a substantial amount of Na Figure 46 (d), Ca and $\mathrm{Zn}$ ions released during the first day, and a small amount released throughout the next 29 days. 


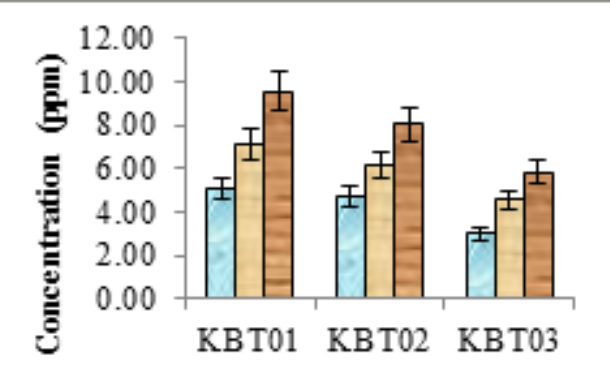

口1 Day $\square 7$ Day $\square 30$ Day

Figure 46.c. Zn ion release (bars represent $S D$ for 5 samples for each cement).

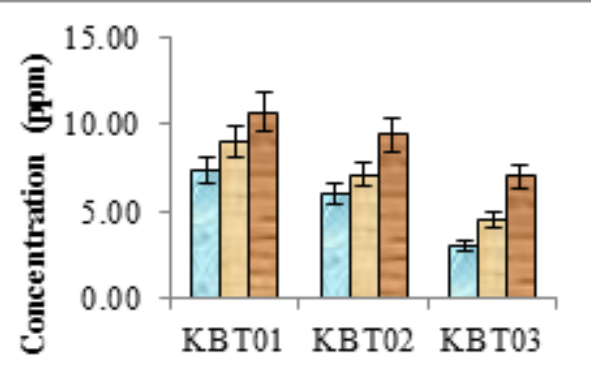

$\square 1$ Day $\square 7$ Day $\square 30$ Day

Figure 46.d. Na ion release (bars represent SD for 5 samples for each cement).

For the $\mathrm{Ca}$ ions there is no significant variance among the ions released at day one and the ions released throughout the next 6 days since there is a very low release afterward. Therefore, $\mathrm{Ca}$ is the most sought after ion by the COO- bonds. It is being used up quickly in order to mature the cement. In turn, resulting in the release of $\mathrm{Ca}$ increasing as the cement ages. Therefore, the reason that all of the ions display a decrease in the cements is due to the addition of Ge in KBT02 and KBT03. This is also true for $\mathrm{Zn}$ with the exclusion of the control cement where the rate of $\mathrm{Zn}$ release reduces very quickly following the first day that there is no statistically significant difference amongst the oneday release and the 30-day release. In regards to the remanding cements, there is a considerable difference between the 7-day values and the 30-day values, which could be a cause of the variance in time periods among the two. A time period of 23 days compared with 6 days might result in a more consistent behavior in the samples, specifically observing the 30 day error bars for $\mathrm{Zn}$. Referring once again to the 1 day $\mathrm{Na}$, $\mathrm{Ca}$ and $\mathrm{Zn}$ ion release in these three cements, this vital release happens because of to the attack on the glass structure and following cross linking throughout the setting reaction. When the glass network is interrupted and the $\mathrm{Na}, \mathrm{Ca}$ and $\mathrm{Zn}$ ions are released they become active, several will crosslink in order to set the cement, and however the residuals will move effortlessly into solution when the cement is positioned into water. Due to the remaining $\mathrm{Na}, \mathrm{Ca}$ and $\mathrm{Zn}$ being locked in the large body of the residual glass particles only a few ions will be released after this preliminary rush. Germanium ion release is presented in Figure 46 (f). Alternatively, the coordination environments of network modifier cations such as $(\mathrm{Ca} / \mathrm{Na} / \mathrm{Sr})$ act as network modifiers in the glass, 
disrupting the support system of the glass network via breaking the bridging oxygen bonds ( $\mathrm{Si} / \mathrm{Ge})-\mathrm{BO}-(\mathrm{Si} / \mathrm{Ge})$, and developing non-bridging ( $\mathrm{Si} / \mathrm{Ge})-\mathrm{NBO}-(\mathrm{Ca} / \mathrm{Na} / \mathrm{Sr})$ [220]. Figure 46 (e) displays the $\mathrm{Sr}$ release from the cements, which is nearly identical to $\mathrm{Ca}$. It was examined that $\mathrm{Sr}$ also increased in the control cement by increasing exposure time following 30 days as depicted in Figure 46 (d).

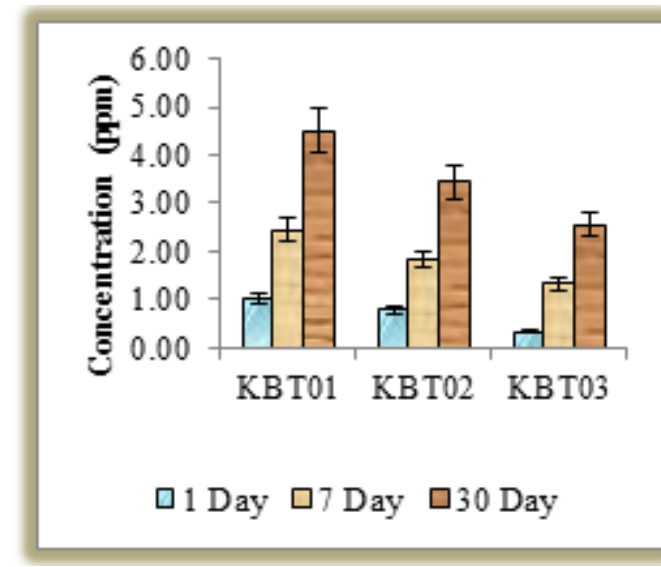

Figure 46. e. Sr ion release (bars represent SD for 5 samples for each cement).

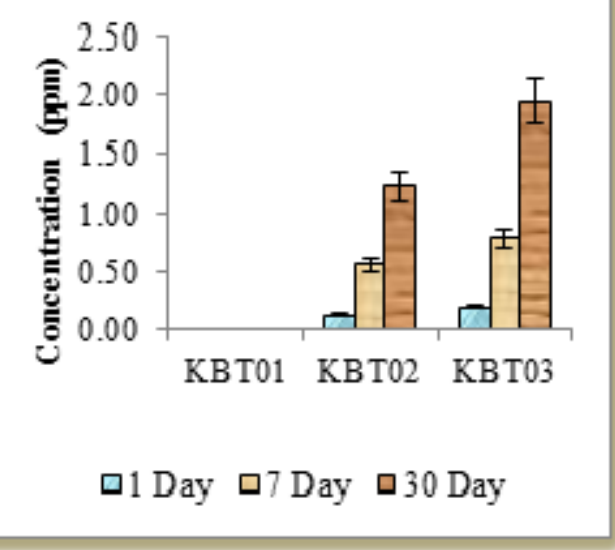

Figure 46 . $f$. Ge ion release (bars represent $S D$ for 5 samples for each cement).

Generally speaking, separately the ions were increasing for the $\mathrm{Ca}, \mathrm{Na}, \mathrm{Sr}$ in each glass, however, for the three glasses combined KBT01, KBT02 and KBT03 the ions were decreasing, this may be due to the addition of Ge in KBT02 and KBT03. Alternatively, the cause for the decrease in ions from the KBT series glass may be the increased binding size due to the PAA 200 having a high molecular weight; subsequently the ions were binding into the polysalt matrix as opposed to releasing the ions into the solution. This verifies that there is an increase in strength. As expected there was no Ge release from the KBT01 (Ge-free) cement, however, as was anticipated there was Ge release from the KBT02 and KBT03 during the 1, 7 and 30 daytime period. Also, as expected there was more Germanium ion release from the KBT03 compared with the KBT02, this is due to a more increased amount of $\mathrm{Ge}$ in KBT03. Germanium release instigates within the first 24 hours in the KBT02 and KBT03 cement and remains throughout the 30-day period. The release of Ge is extremely low when compared to that of other ions, yet that might be a consequence of the low Ge content that exists in the glass. 


\subsection{Radiopacity (x-ray) - microCT}

The radiopacity testing was performed according to the ASTM F640 "Standard Test Methods for Determining Radiopacity for Medical Use" for monitoring the position of permanently implanted medical devices, such as stents, hip and knee implants, and screws [221]. In addition to having suitable mechanical properties, it is vital that bone cements are radiologically detectable to facilitate long term monitoring of the implant [75]. The results of the radiographic testing are shown in Figure 47. The cement is represented by the lighter colored image compared to the bone standard, which is represented as a slightly darker color on the x-ray. Since the cement is represented by a lighter shade on the x-ray image, it is assumed to have a high density [222]. As shown in Figure 48, the cement density was higher than the density of the bone standards. The radiopacity of the bone standards was measured as $1.05 \mathrm{~g} / \mathrm{cm}^{2}$ and, while all the cements were in the region of 1.35 to $1.57 \mathrm{~g} / \mathrm{cm}^{2}$ (S.D. 0.02). Regardless of the level of $\mathrm{Ge}$ addition, it is clear the addition of Ge did not achieve any significant increase in the radiopacity of the cements; this is most likely due to the low levels of germanium inclusion.

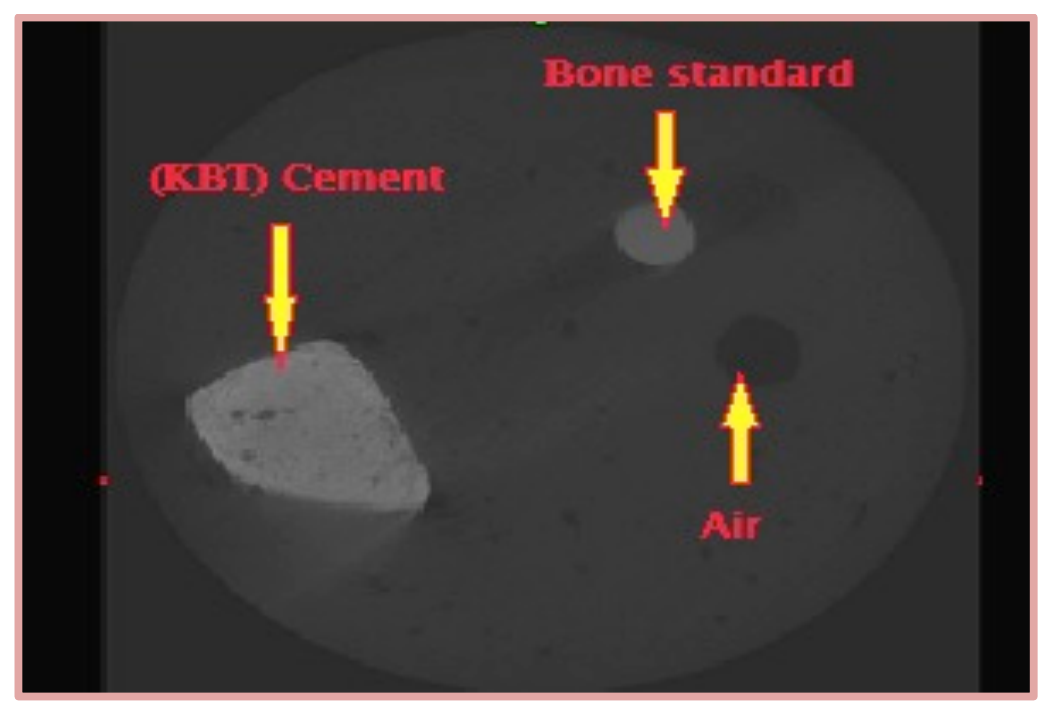

Figure 47. Radiograph image of the cement sample and bone standard. 


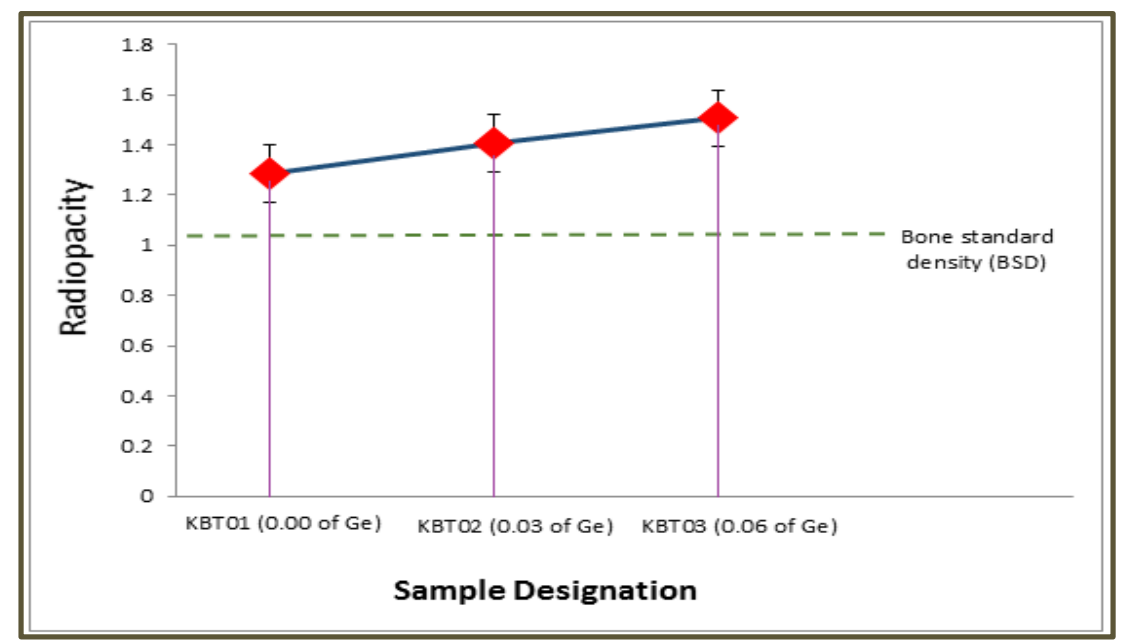

Figure 48: Comparison of the radiopacity of cement

\subsection{Bond strength test}

The work seeks the development of Ge-containing GPCs for fixation purposes in the cranium. Figure 49 a) illustrates the in-vitro bond strength measurements for all cement series in 0 days and over 1, 7 and had strengths recorded in 14 days for the titanium cyclinder to bone. As can be seen, KBT01, 02, and 03 cements $\sim 0.23,0.33$ and 0.41 MPa respectively at $\mathrm{t}=0$ days. The strength was found to increase after 1, 7 and 14 days. During 1 day, KBT01, 02, and 03 cements were $\sim 0.29,0.38$ and $0.46 \mathrm{MPa}$ respectivly. During 7 days, KBT01, 02, and 03 cements were $\sim 0.36,0.43$ and $0.52 \mathrm{MPa}$ respectively. During 14 days, KBT01, 02, and 03 cements were $\sim 0.44,0.48$ and $0.63 \mathrm{MPa}$ respectively.

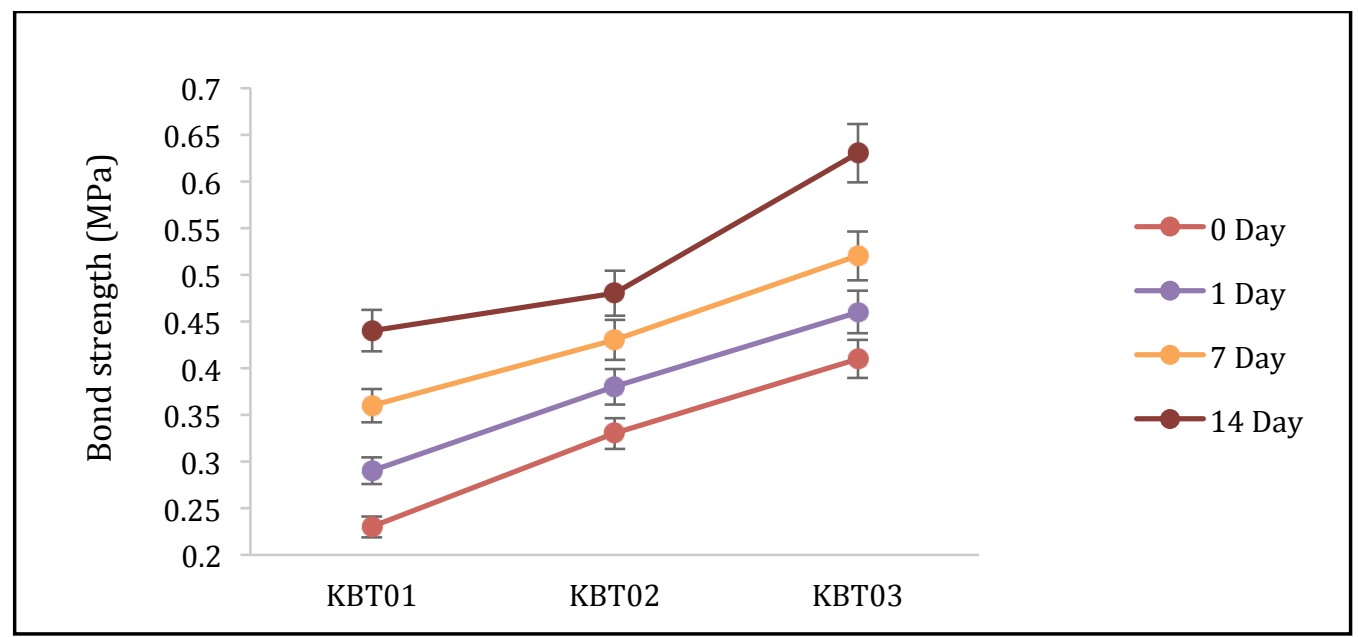

Figure 49 a) Ti (Cylinder) attachment to Bone by KBT cements (bars represent SD for 5 samples for each cement). 
The results of Figure 49 a) shows that the adhesive properties of the cement attachment between titanium to bone changes significantly, which proves that the cement has a chemical bond with the bone during maturity as shown in Figure 50 a-c.

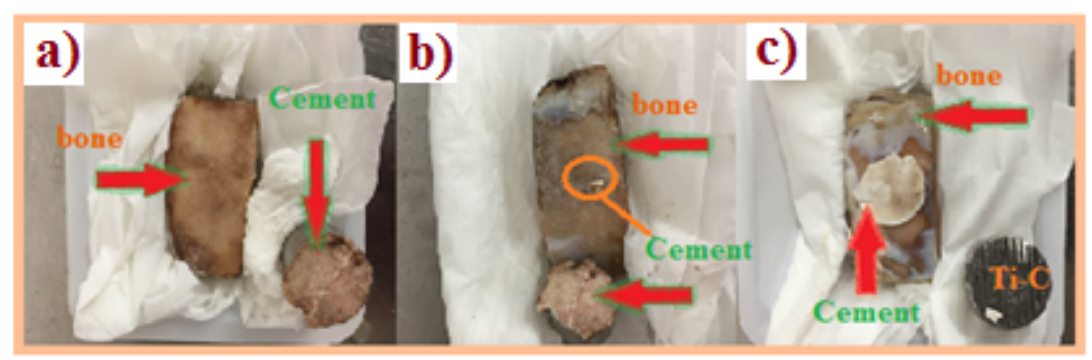

Figure 50: a) 1 day, b) 7 days and c) 14 days

From 0 to 1 day the bond strength test failure occurred between the bone surface and cement. This indicates that the cement was attached to the Ti cylinder surface. Failure at 7 days was between the Ti cylinder surface and bone surface. Some cement was left attached to the Ti cylinder and bone surface, indicating that there was failure at different points in the cement. It is assumed that chemical bonding occured some time between 2 and 7 days. This is due to a failure between the Ti cylinder surface and cement after 14 days testing, indicating that the cement attachment to the bone was stronger then its attachment to the Ti cylinder surface. KBT02 has a higher strength than KBT01, while KBT03 has a higher strength than KBT02, this is due to the additon of Ge in KBT02 and KBT03 cements 0.03 and $0.06 \mathrm{wt} \%$ respectively.

The strength value of the cement attachment between the Ti cylinder and Al plate are displayed in Figure 49 b). As can be seen, KBT01, 02, and 03 cements were $\sim 0.73,0.78$ and $0.86 \mathrm{MPa}$ respectively at $\mathrm{t}=0$ days. After 1 day, KBT01, 02 , and 03 cements were $\sim$ $0.81,0.88$ and $0.93 \mathrm{MPa}$ respectivily. During 7 days, KBT01, 02, and 03 cements were 0.85, 0.94, $0.98 \mathrm{MPa}$ respectively. During 14 days, KBT01, 02 and 03 were $\sim 0.89,0.98$ and 1.05 MPa respectively. The results showed that there is a slight increase during maturity over $0,1,7$ and 14 days. This is due to the increase in mechanical properties of the cement with maturiation, which has been proven in Cs and BFs testing. The failure was found to be between the cement and the Al plate. Figure $49 \mathrm{c}$ ) dispays the strength 
value of the cement attachment between the Ti cylinder and $\mathrm{Ti}$ plate. The results were shown to be similar to the Ti cylinder and Al plate.

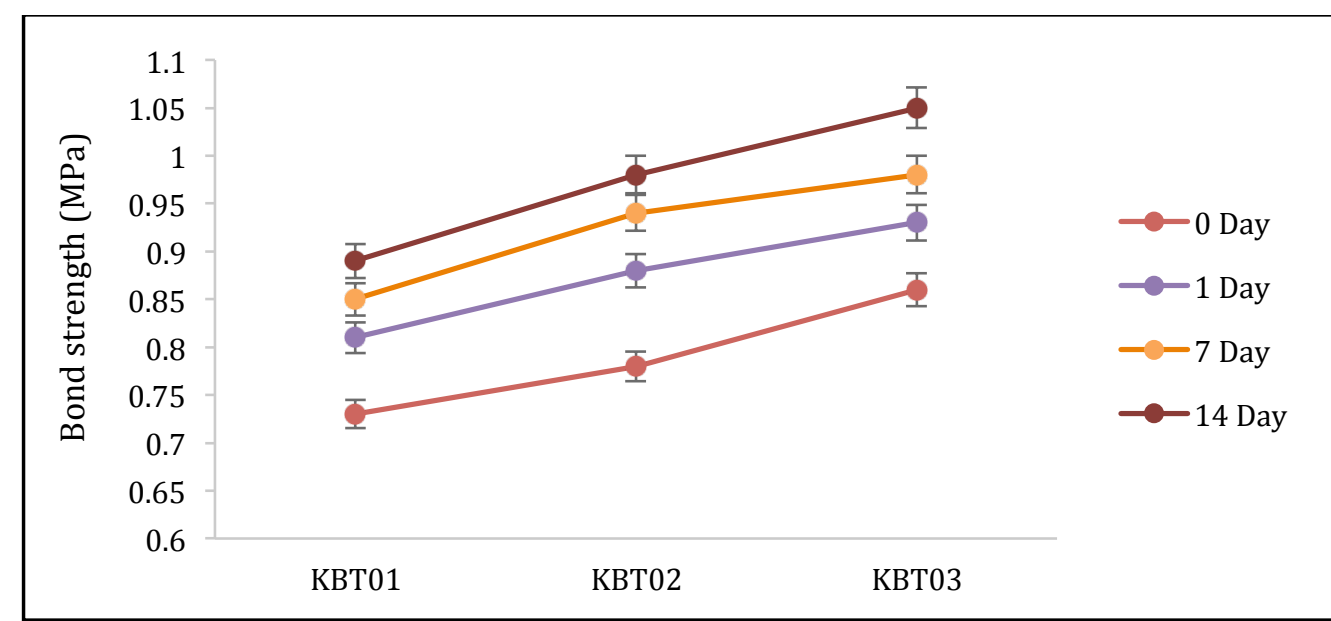

Figure 49.b) Ti (Cylinder) attachment to Al plate by KBT cements (bars represent SD for 5 samples for each cement).

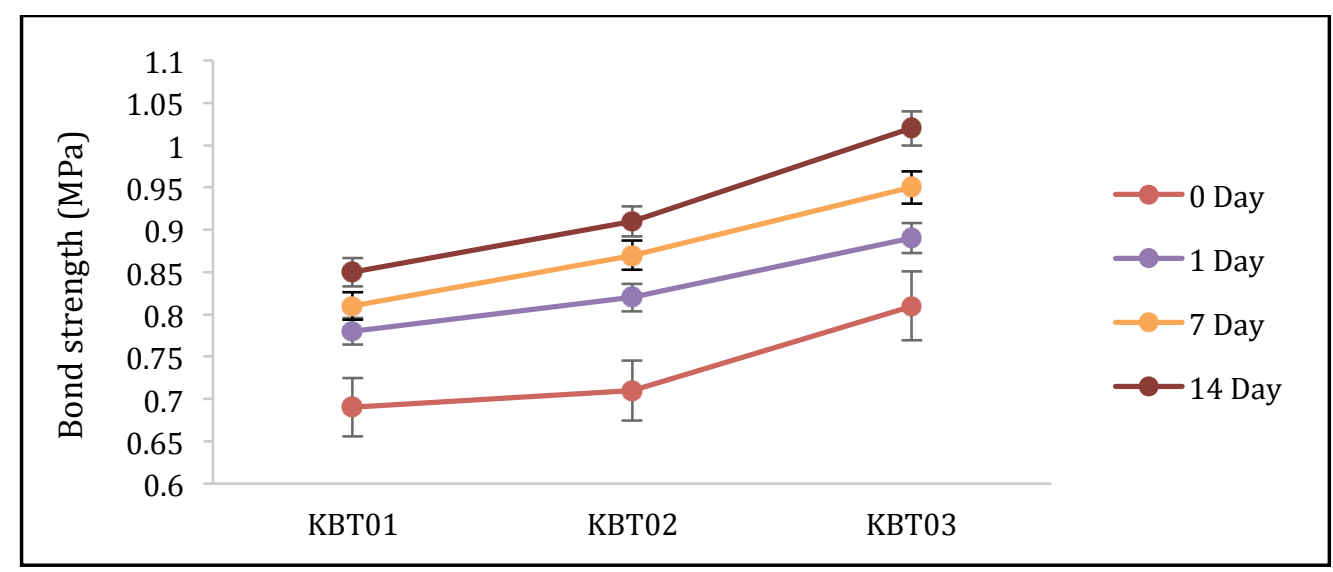

Figure 49 c) Ti (Cylinder) attachment to Ti plate by KBT cements. (bars represent SD for 5 samples for each cement).

However, the Ti plate attachment was shown to have a lower strength value than the Al plate attachment. As can be seen, the KBT01, 02, and 03 cements were $\sim 0.69,0.71$ and $0.81 \mathrm{MPa}$ respectivly for 0 days. During 1 day, the KBT01, 02, and 03 cements were $0.78,0.82$ and $0.89 \mathrm{MPa}$ respectivily. During 7 days, the KBT01, 02, and 03 cements were $\sim 0.81,0.87$ and $0.96 \mathrm{MPa}$ respectively. During 14 days, KBT01, 02 and 03 were $0.85,0.91$ and $1.02 \mathrm{MPa}$ respectively. It is assumed that the slight increase is due to the same reasons associated with the Al plate as previously mentioned. The failure had occured between the cement and the Ti plate. As the results for the adhesive properties 
between Ti cylinder and bone, $\mathrm{Al}$ plate and $\mathrm{Ti}$ plate indicate that the failure for the 14 days for the bone attachment with the Ti cylinder (Figure 51).

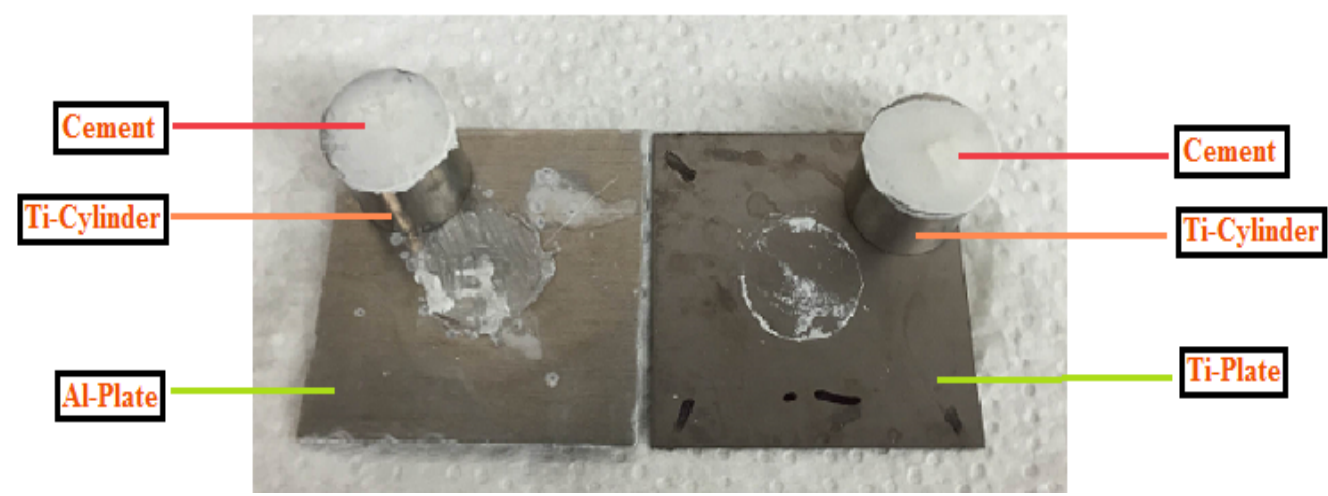

Figure 51: The failure between the Ti cylinder and Al/Ti plate.

The chemical bonding started showing during the 7 days testing and failed completely after 14 days between the Ti cylinder surface and the cement. This failure proves that the cement is able to make the chemical bonding with the bone during maturity.The adhesive properties between cement and bone should have a higher strength value then the cement attachment with the Ti cylinder. This is due to the failures between the cement and the $\mathrm{Al}$ plate and the Ti plate. 


\section{Chapter 5}

\subsection{Conclusion}

The aim of this research was to determine the influence of Ge substitution for $\mathrm{Zn}$ on the rheological and mechanical properties of glass polyalkenoate cements (GPCs) derived from a novel glass series and mixed with polyacrylic acid designed for possible cranioplasty applications. The cements were then categorized and their handling, mechanical and biocompatibility properties were assessed.

> The addition of $\mathrm{Ge}$ did not produce phase changes in the KBT02 and KBT03 glasses, demonstrated by the completely amorphous structure of all fired glasses. At the same time, the KBT01-control glass was also shown to be amorphous without the addition of Ge.

The KBT03 glass was shown to have handling times acquiescent with ISO9917 [11] guidelines while all cements of the KBT glass series set within the required time as outlined by ISO5833 [223] for orthopedic cements, signifying clinical suitability.

$>$ Compressive and flexural strengths of cements appeared to be dependent on the addition of Ge for KBT02 and KBT03 glass. As well as using a PAA200 and aging time. An increase in any of these factors resulted in an increased strength in cement.

Ion release profiles were also dependent on the addition of $\mathrm{Ge}$, resulting in the decreased release of $\mathrm{Si}, \mathrm{Zn}, \mathrm{Ca}, \mathrm{Na}$ and $\mathrm{Sr}$ ions in the cement, however, there was a slight increase in ions for Ge, due to the increasing the Ge content in KBT02 and KBT03 glasses. Furthermore, there was an improvement in the mechanical properties due to the decrease in maturity for the ion release from KBT glass series, while the Cs and BFs showed an increase in maturity. 
$>$ MicroCT can distinguish between bone and cement; the radiopacity of the cement was found to increase with the addition of Germanium.

$>$ The results of the adhesive properties for the attachment between the Ti cylinder and bone with the KBT glass series after 14 days have proven that there is a chemical bond between bone and cement during maturity, the failure was between the $\mathrm{Ti}$ and the cement. It is assumed that the chemical bonding between the bone and the cement could have a higher strength value from the Ti cylinder and cement attachment.

During this study, three glass GPCs were formulated for cranioplasty fixation and stabilization of the miniplate attachment to the cranium while avoiding the use of screws. KBT02 and KBT03 have appeared to be the more suitable cements for cranioplasty fixation application as both cements have met the standards of ISO9917 [11], also the bond strength for both cements were within the average range and similar to the screws examined in section 4.9 . 


\subsection{Future Work}

Development of these cements in cranioplasty requires the extension of their working time and an increase in their biaxial flexural strength. This could be attained through incorporating tri-sodium citrate, a material that has been proven to increase Tw and Ts. Another method would be to anneal the glasses so that the bonds are able to release any residual stresses without deformation in the bulk structure, in turn this will help to increase the Tw and Ts.

The incorporation of Ge has shown to be responsible for an increase in stiffness and strength. As mentioned in section 4.6.2 the mechanical properties of GPCs have been attributed to the cross-link density of cations, which chelate the polyanion chains of the acid, and the extent to which these chains are entangled with one another. An increased cross-link density of divalent cations is assumed to be responsible for the increase in stiffness, as a concurrent increase to strength has been noted in this study.

In addition to Cs and BFs testing, other mechanical properties can be tested, such as hardness, fracture toughness, and fatigue strength could give further insight into the interaction and the affect the particular cement will have on the skull bone with respect to the stress shielding and cyclic loading. 


\section{APPENDICES}

\section{Appendix A: Determination of net setting time ISO 9917-1 [224]}

\section{A.1 Apparatus}

A.1.1 Cabinet, capable of being maintained at a temperature of $(37 \pm 1){ }^{\circ} \mathrm{C}$ and a relative humidity of at least $90 \%$.

A.1.2 Indentor, of mass $(400 \pm 5) \mathrm{g}$, with a needle having a flat end of diameter $(1,0 \pm$ $0,1) \mathrm{mm}$ which is plane and perpendicular to the long axis of the needle.

A.1.3 Metal mould, similar to that shown in Figure A.1. Dimensions in millimeters, with $\pm 0,15$ tolerance on dimensions.

A.1.4 Metal block, of minimum dimensions $8 \mathrm{~mm} \times 75 \mathrm{~mm} \times 100 \mathrm{~mm}$ positioned within the cabinet and maintained at $(37 \pm 1)^{\circ} \mathrm{C}$.

A.1.5 Aluminium foil. A.1.6 Timer, accurate to $1 \mathrm{~s}$.

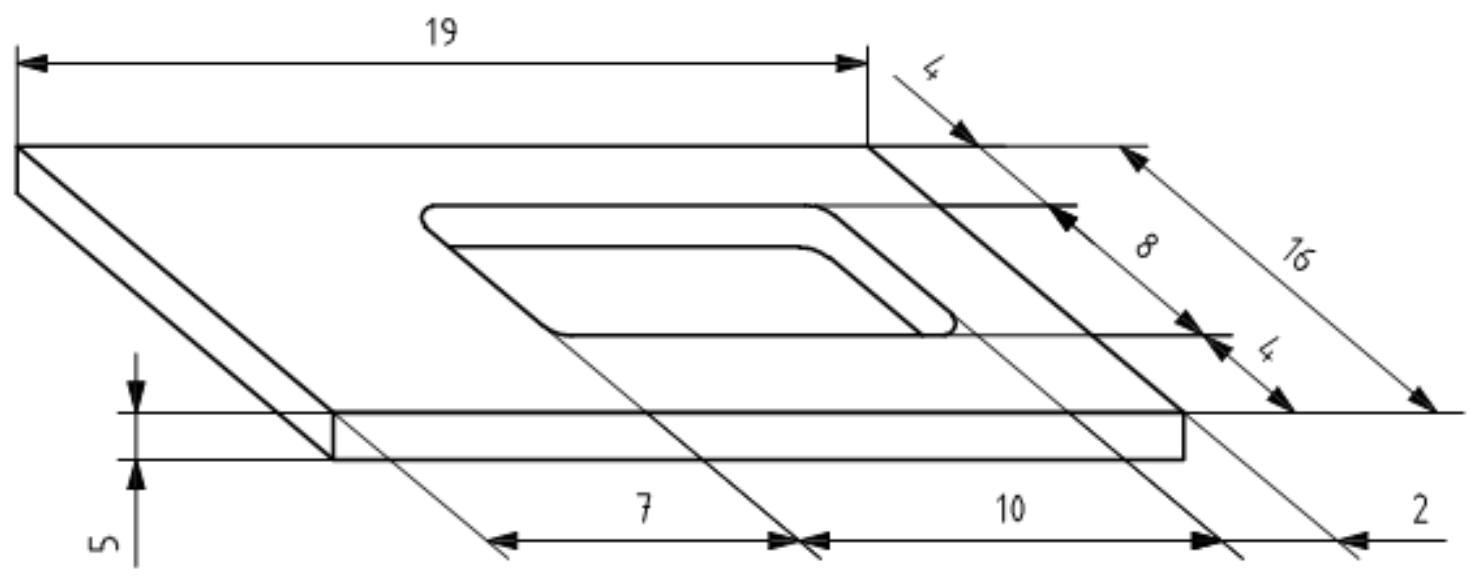

NOTE: Internal corners may be square or rounded.

Figure A.1: Mould for preparation of specimens for determination of net setting time

\section{A.2 Procedure}

Place the mould (A.1.3), conditioned to $(23 \pm 1){ }^{\circ} \mathrm{C}$, on the aluminium foil (A.1.5) and fill to a level surface with mixed cement. Sixty seconds after the end of mixing, place the assembly, comprising mould, foil and cement specimen, on the block (A.1.4), in the 
cabinet (A.1.1). Ensure good contact between the mould and foil, and between the foil and block. Ninety seconds after the end of mixing, carefully lower the indentor (A.1.2) vertically on to the surface of the cement and allow it to remain there for $5 \mathrm{~s}$. Carry out a trial run to determine the approximate setting time, repeating the indentations at $30 \mathrm{~s}$ intervals until the needle fails to make a complete circular indentation in the cement, when viewed using $\times 2$ magnification. Clean the needle, if necessary, between indentations. Repeat the process, starting the indentation at $30 \mathrm{~s}$ before the approximate setting time thus determined, making indentations at $10 \mathrm{~s}$ intervals.

Record the net setting time as the time elapsed between the end of mixing and the time when the needle fails to make a complete circular indentation in the cement. Repeat the test two more times.

\section{A.3 Treatment of results}

Record the results of the three tests. Each result shall fall within the range specified in Table A.1.

Table A.1: Requirements for dental cements ISO 9917-1 [224].

\begin{tabular}{|c|c|c|c|}
\hline Chemical type & Application & $\begin{array}{l}\text { Net setting Time } \\
\text { (Min) } \\
\text { Min-Max }\end{array}$ & $\begin{array}{l}\text { Minimum } \\
\text { Compressive } \\
\text { Strength } \\
\text { (MPa) }\end{array}$ \\
\hline Glass polyalkenoate & Luting & $1.5 \mathrm{~min}-8 \mathrm{~min}$ & 50 \\
\hline Glass polyalkenoate & Restoration & $1.5 \mathrm{~min}-6 \mathrm{~min}$ & 100 \\
\hline Glass polyalkenoate & Base/lining & $1.5 \mathrm{~min}-6 \mathrm{~min}$ & 50 \\
\hline
\end{tabular}




\section{Appendix B: Determination of compressive strength ISO 9917-1 [224]}

\section{B.1 Apparatus}

B.1.1 Cabinet, maintained at a temperature of $(37 \pm 1){ }^{\circ} \mathrm{C}$ and a relative humidity of at least 30 \%. B.1.2 Split mould and plates, as shown in Figure B.1. The mould shall have internal dimensions $(6,0 \pm 0,1) \mathrm{mm}$ high and $(4,0 \pm 0,1) \mathrm{mm}$ diameter. The mould and plates shall be made of stainless steel or a material which will not be affected by the cement. When testing polyacid-based cements, face the plates with acetate sheets to prevent adhesion.

B.1.3 Screw clamps, as shown in Figure B.1.

B.1.4 Screw micrometer or equivalent measuring instrument, having graduations of 2 $\mu \mathrm{m}$ or smaller.

B.1.5 Mechanical tester, capable of being operated at a cross-head speed of $(0,75 \pm 0,30)$ $\mathrm{mm} / \mathrm{min}$ or at a loading rate of $(50 \pm 16) \mathrm{N} / \mathrm{min}$.

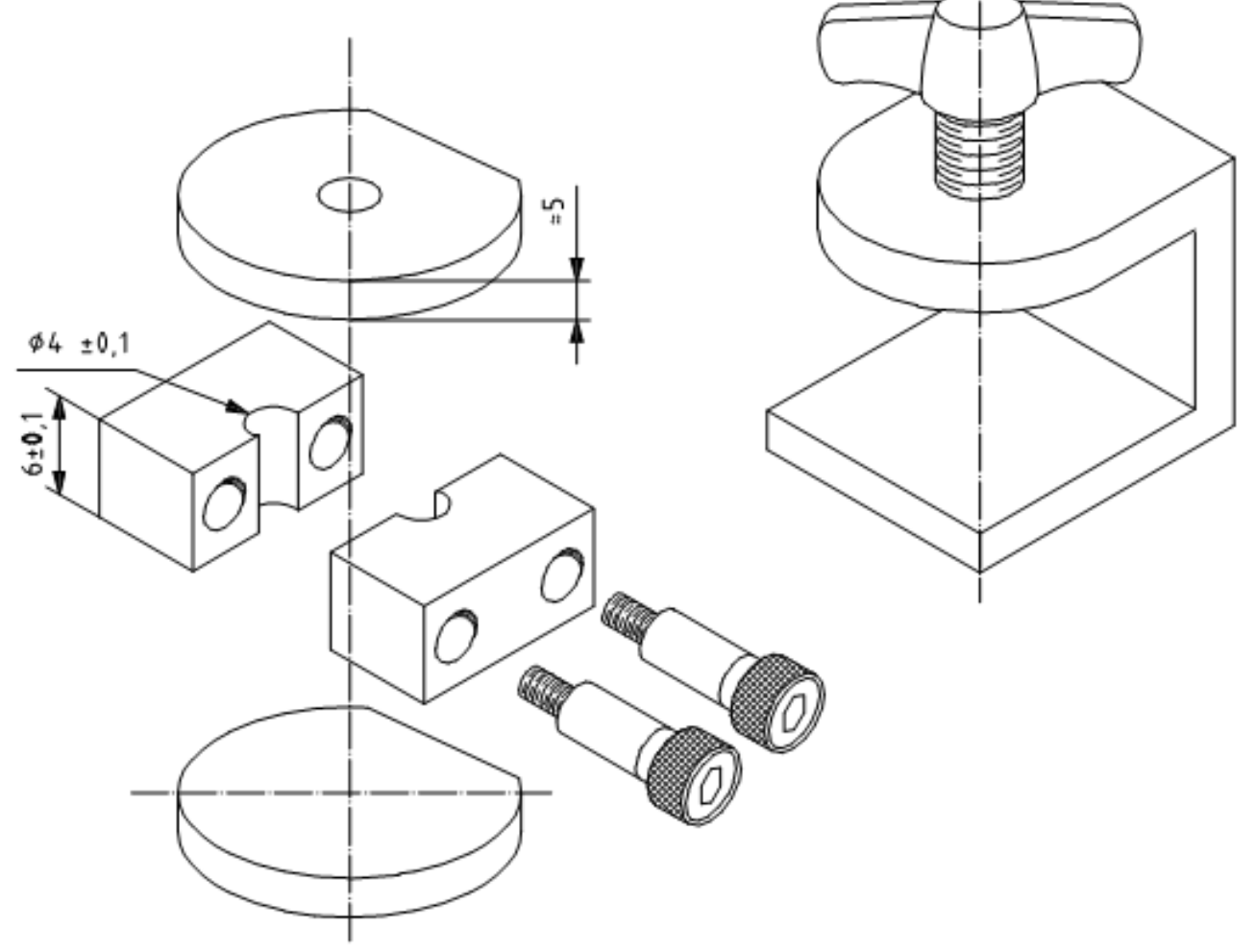

Figure B.1: Mould and clamp for preparation of specimens for compressive strength test. 


\section{B.2 Preparation of test specimens}

Condition the split mould and plates (B.1.2) and screw clamp (B.1.3) at $(23 \pm 1){ }^{\circ} \mathrm{C}$. Within $60 \mathrm{~s}$ of the end of mixing, pack the cement, prepared in accordance with the manufacturer's instructions, to a slight excess in the split mould. In order to consolidate the cement and avoid trapping air, convey the largest convenient portions of mixed cement to the mould and apply to one side using a suitable instrument. Fill the mould to excess in this manner and then place on the bottom plate with some pressure. Remove any bulk-extruded cement, place the top metal plate in position on the mould and squeeze together. Put the mould and plates in the screw clamp and tighten. No later than $120 \mathrm{~s}$ after the end of mixing, transfer the whole assembly to the cabinet (B.1.1).

One hour after the end of mixing, remove the plates and grind the ends of the specimen flat and at right angles to its long axis. An acceptable method for doing this is to use wet 400 grade silicon carbide paper, but in any event the abrasive shall be no coarser.

Remove the specimen from the mould immediately after surfacing and check visually, without magnification, for air-voids or chipped edges. Discard any such defective specimens.

NOTE To facilitate the removal of the hardened cement specimen, the internal surface of the mould may be evenly coated, prior to filling, with a $3 \%$ solution of micro-crystalline or paraffin wax in petroleum ether. Excess ether is allowed to evaporate before the mould can be used. Alternatively, a thin film of silicone grease or PTFE dry-film lubricant may be used.

Prepare five such specimens and, immediately after the preparation of each, immerse it in water, grade 3 as defined in ISO 3696:1987, at $(37 \pm 1)^{\circ} \mathrm{C}$ for $(23 \pm 0,5) \mathrm{h}$. $।$

Calculate the diameter of each specimen by taking the mean of two measurements at right angles to each other, made to an accuracy of 0,01 mm using e.g. a screw micrometer (see B.1.4). 


\section{B.3 Procedure}

Twenty-four hours after the end of mixing place each specimen with the flat ends between the platens of the mechanical tester (B.1.5) and apply a compressive load along the long axis of the specimen. Apply a sheet of damp filter paper (e.g. Whatman No. 1) to both top and bottom platens of the test machine in the area, which will contact the specimens. Use a fresh piece of paper for each test.

Record the maximum force applied when the specimen fractures and calculate the compressive strength, $\mathrm{C}$, in megapascals, using the equation B.1:

\section{$C=4 p / \pi d 2 \quad$ Equation B. 1}

Where:

$\mathrm{p}$ is the maximum force applied, in newtons;

$\mathrm{d}$ is the measured diameter of the specimen, in millimeters.

\section{B.4 Treatment of results}

If at least four of the five results are above the minimum strength specified in Table A.1, the material shall pass the test. If three or more of the five results obtained are below the minimum strength specified in Table A.1, the material shall fail the test.

If only three specimens satisfy the minimum strength requirement in Table A.1, prepare and test a further five specimens. To pass the test, at least eight of the total of ten results shall be above the minimum strength value specified in Table A.1. 
Appendix C: ENERGY DISPERSIVE X-RAYANALYSIS (EDS).
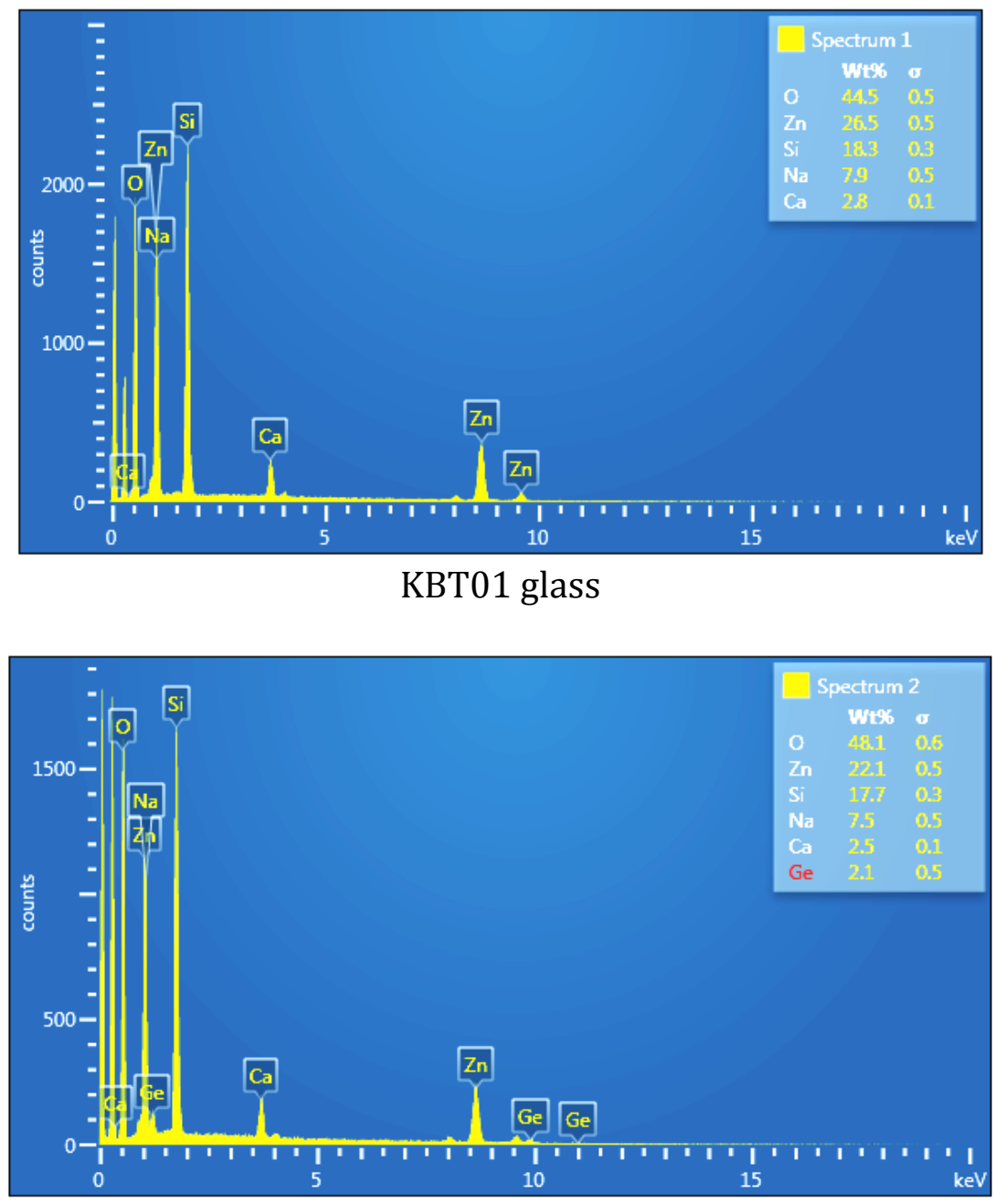

KBT02 glass

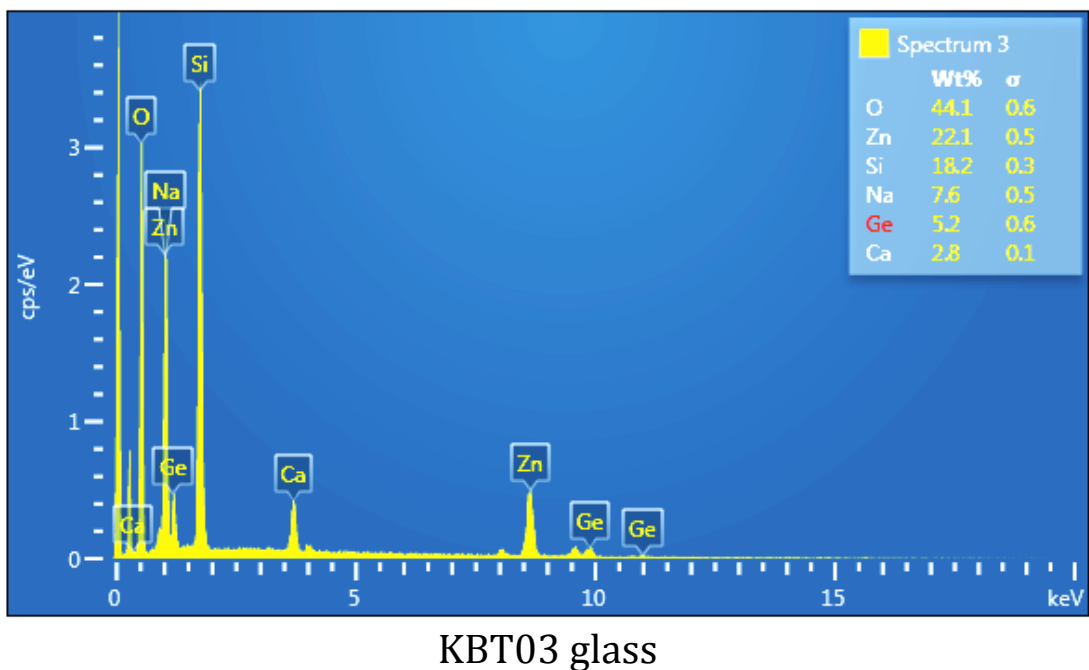




\section{Appendix D: ION RELEASE}

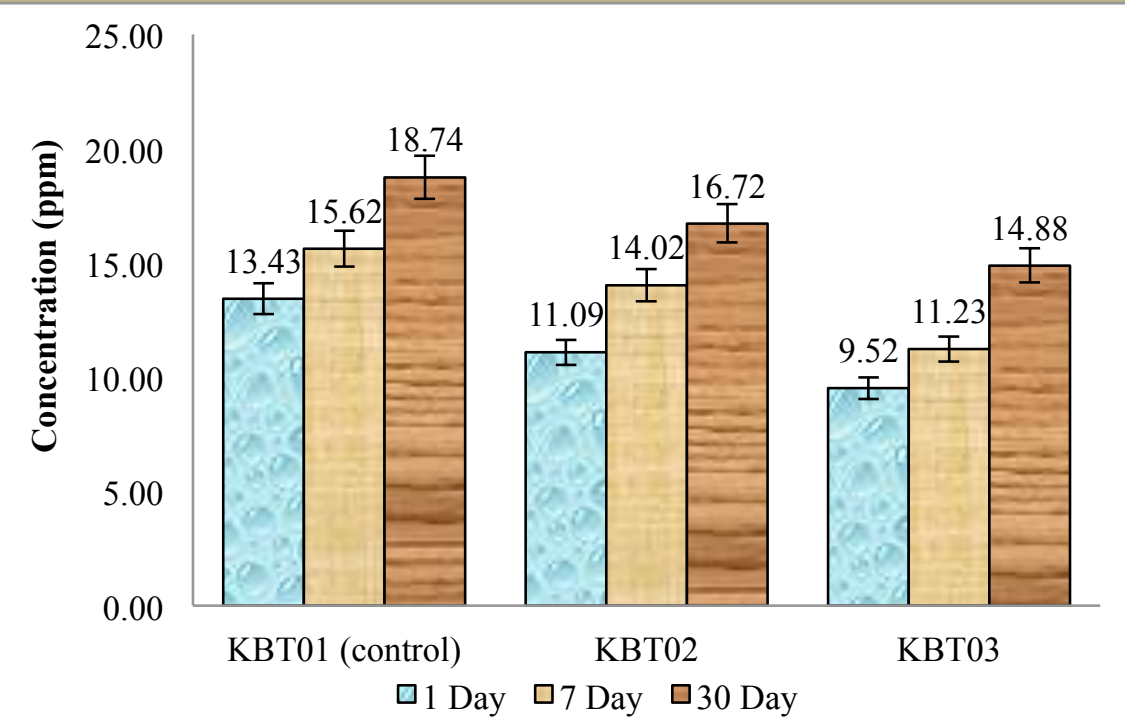

Figure 46 a. Silicon ion release from KBT01-Control, KBT02, and KBT03 (bars represent

SD for 5 samples for each cement)

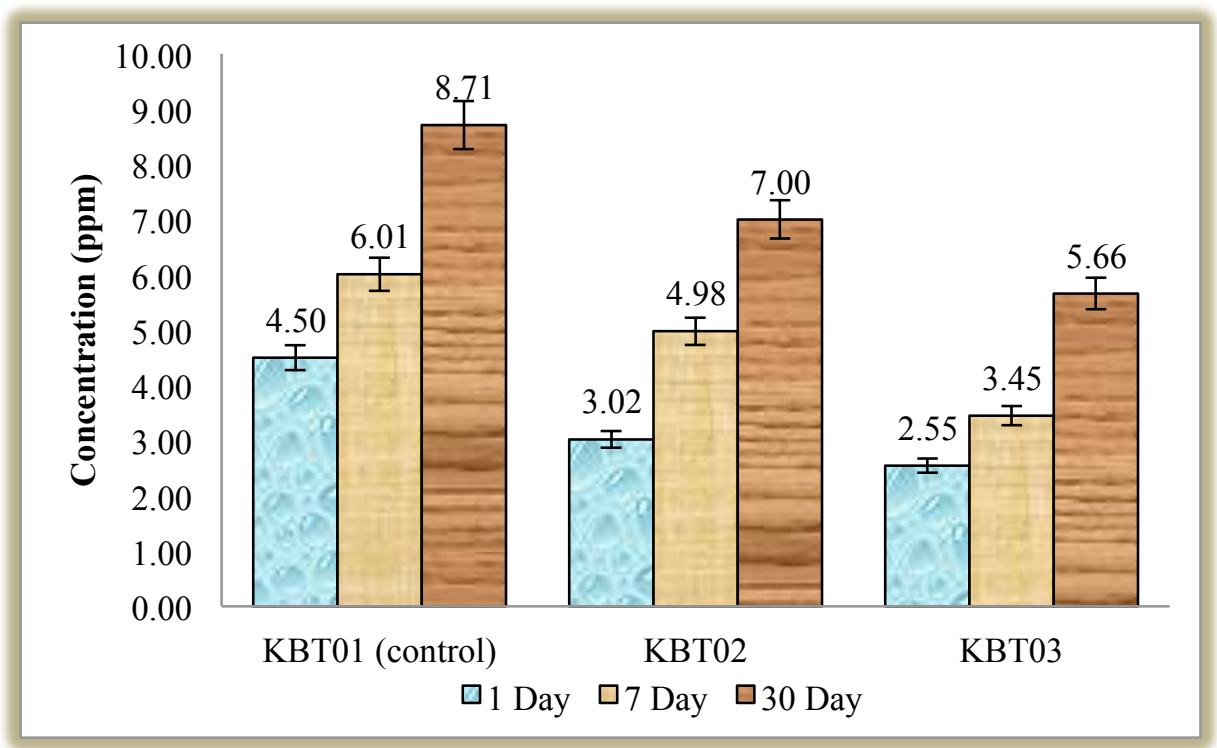

Figure 46 b. Calcium ion release from KBT01-Control, KBT02, and KBT03 (bars represent SD for 5 samples for each cement). 


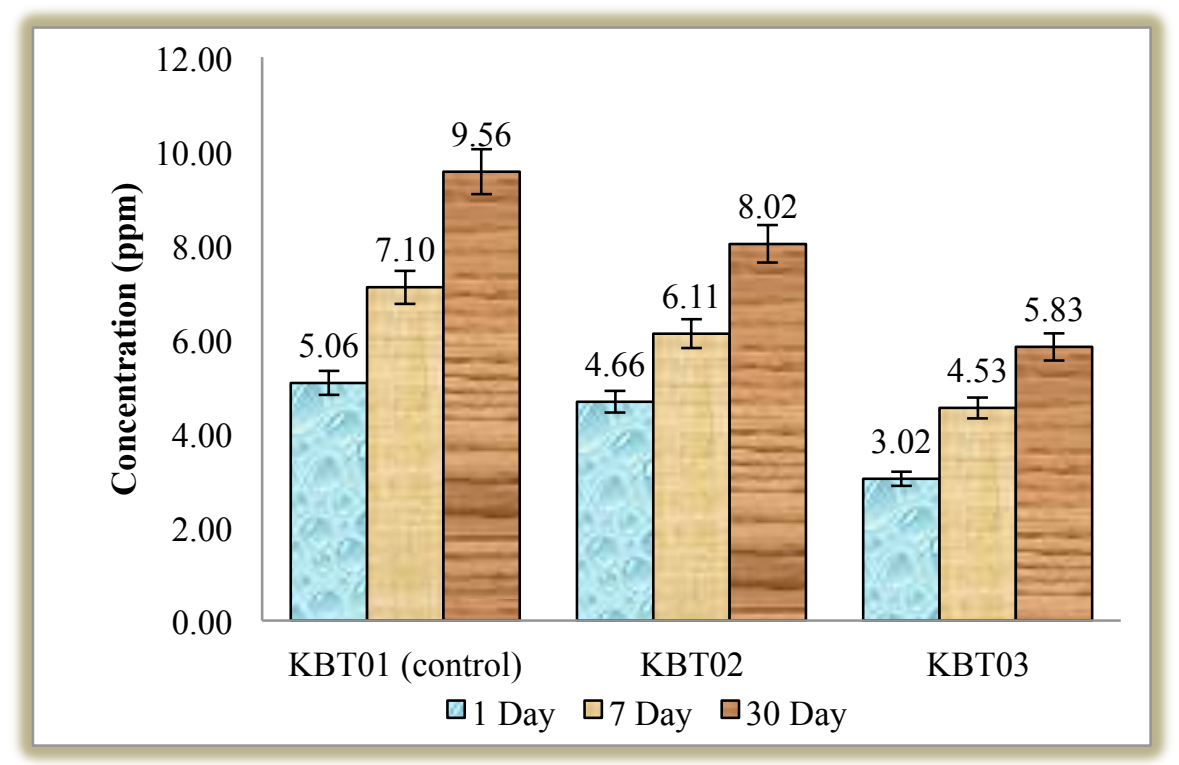

Figure 46 c. Zinc ion release from KBT01-Control, KBT02, and KBT03 (bars represent SD for 5 samples for each cement).

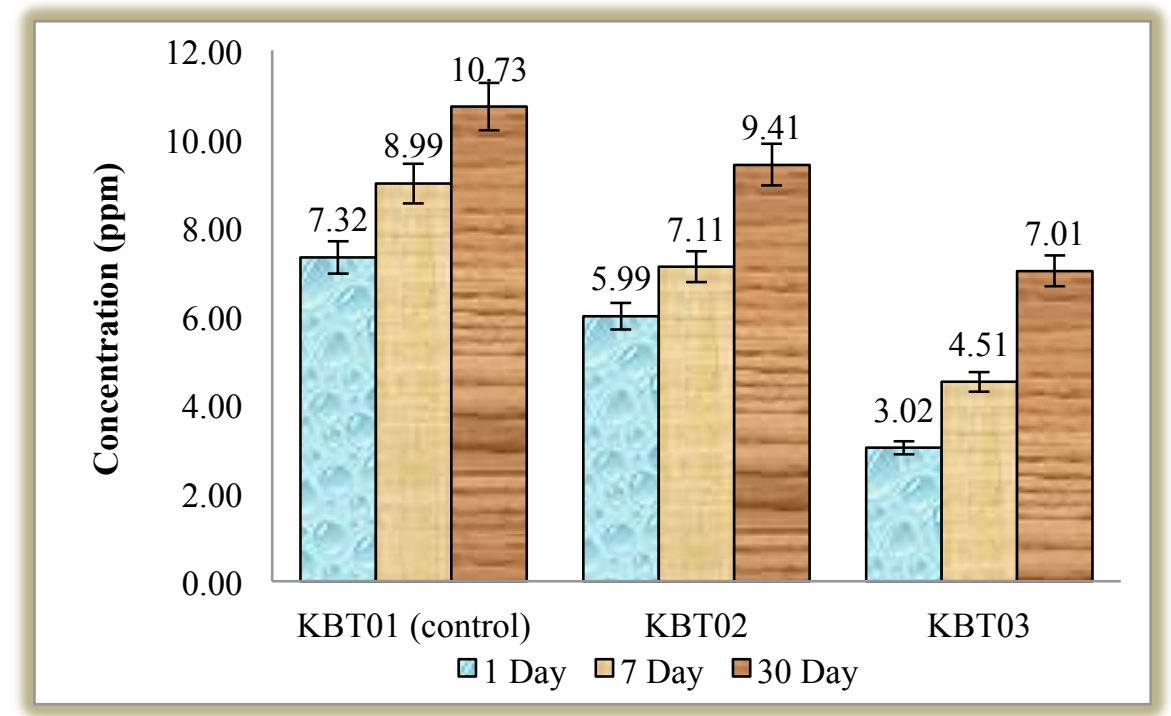

Figure 46 d. Sodium ion release from KBT01-Control, KBT02, and KBT03 (bars represent SD for 5 samples for each cement). 


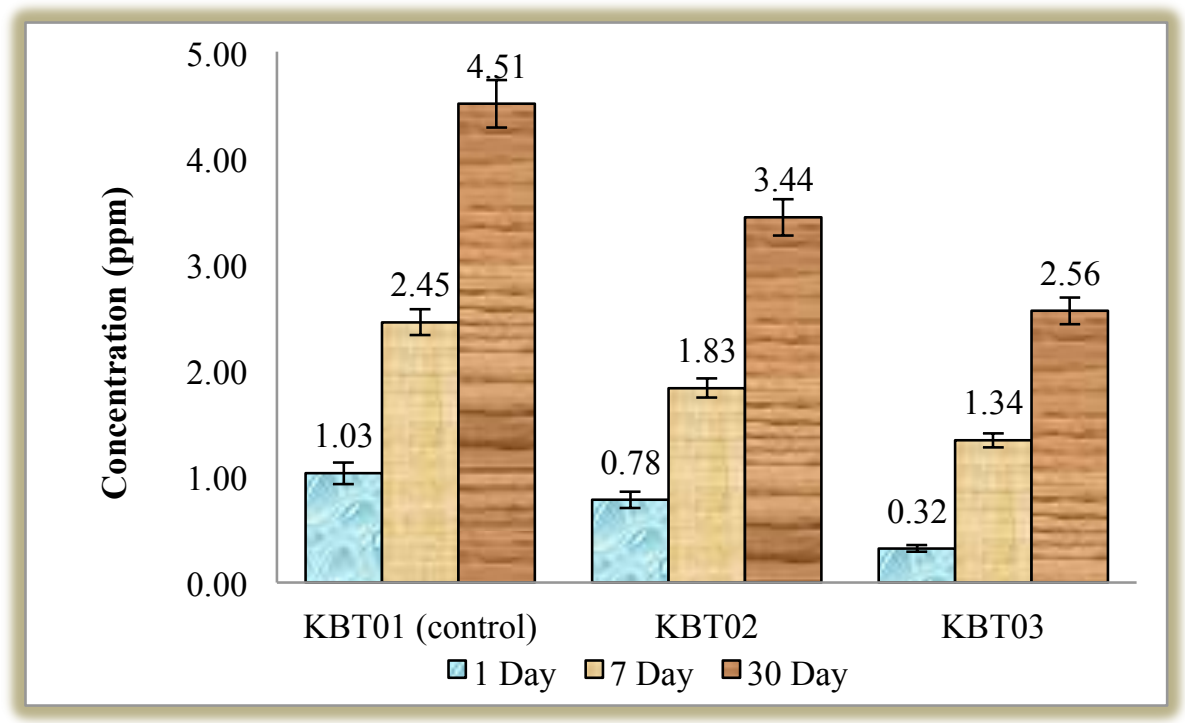

Figure 46 e. Strontium ion release from KBT01-Control, KBT02, and KBT03 (bars represent SD for 5 samples for each cement).

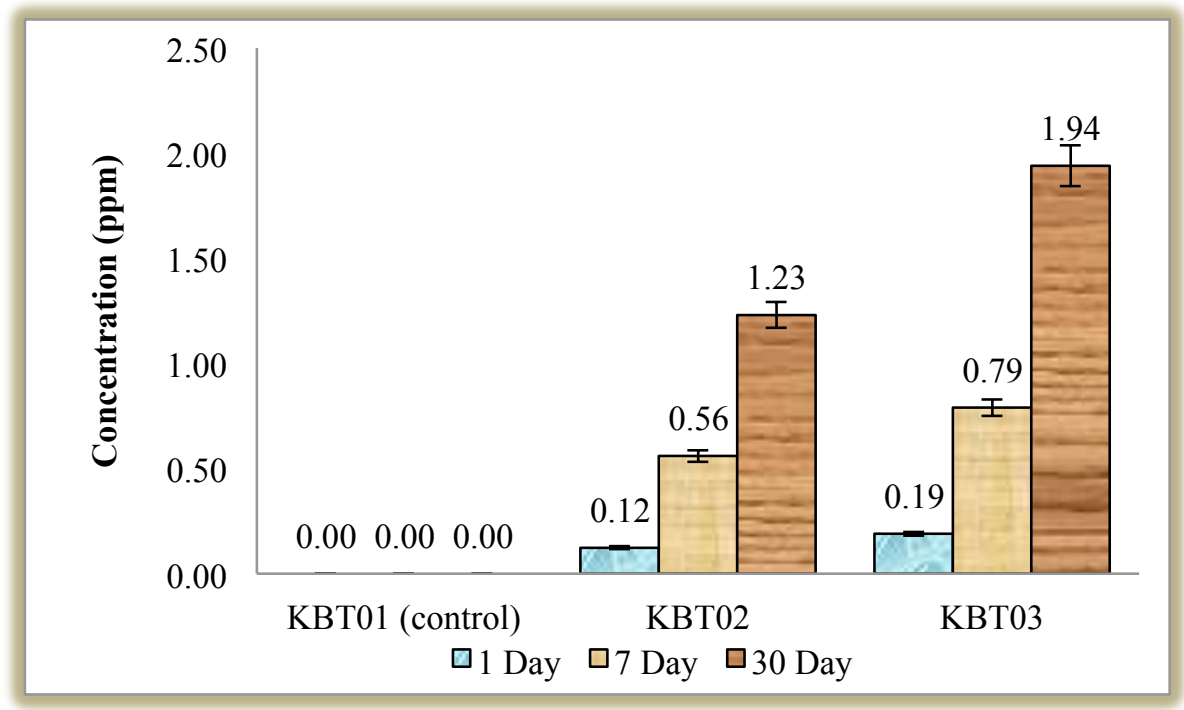

Figure $46 f$. Germanium ion release from KBT01-Control, KBT02, and KBT03(bars represent SD for 5 samples for each cement). 
Appendix E: MicroCT procedure
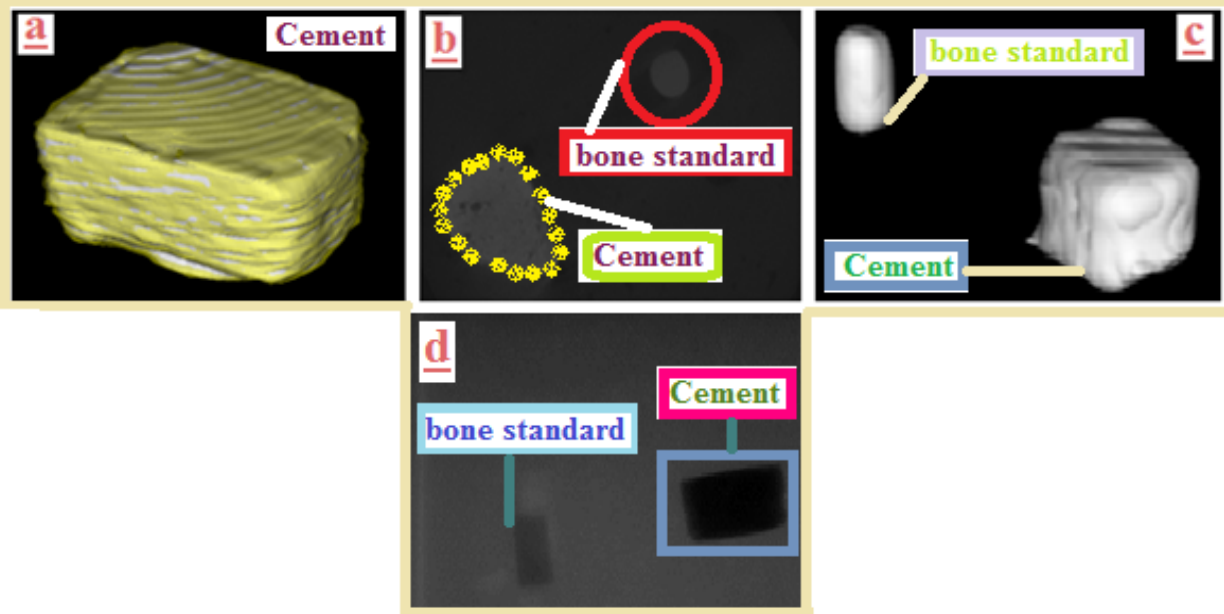

Figure 47 Radiograph image of the cement sample and bone standard. 


\section{Bibliography}

[1] Clarke, B. Normal Bone Anatomy and Physiology. Clin J Am Soc Nephrol, 3, 131- 139, (2008).

[2] Marieb, E. N. \& Hoehn, K. Human anatomy and physiology (9th ed.). London, England: Pearson, (2013).

[3] Steele, D. Gentry. \& Bramblett, Claud A. The anatomy and biology of the human skeleton. College Station: Texas A\&M University Press, (1988).

[4] Mayfield Brain \& Spine institute: Craniotomy (2013). Accessed on: June 2015. Available at: $<$ http://www.mayfieldclinic.com/PE-Craniotomy.html>

[5] Wockhardt hospitals: Cranioplasty and Craniotomy Surgery. Accessed on: June 2015 Available at: $<$ http://www.wockhardthospitals.com/specialities/brain-spine-care/craniotomy-cranioplasty-surgery>

[6] Redfern, R.M, Pullhorn, H. Neurosurgery Article: Cranioplasty. Vol 7. No 5, (2007).

[7] Ellis, M, E. Healthline. Skull Fractures (2012). Accessed on: June 2015. Available at: $<$ http://www.healthline.com/health/skull-fracture\#Overview1>

[8] Spetzler R.F. Bone flap fixation: A new technique. J Neurosurg 87:475-476, (1997).

[9] Nicholson, J. W. Adhesive dental materials -a review. Int. J. adhesion \& adhesives 18, 229-236, (1998).

[10] Reusche, E., Rohwer, J., Forth, W., Helms, J. \& Geyer, G. lonomeric cement and aluminum encephalopathy. The Lancet 345, 1633-1634, (1995).

[11] International standard 9917. Dental Water Based Cements. International Organization for Standardization, Case Postale 56, CH- 1211, Geneve, Switzerland, (1991).

[12] Aydin, S., Kucukyuruk, B., et al. Cranioplasty: Review of Materials and Techniques. 162-167, (2011).

[13] Blake D.P. The use of synthetics in cranioplasty: A clinical review. Mil Med. 159:466-9, (1994).

[14] Shah A.M, Jung H, Skirboll, S. Materials used in cranioplasty: A history and analysis. Neurosurgical Focus, Vol. 36, No. 4, (2014).

[15] Gruber, R., Peter R, Hora J. The prognosis of cranioplasty following large craniectomy in children. Z Kinderchir. 43:375-83, (1988).

[16] Durand, J.L, Renier, D., Marchac, D. The history of cranioplasty. Ann Chir Plast Esthet 42:75-83, (1997).

[17] Munroe, A.R. The operation of cartilage-cranioplasty. Can Med Assoc J 14:47-49, (1924).

[18] Grant, G.A., Jolley, M., Ellenbogen, R.G., Roberts, T.S., Gruss, J.R., Loeser, J.D. Failure of autologous bone-assisted cranioplasty following decompressive craniectomy in children and adolescents. J Neurosurg 100 (2 Suppl Pediatrics), 163-168, (2004).

[19] Matsuno A, Tanaka H, Iwamuro H, Takanashi S, Miyawaki S, Nakashima M, et al. Analyses of the factors influencing bone graft infection after delayed cranioplasty. Acta Neurochir (Wien) 148:535-540, (2006). 
[20] Oladunjoye, A.O., Schrot, R.J., Zwienenberg-Lee, M., Muizelaar, J.P., Shahlaie, K. Decompressive craniectomy using gelatin film and future bone flap replacement. Technical note. $J$ Neurosurg 118:776-782, (2013).

[21] Grant, F.C., Norcross, N.C. Repair of cranial defects by cranioplasty. Ann Surg 110:488-512, (1939).

[22] Prolo, D.J., Oklund, S.A. The use of bone grafts and alloplastic materials in cranioplasty. Clin Orthop Relat Res. 268:270-8, (1991).

[23] Booth J.A, Curtis B, F. Report of a case of tumor of the left frontal lobe of the cerebrum; operation; recovery. Ann Surg 17:127-139, (2008).

[24] Sanan, A., Haines, S.J. Repairing holes in the head: a history of cranioplasty. Neurosurgery 40:588-603, (1997).

[25] Makela, T. Tantalum cranioplasty of war wounds of the skull. Ann Chir Gynaecol Fenn. 38:13-9, (1949).

[26] Levine, B.R., Della Valle, C.J., Jacobs, J.J. Perspectives in modern orthopaedics: applications of porous tantalum in total hip arthroplasty. J Am Acad Orthop Surg, (2006).

[27] De Santis, R., Gloria, A., Ambrosio, L. Materials and Technologies for Craniofacial Tissue Repair and Regeneration. Topics in Medicine. Special Issue 1-4, (2010).

[28]. Kuttenberger, J.J., Hardt, N. Long-term results following reconstruction of craniofacial defects with titanium micro-mesh systems. J Craniomaxillofac Surg. 29:75-8, (2001).

[29] Mislow, J.M., Proctor, M.R., McNeely, P.D., Greene, A.K., Rogers, G.F. Calvarial defects associated with neurofibromatosis Type 1. Report of two cases. J Neurosurg 106 (6 Suppl): 484-489, (2007)

[30] Aciduman, A., Belen, D. The earliest document regarding the history of cranioplasty from the Ottoman era. Surg Neurol 68:349-353, (2007).

[31] Chicarilli, Z.N., Ariyan, S. Cranioplasty with a silicone prosthesis and split rib grafts. Head Neck Surg. 8:355-62, (1986).

[32] Mears, D. C., Rothwell, G. P. Materials and orthopaedic surgery, Williams \& Wilkins, Baltimore, pp. 59-63. In: Mears, D. C., ed, (1979).

[33] Bahar, H., Yaffe, A., Boskey, A., Binderman, I. Influence of bone-derived matrices on generation of bone in an ectopic rat model. J Orthop Res. 28(5):664-70, (2010).

[34] Le Guéhennec, L., Layrolle, P., Daculsi, G. A review of bioceramics and fibrin sealant. Eur Cell Mater. 8:1-10; discussion 10-1, (2004).

[35] Towler, M.R. Processing, characterisation and mechanical properties of hydroxyapatite-zirconia composites for skeletal implants. Research Center in Biomedical Materials. London, Queen Mary and Westfiels College, UCL, (1997).

[36] Kalita, S.J., Bhardwaj, A., Bhatt, H.A. Nanocrystalline calcium phosphate ceramics in biomedical engineering. Materials Science \& Engineering, 27), 441-449, (2006). 
[37] Kumta, P.N., Sfeir, C., Lee, D.H., Olton, D., Choi, D. Nanostructured calcium phosphates for biomedical applications: novel synthesis and characterisation, Acta Biomaterialia, 65-83, (2004).

[38] Cohen, M.S., Whitman, K. Calcium phosphate bone cement - the norian skeletal repair system in orthopedic surgery. Perioperative Pharmacology, 65(5), 958-952, (1997).

[39] Cao, W., Hench, L.L. Bioactive materials. Ceramics International, 22(493-507), (1995).

[40] Curran, D. J. Hydroxyapatite-Zirconia Composites and Strontium-Hydroxyapatite for Skeletal Applications; Ph.D. Thesis. University of Limerick, (2010).

[41] Ahn, E.S., Gleason, N.J, Nakahira, A., Ying, J.Y. Nanostructure processing of hydroxyapatite based bioceramics. Nano Letters. 1 (3), 149-154, (2001).

[42] Prabakaran, K., Kannan, S., Rajeswari, S. Development and characterisation of zirconia and hydroxyapatite composites for orthopaedic applications. Trends Biomater Artif Organs. 18(2): 114-6, (2005).

[43] Manley, M.T., Sutton, K., Dumbleton, J. Calcium phosphates: a survey of the orthopaedic literature. In: Epinette JA, Manley MT, editors. Fifteen years of clinical experience with hydroxyapatite coatings in joint arthroplasty. New York: Springer-Verlag; p. 452, (2004).

[44] Itoh, S., Kikuchi, M., Takakuda, K., Koyama, Y., Matsumoto, H.N., Ichinose, S., et al. The biocompatibility and osteoconductive activity of a novel hydroxyapatite/collagen composite biomaterial, and its function as a carrier of rhBMP-2. J Biomed Mater Res. 54(3): 445-53, (2000).

[45] Anselme, K., Noel, B., Flautre, B., Blary, M.C., Delecourt, C., Des- camps, M., et al. Association of porous hydroxyapatite and bone marrow cells for bone regeneration. Bone. 25(2): 51S-4S, (1999).

[46] Erbe, E.M., Marx, J.G., Clineff, T.D., Bellincampi, L.D. Potential of an ultraporous b-tricalcium phosphate synthetic cancellous bone void filler and bone marrow aspirate composite graft. Eur Spine J.10 (2): S141-6, (2001).

[47] Curran, D.J, Fleming, T.J., Towler, M.R., Hampshire, S. Mechanical properties of hydroxyapatite-zirconia compacts sintered by two different sintering methods. Journal of Materials Science: Materials in Medicine, (2009).

[48] Heimann, R.B., Vu, T.A. Effects of $\mathrm{CaO}$ on thermal decomposition during sintering of composite hydroxyapatite-zirconia mixtures for monolithic bioceramic implants. J Mater Sci Lett. 16(6): 437-9, (1997).

[49] White, A.A., Best, S.M., Kinloch, I.A. Hydroxyapatite-carbon nanotube composites for biomedical applications: a review. Int J Appl Ceram Technol. 4(1): 1-13, (2007).

[50] Bernache-Assollant, D., Ababou, A., Champion, E., Heughebaert, M. Sintering of calcium phosphate hydroxyapatite Ca10(PO4)6(OH)2. I Calcination and grain growth. J Eur Ceram Soc. 23(2): 229-41, (2003).

[51] Hing, K.A., Gibson, I.R., Di Silvio, L., Best, S.M., Bonfield, W. Effect of variation in Ca:P ratio on the cellular response of primary human osteoblast-like cells to hydroxyapatite-based ceramics. Bioceramics. 11:293-6, (1998). 
[52] Nagarajan, V.S, Rao, K.J. Structural, mechanical and biocompatibility studies of hydroxyapatitederived composites toughened by zirconia addition. J Mater Chem. 3(1): 43-51, (1993).

[53] Brosnan, K.H. Sintering of alumina parts with microwave energy. USA: The Pennsylvania State University; p. 67, (2002).

[54] Ciacchi, F.T., Nightingale, S.A, Badwal, S.P.S. Microwave sintering of zirconia-yttria electrolytes and measurements of their ionic conductivity. Solid State Ion. 86-88(2): 1167-72, (1996).

[55] Towler, M.R., Gibson, I.R. The effect of low levels of zirconia addition on the mechanical properties of hydroxyapatite. J Mater Sci Lett. 20(18): 1719-22, (2001).

[56] Evis, Z. Reactions in hydroxylapatite-zirconia composites. Ceram Int. 33(6): 987-91, (2006).

[57] Ruys, A.J., Wei, M., Sorrell, C.C., Dickson, M.R., Brandwood, A., Milthorpe, B.K. Sintering effects on the strength of hydroxyapatite. Biomaterials. 16(5): 409-15, (1995).

[58] Sanus, G.Z., Tanriverdi, T., Ulu, M.O., Kafadar, A.M., Tanriover, N., Ozlen, F. Use of Cortoss as an alternative material in calvarial defects: The first clinical results in cranioplasty. J Craniofac Surg. 19:88-95, (2008).

[59] Johnell, O. Economic Implication of Osteoporotic Spine Disease: Cost to Society. Eur. Spine J. 12(Suppl. 2), S168, (2003).

[60] Macksey Fitzgerald, L. Surgical procedures and anesthetic implications: a handbook of nurse anesthesia practice. Sudbury, MA Publisher: Jones \& Bartlett, (2012).

[61] Lerch, K.D. Reliability of cranial flap fixation techniques: comparative experimental evaluation of suturing, titanium miniplates, and a new rivet-like titanium clamp (CranioFix): technical note. Neurosurgery. 44:902-905, (1999).

[62] Estin, D., Troffkin NoHeilman, C.B. Boneflap fixation with titanium clamps: a new technique.Surg Neurol 53:391, (2000).

[63] Julian, O. C., Lopez-Belio, M., Dye, W. S., Javid, H. \& Grove, W. J. The median sternal incision in intracardiac surgery with extracorporeal circulation; a general evaluation of its use in heart surgery. Surgery, 42, 753-761, (1957).

[64] Wang, Y. R., Su, Z, et al. Biomechanical Evaluation of Cranial Flap Fixation Techniques: Comparative Experimental Study of Suture, Stainless Steel Wire, and Rivetlike Titanium Clamp. 388391, (2007).

[65] Yoshihide, T. Development of titanium fixation screw for hydroxyapatite osteosynthesis (APACERAM). Department of Neurosurgery, Yokosuka Kyousai Hospital, Yokosuka, Kanagawa 2380011, Japan, (2008).

[66] Shu-xu, Y., Zhi-peng S., Zhang, H., et al. A Study of Fractured Cranial Flap Refixation. Journal of Plastic, Reconstructive \& Aesthetic Surgery. 1424-1427, (2008).

[67] Frenzel, O., Lerch, K.O. CranioFix titanium clamp for refixation of cranial bone flaps: Clinical long-term results in comparison with suture maierial. Zentralbl Neurochir Suppl 24, (1998)

[68] Gordon, D.S, Blair, G.A.S. Titanium Cranioplasty. British Medical Journal. 2, 478-481, (1974). 
[69] Bahrani, A.S., Blair, G.A.S, and Crossland, B. Slow Rate Hydraulic Forming of Stainless Steel Dentures. British Dental Journal, 118: 425-431, (1965).

[70] Changing Faces India. Center of Anaplastology and Advance Dental Rehabition. Cranioplasty Implants. (2011-2012). Accessed on: May 2015.

Available at: $<$ http:// www.changingfacesindia.com/cranioplasty.html $>$

[71] KLS Martin Group. Patient Contoured Implants. Accessed on: May 2015.

Available at: < http://www.klsmartinnorthamerica.com/products/implants/cranial/ $>$

[72] Blair, G.A.S, Fannin, T.F, D.S, Gordon. Titanium-strip Cranioplasty. British Medical Journal, 2, 907-908, (1976).

[73] Fusetti, S., Hammer, B., Kellman, R., Matula C., Strong, EB., Di leva, A. Cranial Vault \& Skull Base-Special considerations: Cranioplasty (bone versus alloplast). v1.0 2011-05-14. Accessed on: May 2015. Available at:

$<$ https://www2.aofoundation.org/wps/portal/!ut/p/a0/04_Sj9CPykssy0xPLMnMz0vMAfGjzOKN_A0

M3D2DDbz9_UMMDRyDXQ3dw9wMDAzMjfULsh0VAbWjLW0!/?bone=CMF\&classification=93-

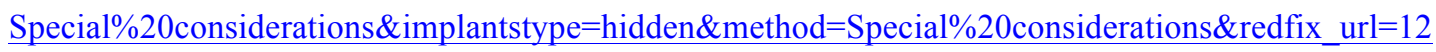
$\underline{89999576062 \& \text { segment }=\text { Cranium\&showPage }=\text { redfix\&treatment }>}$

[74] Laskin, R. S. Controversies in total knee arthroplasty. University press, Oxford; New York, (2001).

[75] Boyd, D. Zinc-based glass polyalkenoate cements for skeletal applications, in: College of Engineering, vol Doctor of Philosophy, University of Limerick, Limerick, (2005).

[76] Marchac, D., Greensmith, A. Long-term experience with methymethacrylate cranioplasty in craniofacial surgery. J Plast Reconstr Aesthet Surg 61: 744-753, (2008).

[77] Zoltán, B, Gábor, T, István, H. Substitution of skull defects with methylacrylate. Magy Traumatol Orthop Helyreallito Seb.19:259-68, (1976).

[78] Drosos, G.I, Babourda, E, Magnissalis, E.A, Giatromanolaki, A, Kazakos, K, Verettas, D.A. Mechanical characterization of bone graft substitute ceramic cements. Injury, (2011).

[79] Charnley, J. Total Hip Replacement by Low-Friction Arthroplasty. Clinical Orthopaedics and Related Research, 7, (1970).

[80] Asimacopoulos, T.J, Papadakis, N, Mark, V.H. A new method of cranioplasty. Technical note. $J$ Neurosurg 47:790-792, (1977).

[81] Petty, W. The effect of methylmethacrylate on the chemotaxis of polymorphonuclear leukocytes. J. Bone and Joint Surgery 60a, 492-497, (1978).

[82] Donkerwolcke, M, Burny, F, Muster, D. Tissues and bone adhesives-historical aspects. Biomaterials. 19 9160: 1461-6, DOI: 10. 1016/S0142-9612(98) 00059-3, (1988).

[83] Kreigel, R.J, Schaller, C; Clusmann, H. Cranioplasty for large skull defects with PMMA (Polymethylmethacrylate) or Tutoplast processed autogenic bone grafts. Zentralbl Neurochir. 68 (4): 
182-9. DOI:10.1055/s-2007-985857, (2007).

[84] Greene, A., Warren, S.M., McCarthy, J.G. European Association for Cranio-Maxillofacial Surgery, 138-142, (2007).

[85] Jackson, I.J, Hoffmann, G.T. Depressed comminuted fracture of a plastic cranioplasty. J Neurosurg 13: 116e117, (1956).

[86] Blum, K.S, Schneider, S.J, Rosenthal, A.D. Methyl methacrylate cranioplasty in children: longterm results. Pediatr Neurosurg 26: 33e35, (1997)

[87] Cho, Y.R, Gosain, A.K. Biomaterials in craniofacial reconstruction. Clin Plast Surg 31: 377e385, (2004)

[88] Berry, J.P. Surface characteristics of fractured poly(methyl methacrylate. Nature 185: 91e92, (1960)

[89] James, S.P, Jasty, M, Davies, J, Piehler, H, Harris, W.H. A fractographic investigation of PMMA bone cement focusing on the relationship between porosity reduction and increased fatigue life. $\mathrm{J}$ Biomed Mater Res 26: 651e662, (1992)

[90] Kricun, R, Chovanes, G.I, Shoemaker, E.I. CT and MR appearance of cervical acrylic struts. J Comput Assist Tomogr 15: 519e521, (1991)

[91] Remsen, K, Lawson, W, Biller H.F. Acrylic frontal cranioplasty. Head Neck Surg 9: 32e41, (1986)

[92] Persing, J.A, Cronin, A.J, Delashaw, J.B, Edgerton, M.T, Henson S.L, Jane J.A. Late surgical treatment of unilateral coronal synostosis using methyl methacrylate. J Neurosurg 66: 793e799, (1987).

[93] Benzel E.C, Thammavaram K, Kesterson L, Nachbar J.M. A new method of methyl methacrylate fixation in skull reconstruction. Plast Reconstr Surg 87: 153e156, (1991)

[94] Wong L, Manson P.N. Rigid mesh fixation for alloplastic cranioplasty. J Craniofac Surg 5: 265e269, (1994)

[95] Replogle R.E, Lanzino G, Francel P, Henson S, Lin K, Jane J.A. Acrylic cranioplasty using miniplate struts. Neurosurgery 39: 747e749, (1996).

[96] Gibbons K.J, Hicks Jr W.L, Guterman L.R. A technique for rigid fixation of methyl methacrylate cranioplasty: the vault-locking method. Surg Neurol 52: 310e314, (1999).

[97] Raja A.I, Linskey M.E. In situ cranioplasty with methylmethacrylate and wire lattice. Br J Neurosurg 19: 416e419, (2005)

[98] De Santis R., Mollica F., Ambrosio L., Nicolais L., Ronca D. Dynamic mechanical behavior of PMMA based bone cements in the wet environment. J Mater Sci Mater Med. 14 (7): 583-594, (2003).

[99] Kuehn K.D. Bone cements: up-to-date comparision of physical and chemical properties of commercial materials. Springer-Verlag, Heidelberg, (2000).

[100] Lara W. C., Schweitzer J., Lewis R.P., Odum B.C., Edlich R.F., Gampper T.J. Technical considerations in the use of polymethlmethacrylate in cranioplasty. J Long Term Eff Med Implants. 8 (1): 43-53, (1998). 
[101] Lung C.Y., Darvell B. W.: Minimization of the inevitable residual monomer in denture base acrylic. Dent Mater 21 (12): 1119-1128, (2005).

[102] Winder J. Computer assisted cranioplasty (Chapter 1). In: B. Bidanda, P. Bartolo (editors): Virtual Prototyping \& Bio Manufacturing in Medical Applications. Springer, New York, 1-19, (2008).

[103] Argenta, L. C., Newman, M. H. The use of methyl methacrylate cranioplasty in forehead reconstruction. European Journal of Plastic Surgery 9(3): 94-99, (1986).

[104] Ginebra, M.P., et. al. Relationship between the morphology of PMMA particles and the properties of acrylic bone cements. J. Mat. Sci. Mat. Med. 7, 375-379, (1996).

[105] Dalby, M.J., et. al. Increasing hydroxyapatite incorporation into poly(methylmethacrylate) cement increases osteoblast adhesion and response. Biomaterials, 569-576, (2002).

[106] Jones, J.C., Hungerford, D.S. Cement disease. J. Clin. Ortho. Rel. Res. 225, 192-203, (1987).

[107] Santin, M., Motta, A., Borzachiello, A., Nicolais, L., Ambrosio, L. Effect of PMMA cement radical polymerization on the inflammatory response. Journal of Materials Science: Materials in Medicine. Volume 15, Issue 11, pp 1175-1180, (2004).

[108] Berman, A. T., et. al. Emboli observed with use of transesophageal echocardiography immediately after tourniquet release during total knee arthroplasty with cement. J. Bone and Joint Surgery 80a, 389-395, (1998).

[109] Williams, D. F. Materials science and technology, a comprehensive treatment; medical and dental materials (VCH, Weinheim, New York, Basel, Cambridge, (1992).

[110] Chow, C.L. Takagi, S. A natural bone cement - a laboratory novelty led to the development of revolutionary new biomaterials. J. Res. Natl. Inst. Tech. 1029-1033, (2001).

[111] Wang, X., et. al. Bone repair in radii and tibias of rabbits with phosphorylated chitosan reinforced calcium phosphate cements. Biomaterials, 4167-4176, (2002).

[112] Ambard, A.J., Mueninghoff, L. Calcium phosphate cement: review of mechanical and biological properties. Journal of Prosthodontics, 15 (5) p.321-328, (2006).

[113] Wren, A. W. Strontium Substituted Glass Ionomer Cements for Skeletal Applications; Ph.D. Thesis. University of Limerick, (2008).

[114] Dorozhkin, S.V. Self-Setting Calcium Orthophosphate Formulations. J Funct. Biomater. 209311; DOI:10.3390/jfb4040209, (2013).

[115] Dreissens, F.C.M., et. al. Effective formulations for the preparation of calcium phosphate bone cements. J. Mat. Sci. Mat. Med., 164-170, (1994).

[116] Miyamoto, Y., et. al. In vivo setting behaviour of fast setting calcium phosphate cement. Biomaterials, 855-860, (1995).

[117] Yamamoto, H. Mechanical strength of calcium phosphate cement. Biomaterials, 1587-1591, (1998).

[118] Kuemmerle, J.M, Oberle A, Oechslin C, Bohner M, Frei C, Boecken I et al; Assessment of suitability of a new brushite calcium phosphate cement for cranioplasty- an experimental study in 
sheep. J Cranio-maxillofac Surg 33: 37-44, (2005).

[119] Ishikawa, K., et. al. Properties of fast setting calcium phosphate cements. J. Mat. Sci. Mat. Med., 528-533, (1995).

[120] Baker S.B, Weinzweig J, Kirschner R.E, Bartlett S.P. Applications of new carbonated calcium phosphate bone cement; early experience in pediatric and adult craniofacial reconstruction. Plastic Reconstr Surg 109: 1789-1796, (2002).

[121] Chen T.M, Wang H.J, Chen S.L, Lin F.H: Reconstruction of post traumatic frontal-bone depression using hydroxyapatite cement. Ann Plast Surg 52: 303-308, (2004).

[122] Gomez E, Martin M, Arias J, Carceller F. Clinical application of Norian SRS (calcium phosphate cement) in cement in craniofacial reconstruction in children: our experience at Hospital La Paz since 2001. J Oral Maxillofac Surg 63: 8-14, (2005).

[123] Mahr M.A, Bartley G.B, Bite U, Clay R.P, Kasperbauer J.L, Holmes J.M. Norian craniofacial repair system bone cement for the repair of craniofacial skeletal defects. Ophthal Plast Reconstr Surg: 393-398, (2000).

[124] Turk J.B, Parhiscar A. Bone Source for craniomaxillofacial reconstruction. Facial Plast Surg 16: 7-14, (2000).

[125] Verheggen R, Merten H.A. Correction of skull defects using hydroxyapatite cement (HAC)evidence derived from animal experiments and clinical experience. Acta Neurochir (Wien) 143: 919926, (2001).

[126] Wolff K.D, Swaid S, Nolte D, Bockmann RA, Holzle F, Muller-Mai C. Degradable injectable bone cement in maxillofacial surgery: indications and clinical experience in 27 patients. $\mathrm{J}$ Craniomaxillofac Surg 32: 71-79, (2004).

[127] Theiss F, Apelt D, Brand B, Kutter A, Zlinszky K, Bohner M., et al. Biocompatibility and resorption of a brushite calcium phosphate cement. Biomaterials. 26:4383-4394, (2005).

[128] Kubo S, Takimoto H, Kato A, Yoshimine T. Endoscopic cranioplasty with calcium phosphate cement for pterional bone defect after frontotemporal craniotomy : technical note. Neurosurgery. 51:1094-1096, (2002).

[129] Matic D, Phillips J. A contraindication for the use of hydroxyapatite cement in the pediatric population. Plast Reconstr Surg. 110:1-5, (2002).

[130] Matsumoto K, Akagi K, Abekura M, Ohkawa M, Tasaki O, Tomishima T. Cosmetic and fuctional reconstruction achieved using a split myofascial bone flap for pterional craniotomy. Technical note. J Neurosurg. 94:667-670, (2001).

[131] Raza S.M, Thai Q.A, Pradilla G, Tamargo R.J. Frontozygomatic titanium cranioplasty in frontosphenotemporal ("pterional") craniotomy. Neurosurgery. 62:262-264, (2008).

[132] Tadros M, Costantino P.D. Advances in cranioplasty: a simplified algorithm to guide cranial reconstruction of acquired defects. Facial Plast Surg. 24:135-145, (2008).

[133] Xia Z, Grover L.M, Huang Y, Adamopoulos I.E, Gbureck U, Triffit J.T., et al. In vitro 
biodegradation of three brushite calcium phosphate cements by a macrophage cell-line. Biomaterials. 27:4557-4565, (2006).

[134] Ji C., Ahn, J. Clinical Experience of the Brushite Calcium Phosphate Cement for the Repair and Augmentation of Surgically Induced Cranial Defects Following the Pterional Craniotomy. Korean Neurosurg Soc. 47(3): 180-184, (2010).

[135] Nicholson, J. W. The chemistry of medical and dental materials, Royal society of chemistry, Cambridge, (2002).

[136] E. Britannica, Amorphous Solid, in: Encyclopædia Britannica, (2007).

[137] Coughlan, A. Biofilm inhibitory coatings formulated from glass polyalkenoate cement chemistry, in Faculty of Science \& Engineering, vol Doctor of Philosophy. University of Limerick, Limerick, (2009).

[138] Kramer, E.J. Glasses and amorphous materials. Weinheim, New York, (1991).

[139] Wilson, A. D., Nicholson, J. W. Acid-base cements, their biomedical and industrial applications. University Press, Cambridge, (1993).

[140] Paul, A. Chemistry of Glasses, (1990).

[141] Hill, R. G., Wilson, A. D. Some structural aspects of glasses used in ionomer cements. Glass Technology. 29, 150-158, (1988).

[142] Lowenstein, W. The distribution of aluminium in the tetrahedra of silicates and aluminates. American Minerologist 39, 92-96, (1954).

[143] Ray, N. H. Inorganic Polymers, Academic Press, London, (1978).

[144] De Barra, E. in Materials Science and Technology, University of Limerick, Limerick, (1997).

[145] Wu, W., Xie, D., Puckett, A., Mays, J. W. Synthesis and formulation of vinyl- containing polyacids for improved light-cured glass-ionomer cements, European Polymer Journal 39, 663-670, (2003).

[146] Boyd, D., Clarkin, O. M., Wren, A. W., Towler, M. R. Zinc-based glass polyalkenoate cements with improved setting times and mechanical properties. Acta Biomaterialia, 425-431, (2008).

[147] Mun, G. A., Nurkeeva, Z. S., Khutoryanskiy, V. V., Sarybayeva, G. S., Dubolazov A. V. pHeffects in the complex formation of polymers I. Interaction of poly(acrylic acid) with poly(acrylamide), European Polymer Journal 39, 1687- 1691, (2003).

[148] Voelkel, E., Andrzejewska, H., Limanowska-Shaw, M., Andrzejewski. Acid- base surface properties of glass-ionomers determined by IGC, Applied Surface Science 245, 149-154, (2005).

[149] Griffin, S., Hill, R. Influence of poly(acrylic acid) molar mass on the fracture properties of glass polyalkenoate cements Journal of Materials Science 33, 5383- 5396, (1998).

[150] Crisp S., Merson, S.A., Wilson, A.D. Modification of ionomer cements by the addition of simple metal salts, Industrial and Engineering Chemistry, Research and Development 19, 403-408, (1980).

[151] Attar, N., Tam, L. E., McComb, D. Mechanical and physical properties of contemporary dental luting agents, The Journal of Prosthetic Dentistry 89, 127-134, (2003). 
[152] Diaz-Arnold, A.M., Vargas, M.A., Haselton D.R. Current status of luting agents for fixed prosthodontics, J Prosthet Dent 81, 135-141, (1999).

[153] Kydd, W.L., Nicholls, J.I., Harrington, G., Freeman, M. Marginal leakage of cast gold crowns luted with zinc phosphate cement: an in vivo study, J Prosthet Dent 75, 9-13, (1996).

[154] Swartz, M.L., Phillips, R.W., Clark, H.E. Long-term F release from glass ionomer cements, $J$ Dent Res 63, 158-160, (1984).

[155] McLean, J. W., Gasser, O. Glass-cermet cements, Quintessence Int 16-333- 343, (1985).

[156] Mitra S.B., Kedrowski, B.L. Long-term mechanical properties of glass ionomers, Dental Materials 10-78-82, (1994).

[157] Gladys, S., Meerbeek, B.V., Braem, M., Lambrechts P., Vanherle G. Comparative physicomechanical characterization of new hybrid restorative materials with conventional glass-ionomer and resin composite restorative materials, J Dent Res 76-883-894, (1997).

[158] Kovarik, R.E., Muncy, M.V. Fracture toughness of resin-modified glass ionomers., Am J Dent 8145-148, (1995).

[159] El-Mowafy, O.M, Fenton, A.H., Forrester, N., Milenkovic, M. Retention of metal ceramic crowns cemented with resin cements: effects of preparation taper and height., J Prosthet Dent 76-524529, (1996).

[160] White, S.N., Yu, Z. Physical properties of fixed prosthodontic, resin compositeuting agents, Int J Prosthodont 6-384-389, (1993).

[161] Love, M.R., Purton, D.G. Retention of posts with resin, glass ionomer and hybrid cements, $J$ Dent 26, 599-602, (1998).

[162] El-Mowafy, O.M., Milenkovic, M. Retention of paraposts cemented with dentin- bonded resin cements, Oper Dent 19-176-182, (1994).

[163] Christensen, G.J. Seating nonmetal crowns or fixed partial dentures with resin cement., $J \mathrm{Am}$ Dent Assoc 129-239-241, (1998).

[164] Donovan, T.E., Cho, G.C. Contemporary evaluation of dental cements, Compend Contin Educ Dent 20-197-199, 202-198, 210, (1999).

[165] Johnson, W.W., Dhuru, V.B, Brantley, W.A. Composite microfiller content and its effect on fracture toughness and diametral tensile strength., Dental Materials 9-95-98, (1993).

[166] Lloyd, C.H., Iannetta, R.V. The fracture toughness of dental composites. I. The development of strength and fracture toughness., J Oral Rehabil 9-55-66, (1982).

[167] Pilliar, R.M., Vowles, R., Williams, D.F. The effect of environmental aging on the fracture toughness of dental composites, $J$ Dent Res 66-722-726, (1987).

[168] Willems, G., Lambrechts, P., Braem, M., Vanherle, G.Composite resins in the 21st century, Quintessence Int 24-641-658, (1993).

[169] El-Mowafy, O.M., Rubo, M.H., El-Badrawy, W.A. Hardening of new resin cements cured through a ceramic inlay, Oper Dent 24-38-44, (1999). 
[170] Peutzfeldt, A. Dual-cure resin cements: in vitro wear and effect of quantity of remaining double bonds, filler volume, and light curing. Acta Odontol Scand 53-29-34, (1995).

[171] White, S.N., Tom, Z. Y. Z, J. F., Sangsurasak, S. In vivo microleakage of luting cements for cast crowns, J Prosthet Dent 71-333-338, (1994).

[172] Oilo, G. Sealing and retentive ability of dental luting cements, Acta Odontol Scand 36-317-325, (1978).

[173] Bebermeyer, R.D., Berg, J.H. Comparison of patient-perceived postcementation sensitivity with glass-ionomer and zinc phosphate cements. Quintessence Int 25-209-214, (1994).

[174] Johnson, G.H., Powell, L.V., DeRouen, T.A. Evaluation and control of postcementation sensitivity: zinc phosphate and glass ionomer luting cements. J Am Dent Assoc 124-38-46, (1993).

[175] Kern, M., Kleimeier, B., Schaller, H.G, Strub, J.R. Clinical comparison of postoperative sensitivity for a glass ionomer and a zinc phosphate luting cement. J Prosthet Dent 75, 159-162, (1994).

[176] Fennell, B., Hill, R.G. The influence of poly(acrylic acid) molar mass and concentration on the properties of polyalkenoate cements. Part III. Fracture toughness and toughness, Journal of Materials Science 36-5185-5192, (2001).

[177] Hanting, C., Hanxing, L., Guoqing, Z. The setting chemistry of glass ionomer cement, Journal of Wuhan University of Technology--Materials Science Edition 20-110-112, (2005).

[178] Yamazaki, Y. Hibino, M. Honda, Y. Nagasawa, J. Omatsu, Y. Hasegawa, A. Harashima, H. Nakajima, Effect of Powder-liquid Ratio on Shear Strength of Glass Ionomer Cements for Luting J J Dent MateVol. 26 No. 1 40-49 26 40-49, (2007).

[179] Hill, R.G., Wilson, A.D., Warrens, C.P. The influence of poly(acrylic acid) molecular weight on the fracture toughness of glass-ionomer cements. J. Mat. Sci. Mat. Med. 24, 363-371, (1989).

[180] Hill, R.G. The fracture properties of glass polyalkenoate cements as a function of cement age., Journal of Materials Science 28-3851-3858, (1993).

[181] DeBarra, E., Hill, R., Influence of alkali metal ions on the fracture properties of glass polyalkenoate (ionomer) cements. Biomaterials, 19 p.495-502, (1998).

[182] Crisp, S., Lewis, B.G., Wilson, A.D. Characterization of glass-ionomer cements: 2. Effect of the powder: liquid ratio on the physical properties, Journal of Dentistry 4-287-290, (1976).

[183] Yap, U.J., Pek, Y.S., Kumar, R.A., Cheang, P., Khor, K.A. Experimental studies on a new bioactive material: HAIonomer cements, Biomaterials 23-955- 962, (2002).

[184] Cattani-Lorente, M.A., Godin, C., Meyer, J.M. Mechanical behavior of glass ionomer cements affected by long-term storage in water, Dental Materials 10-37-44, (1994).

[185] Xie, D., Culbertson, B.M., Wang, G. Microhardness of N-Vinylpyrrolidone Modified GlassIonomer Cements, Journal of Macromolecular Science, Part A 35, 547 - 561, (1998).

[186] Billington, R.W., Williams, J.A., Pearson, G.J. Ion processes in glass ionomer cements, Journal of Dentistry 34-544-555, (2006). 
[187] Jevniker, P., Jarh, O., Sepe, A., Pintar, M.M., Funduk, N.Micro magnetic resonance imaging of water uptake by glass ionomer cements, Dental Materials 13-20-23, (1997).

[188] Peters, W.J., Jackson, R.W., Iwano, K., Smith, D.C. The biological response to zinc polyacrylate cement, Clinical orthopaedics and related research 88-228- 233, (1972).

[189] Boyd, D., Li, H., Tanner, D. A., Towler, M. R., Wall, J. G. The antibacterial effects of zinc ion migration from zinc-based glass polyalkenoate cements. J Mater Sci Mater Med, 17, 489-494, (2006). [190] Wilson, A. D. The Nature of the Zinc Polycarboxylate Cement Matrix. Journal of Biomedical Materials Research 16, 549-557, (1982).

[191] Nicholson, J. W., Hawkins, S. J., Wasson, E. A. A Study of the Structure of Zinc Polycarboxylate Dental Cements. Journal of Materials Science-Materials in Medicine 4, 32-35, (1993).

[192] Peters, W.J., Jackson, R.W., Smith, D.C. Studies of the Stability and Toxicity of Zinc Polyacrylate (polycarboxylate) cements (PAZ), J. Biomed. Mater. Res 8, 53- 60, (1974).

[193] Mizrahi, E., Smith, D.C. Direct cementation of orthodontic brackets to dental enamel. An investigation using a zinc polycarboxylate cement., British dental journal 127-371-375, (1969).

[194] Hill, R.G., Labok, S.A. The influence of poly(acrylic acid) molecular weight on the fracture of zinc polycarboxylate cements., Journal of Materials Science 26-67-74, (1991).

[195] King, J.A. Water treatment composition in: F. P. Online (Ed.), United States, vol. 6551609, (2003).

[196] Towler, M., Kenny, S., Boyd, D., Pembroke, T., Buggy, M., Guida, A., Hill, R. Calcium and zinc ion release from polyalkenoate cements formed from zinc oxide/apatite mixtures, Journal of Materials Science: Materials in Medicine 17-835-839, (2006).

[197] Hill, R.G., Towler, M., Kenny, S. The influence of poly(acrylic acid) molar mass on the properties of polyalkenoate cements formed from zinc oxide/apatite mixtures, Journal of Materials Science: Materials in Medicine 11-847-853, (2000).

[198] Moreira-Gonzalez A, Jackson IT, Miyawaki T, Barakat K, DiNick V. Clinical outcome in cranioplasty: critical review in long-term follow-up. J Craniofac Surg 14: 144-153, (2003).

[199] Bruens M.L, Pieterman H, de Wijn J.R, Vaandrager J.M. Porous polymethylmethacrylate as bone substitute in the craniofacial area. J Craniofac Surg 14: 63-68, (2003).

[200] Cohen M.S, Costantino P.D, Friedman C.D. Biology of implants used in head and neck surgery. Fac Plast Surg Clin North Am 7: 17-33, (1999).

[201] Barone, C.M, Jimenex, D.F, Beckert, B.W, Clapper, A. T. Effects of synthetic craniofacial materials on cerebral microcirculation. J Craniofac Surg 12: 191-193, (2001).

[202] Costantino, P.D, Friedman M.D, Jones, K, Chow, L.C, Sisson, G.A: Experimental hydroxyapatite cement cranioplasty. Plast Reconstr Surg 90: 174-185, (1992).

[203] Dickey, B. Novel adaptations to zincsilicate glass polyalkenoate cements: The unexpected influences of germanium based glasses on handling characteristics and mechanical properties. Journal 
of the Mechanical Behaviour of Biomedical Materials, 23:8-21, (2013).

[204] Beals S.P, Munro I.R. The use of miniplates in craniomaxillofacial surgery. Plast Reconstr Surg. 79:33-8, (1987).

[205] Simpson D. Titanium in cranioplasty. J Neurosurg 22:292-3, (1996).

[206] Ono I, Suda K, Tateshita T, Gunji H, Kaneko F. Analysis of strength and bone conduction of hydroxyapatitic ceramics. J Jpn PRS 13:561-71, (1993).

[207] Ono I, Gunji H, Suda K, et al. Orbital reconstruction with hydroxyapatite ceramic implant. Scand J Reconstr Hand Surg 28:193-8, (1994).

[208] Varshneya, A.K., et al. Fundamentals of inorganic glasses. Academic Press, Boston (1994).

[209] Boyd, D., Clarkin, O.M., Wren, A.W., Towler, M.R. Zinc-based glass polyalkenoate cements with improved setting times and mechanical properties, Acta Biomaterialia 4-425-431, (2008).

[210] Williams, J. A., Billington, R. W., Pearson, G. J. The effect of the disc support system on biaxial tensile strength of a glass ionomer cement. Dent Mater, 18, 376- 379, (2002).

[211] Itinoche, K. M., Ozcan, M., Bottino M. A., Oyafuso, D. Effect of mechanical cycling on the flexural strength of densely sintered ceramics. Dental Materials, Vol. 22, 1029-1034, (2005).

[212] Pfeiffer, F., Kottler, C., Bunk, O., David, C. Hard X-Ray Phase Tomography with LowBrilliance Sources.Phys. Rev. Lett. 98, 108105, (2007).

[213] Prentice, L. H., Tyas, M. J. \& Burrow, M. F. The effect of mixing time on the handling and compressive strength of an encapsulated glass- ionomer cement. Dental Materials, Vol 22, 746-757, (2006).

[214] Wren, A. W., Cummins, N. M., Laffir, F. R., Hudson, S. P., Towler, M. R. The bioactivity and ion release of titanium-containing glass polyalkenoate cements for medical applications. J Mater Sci: Mater Med, 22, 19-28, (2001).

[215] Boyd, D., Towler, M.R. The Processing, Mechanical Properties and Bioactivity of Zinc Based Glass Ionomer Cements, J. Mat. Sci: Materials in Medicine 16-843- 850, (2005).

[216] Clarkin, O., Boyd, D., Towler, M.R. Strontium-based Glass Polyalkenoate Cements for Luting Applications in the Skeleton'. J. Biomat. App. DOI:10.1177/0885328208099085, (2008).

[217] Wren, A. W., Coughlan, A., Placek, L., Towler, M. R. Gallium containing glass polyalkenoate anti-cancerous bone cements: glass characterization and physical properties. J Mater Sci: Mater Med, 23, 1823-1833, (2012).

[218] Palin, W.M., Fleming, G.J.P., Trevor Burke, F.J., Marquis, P.M. and Randall, R.C. The Reliability in Flexural Strength Testing of a Novel Dental Composite, Journal of Dentistry, 31(8): 549557, (2003).

[219] De Barra, E., Hill, R., et al. Influence of poly(acrylic acid) content on the fracture behaviour of glass polyalkenoate cements. Journal of Materials Science 33, 5487-5497, (1998).

[220] Xiang, Y, Jincheng D, Lawrie B, S., Benmore, J,C, Wren., A. W., Boyd J.D \&Towler M.R. Structure and diffusion of $\mathrm{ZnO}-\mathrm{SrO}-\mathrm{CaO}-\mathrm{Na}_{2} \mathrm{O}-\mathrm{SiO}_{2}$ bioactive glasses: a combined high energy X-ray 
diffraction and molecular dynamics simulations study. RSc Advances; DOI: 10.1039/c3ra23231j, (2013).

[221] ASTM F640 "Standard Test Methods for Determining Radiopacity for Medical Use."

[222] Radiology Masterclass: Basics of X-Ray Physics. (2007-2015). Accessed on: June 2015. Available at:

$<$ http://radiologymasterclass.co.uk/tutorials/physics/xray_physics_densities.html\#top_third_img $>$

[223] International standard 5833,(E). Implants for Surgery Acrylic Resin Cements. International Organization for Standardization, Geneve, Switzerland, Case Postale 56, CH-1211, (1992).

[224] ISO9917, Dentistry: water-based cements, (2007). 